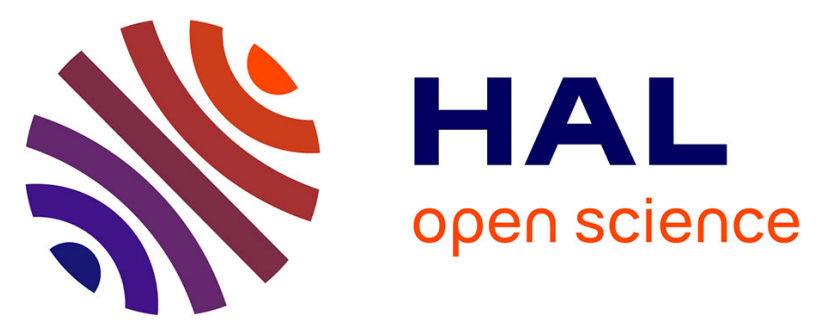

\title{
Le strigile en Gaule, objet utilitaire et vecteur de romanité : l'exemple du strigile de la villa des Champs-de-Choisy à Charny (Seine-et-Marne)
}

Franck Mallet, Fabien Pilon

\section{- To cite this version:}

Franck Mallet, Fabien Pilon. Le strigile en Gaule, objet utilitaire et vecteur de romanité: l'exemple du strigile de la villa des Champs-de-Choisy à Charny (Seine-et-Marne). Gallia - Archéologie de la

France antique, 2009, 66 (2), pp.113-151. 10.3406/galia.2009.3368 . hal-01899002

\section{HAL Id: hal-01899002 \\ https://hal.science/hal-01899002}

Submitted on 19 Dec 2019

HAL is a multi-disciplinary open access archive for the deposit and dissemination of scientific research documents, whether they are published or not. The documents may come from teaching and research institutions in France or abroad, or from public or private research centers.
L'archive ouverte pluridisciplinaire HAL, est destinée au dépôt et à la diffusion de documents scientifiques de niveau recherche, publiés ou non, émanant des établissements d'enseignement et de recherche français ou étrangers, des laboratoires publics ou privés.

\section{(ㅇ)(1) $\$$}

Distributed under a Creative Commons Attribution - NonCommercial - NoDerivatives $\mid 4.0$ 


\title{
LE STRIGILE EN GAULE, OBJET UTILITAIRE ET VECTEUR DE ROMANITÉ
}

\author{
L'exemple du strigile de la villa des Champs-de-Choisy à Charny \\ (Seine-et-Marne)
}

\author{
Franck MALLET ${ }^{*}$ \\ avec la participation de Fabien PILON**
}

Mots-clés. Strigile, damasquinure, époque grecque, époque augustéenne, romanité, objet cultuel, funéraire.

Résumé. Les fouilles archéologiques menées au lieu-dit les Champs-de-Choisy sur la commune de Charny (Seine-et-Marne) en 2004 ont permis de mettre au jour une villa bâtie à l'époque augustéenne et occupée jusque dans les premières décennies du IV $V^{e}$. Les fossés d'enclos de l'établissement précoce ont livré un riche et abondant mobilier, parmi lequel un strigile décoré de damasquinure, un buste anthropomorphe en calcaire et un fragment de bétyle. La présence de ce strigile sur un site et dans une région où les thermes ne semblent pas apparaître avant la seconde moitié du $I^{e r}$ s. apr. J.-C. soulève d'innombrables questions, mais apporte également de nombreuses informations sur le symbolisme dont il est empreint. Le mobilier associé à cette découverte permet de se faire une idée sur la portée symbolique qu'a pu recouvrir cet objet et ainsi d'apporter des informations inédites sur le statut et la romanité du propriétaire des lieux.

Key-words. Strigil, damascening, Greek period, Augustan period, romanitas, cultual artefact, funerary.

Abstract. A Roman villa, built during the Augustan period and occupied until the first years of the $4^{\text {th }}$ century A.D., was discovered during an excavation at Charny "les Champs-de-Choisy" (Seine-et-Marne) in 2004. The numerous finds from the ditches of the first enclosure include a limestone anthropomorphic bust, a fragmentary stela and a damask strigil. The presence of this artefact raises a number of questions about the site, as there seems to have been no public baths in the area until the second half of the $1^{\text {st }}$ century A.D. However the associated finds give a fair idea of the symbolism of this type of artefact and provide new evidence concerning the Roman status of the villa's landowners.

Translation: Isabelle FAUDUET

Schlüsselwörter. Strigilis, Tauschierung, Römische Kultur, kultischer Gegenstand, Grabsitten.

Zusammenfassung. Bei den archäologischen Grabungen, die 2004 in Champs-de-Choisy auf dem Gebiet der Gemeinde Charny (Departement Seine-et-Marne) durchgeführt wurden, konnte eine in augusteischer Zeit gegründete und bis in die ersten Jahrzehnte des 4. Jh. belegte villa freigelegt werden. Die Umfassungsgräben der frühen Siedlungsphase lieferten ein luxuriöses und umfangreiches Mobiliar, darunter eine anthropomorphe Büste aus Kalkstein, das Fragment eines Bätyls und einen mit Tauschierung dekorierten Strigilis. Das Vorhandensein dieses Strigilis an einem Ort und in einer Region, in der vor der zweiten Hälfte des 1. Jh. n. Chr. keine Thermen bezeugt sind, wirft einerseits zahlreiche Fragen auf, liefert andererseits jedoch auch zahlreiche Erkenntnisse zum Symbolismus, dessen Ausdruck er ist. Das mit dieser Entdeckung in Zusammenhang stehende Mobiliar erlaubt es, sich eine Vorstellung von der symbolischen Tragweite dieses Gegenstandes zu machen, und völlig neue Informationen zum Status und des Besitzers dieser villa als Träger der römischen Kultur zu erbringen.

* Inrap, 56 boulevard de Courcerin, F-77183 Croissy-Beaubourg. Courriel : franck.mallet@inrap.fr

** 10 rue des Chardonnerets, F-37170 Chambray-lès-Tours. Courriel : fabien.pilon@wanadoo.fr 
La mise au jour de strigiles en Gaule lors de fouilles archéologiques préventives est peu commune ; l'essentiel des découvertes ayant été fait fortuitement et pour une bonne part dans le courant du XIX ${ }^{\mathrm{e}} \mathrm{s}$. et au début du XX ${ }^{\mathrm{e}} \mathrm{s}$. Si cet objet de toilette semble fréquent en Narbonnaise, région directement influencée par la culture méditerranéenne, il reste plus anecdotique dans les provinces septentrionales. Ainsi, la découverte en 2003 d'une étrille en fer dans un établissement rural, à l'occasion d'une intervention archéologique en Pays melde, est surprenante. Cette trouvaille est d'autant plus remarquable que ce strigile porte un décor damasquiné. La présence d'un tel objet dans un établissement fondé précocement nous a conduit à porter un intérêt tout particulier à ces étrilles et à mener la présente étude.

\section{LA VILLA PRÉCOCE DE CHARNY}

La commune de Charny se situe dans le nord de la Seine-et-Marne, à l'ouest de Meaux et à l'est de Paris, sur le plateau de la Plaine de France, région qui dans l'Antiquité était partagée entre le territoire des Meldes et celui des Parisii (fig. 1). La fouille s'est déroulée dans le périmètre de la Routière de l'est parisien, entreprise chargée d'exploiter les sables, les gravillons et les sablons.

De nombreuses prospections pédestres et aériennes ont été menées dans les environs par diverses associations.

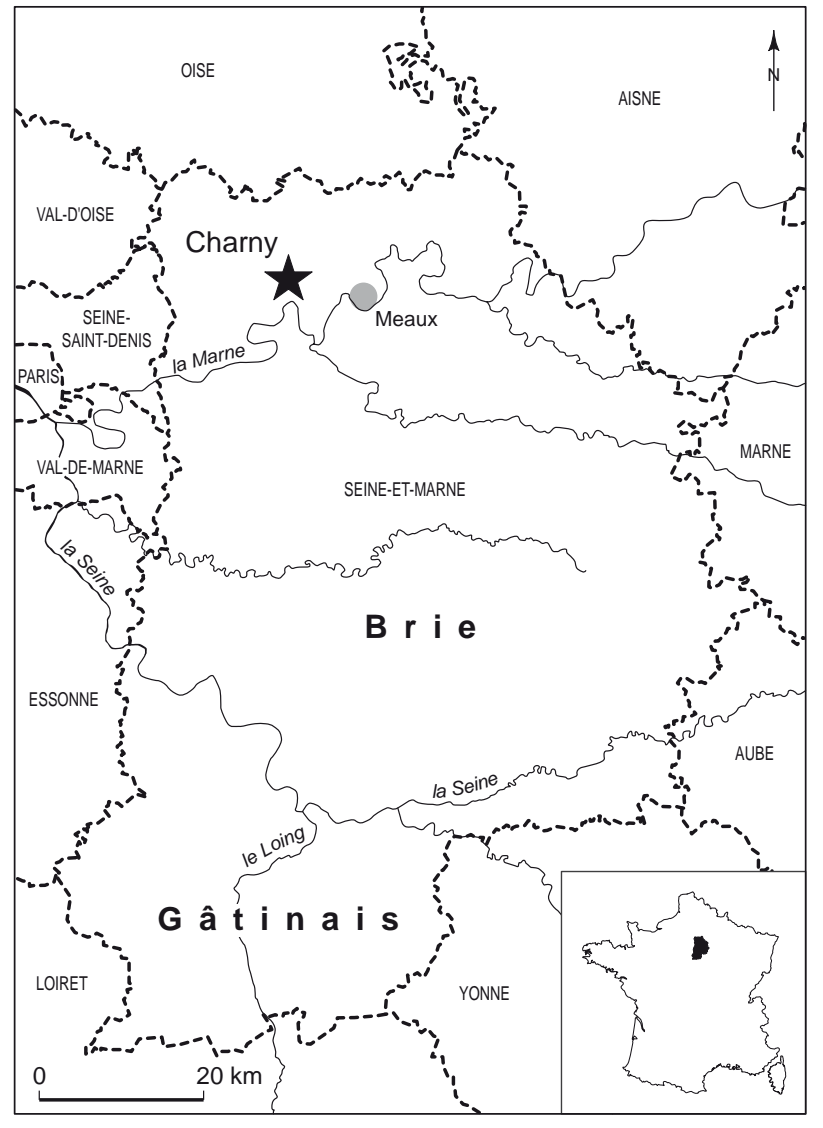

Fig. 1 - Localisation de la commune de Charny (Seine-et-Marne) (DAO : P. Pihuit, Inrap).

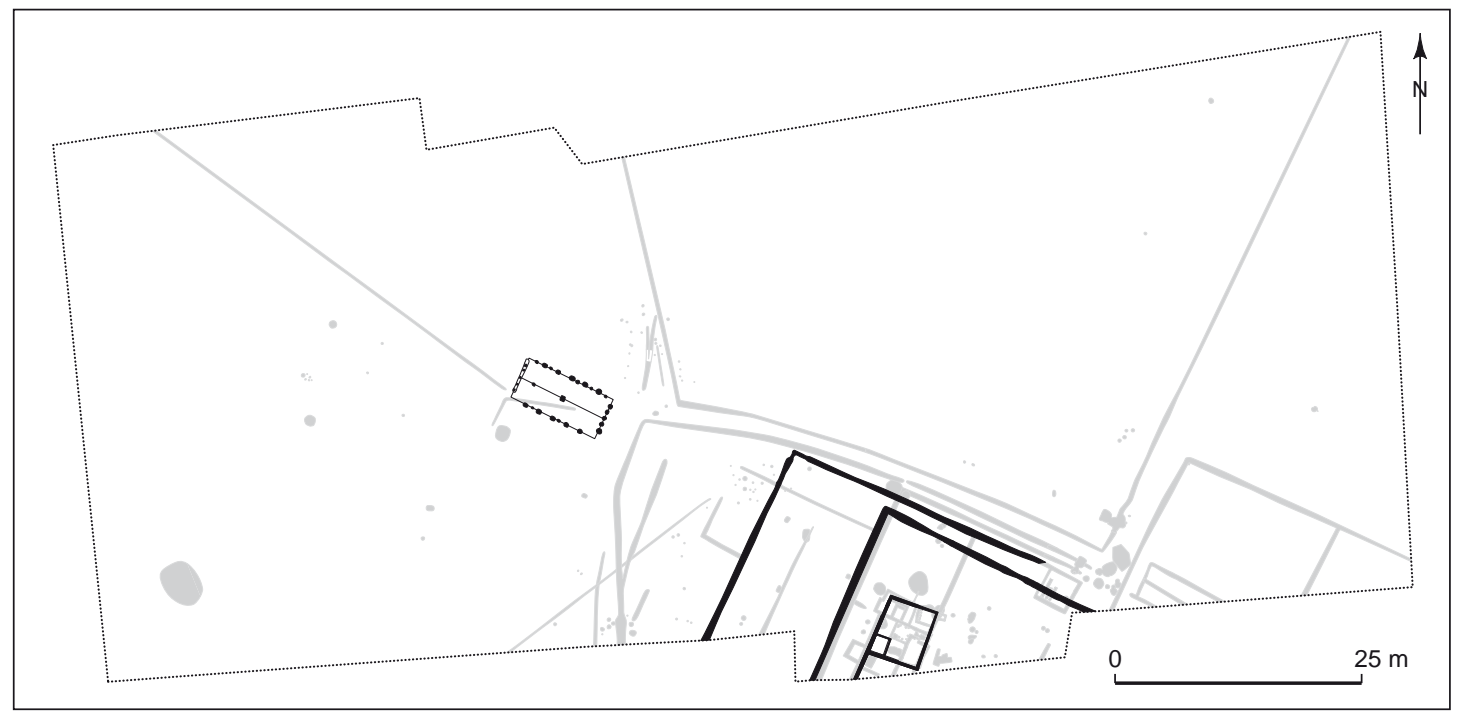

Fig. 2 - Plan général des vestiges augustéens des Champs-de-Choisy à Charny (DAO : P. Pihuit, Inrap). 
Des opérations archéologiques conduites par l'Afan puis l'Inrap ont révélé une série d'occupations protohistoriques et gallo-romaines (Ginoux, 2001 et 2002). Le décapage archéologique, réalisé aux Champs-de-Choisy en 2004, a couvert une superficie d'environ 2,9 ha et a livré seulement la partie septentrionale de la zone résidentielle d'un établissement gallo-romain, l'exploitation des carrières à la fin des années 1970 ayant fait disparaître l'intégralité des vestiges plus au sud.

C'est au tournant de notre ère, à l'époque augustéenne, que les propriétaires de la villa s'installent sur la future commune de Charny. Les vestiges, et en particulier le bâtiment résidentiel, ont eu à souffrir des nombreux aménagements effectués au cours des II $^{\mathrm{e}}$ et $\mathrm{III}^{\mathrm{e}} \mathrm{s}$. Les quelques témoins montrent un établissement qui comporte un bâtiment résidentiel avec cave intérieure, enserré dans un double enclos fossoyé encore visible, dont l'activité est tournée vers l'agriculture et l'élevage des suidés. En dehors du système fossoyé, un vaste bâtiment de $144 \mathrm{~m}^{2}$, vraisemblablement dévolu aux activités agricoles, a été construit sur poteaux à l'ouest (Mallet, 2006a ; Mallet et al., 2006) (fig. 2).

Les fossés d'enclos, localisés immédiatement à proximité du bâtiment résidentiel, ont livré une très grande quantité de mobilier archéologique qui mêlait céramiques, monnaies, nombreux restes de faune, objets en bronze et éléments sculptés. En dépit de la partie disparue du site, l'étude des éléments découverts pendant la fouille apporte des informations importantes sur la villa précoce et ses occupants (Séguier et al., 2005).

Un strigile à décor damasquiné a également été découvert dans le remplissage d'un des fossés d'enclos, retenant toute notre attention.

\section{LE STRIGILE DE CHARNY}

Les strigiles possèdent généralement un manche (capulus) portant une poignée, dans laquelle on pouvait passer la main (clausula), et une lame recourbée (ligula) creusée en canal (tubulatio) où pouvaient couler, comme dans une gouttière, l'humidité et la sueur que l'ustensile exprimait de la peau (Apulée, Florides, II, 9, 2) (fig. 3).

Le strigile de Charny a été découvert associé à un mobilier exceptionnellement riche, ce qui laisse à penser que le propriétaire de la villa, fondée entre 10 av. J.-C. et 15 apr. J.-C., a pu bénéficier d'un statut social privilégié. Cet objet en fer, bien que fortement corrodé (fig. $4, \mathrm{n}^{\mathrm{o}} 1$ ), était relativement bien conservé (seule la ligula était cassée) et

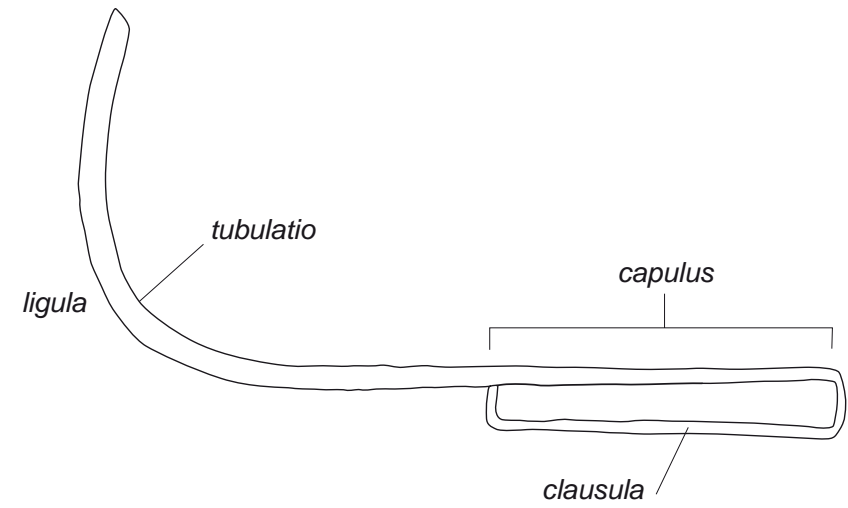

Fig. 3 - Description d'un strigile (DAO : P. Pihuit, Inrap).

son identification a été rapide. Il a été décidé de procéder à sa restauration ${ }^{1}$ et, à l'issue de cette opération, le capulus de ce strigile a révélé un décor exceptionnel et inédit (fig. 4, no 2).

Ce strigile mesure $22 \mathrm{~cm}$ de hauteur et présente un manche de $10,5 \mathrm{~cm}$ de longueur, dont la section est rectangulaire $(0,7 \mathrm{~cm} \times 1,7 \mathrm{~cm})$. Il ne présente pas de clausula et aucun élément ne permet de penser que son manche disposait d'un aménagement particulier pour le suspendre à un anneau (fig. 5). Le manche présente un décor de damasquinure, technique répandue au haut Moyen Âge mais très rare à l'époque gallo-romaine (Salin, 1951, 1953a et b). La damasquinure (de damaschino, mot italien dérivé de Damas) est une incrustation dans la surface métallique d'un motif décoratif réalisé avec un filet de métal choisi pour sa couleur (or, argent ou cuivre) ${ }^{2}$. La surface que l'on veut damasquiner est préalablement ciselée, puis l'incrustation est faite à l'aide d'un marteau (Maryon, 1960).

Le métal utilisé pour le damasquinage du strigile de Charny est du laiton, alliage comprenant du cuivre et du zinc (voir annexe II, p. 143-145). Le décor est disposé au milieu du manche, sur le dessous : il s'agit d'un sablier encadré, dans la partie supérieure, de deux lignes parallèles espacées de $1 \mathrm{~cm}$ et, dans la partie inférieure, de deux lignes également parallèles mais plus resserrées, espacées de $0,5 \mathrm{~cm}$ (fig. 6). Le dos de la ligula ne porte pas de décor, alors que cela est courant sur les étrilles en bronze.

1. Cette opération a été effectuée par UTICA (8, rue Franciade, F-93200 Saint-Denis), sous le numéro d'inventaire 2005-24.

2. La technique de la damasquinure aurait été inventée par Glaucos de Chios (Hérodote, Histoires, livre I, XXV). Les Latins appelaient cette technique ferruminatio ou encore arum qui argentum includere. 

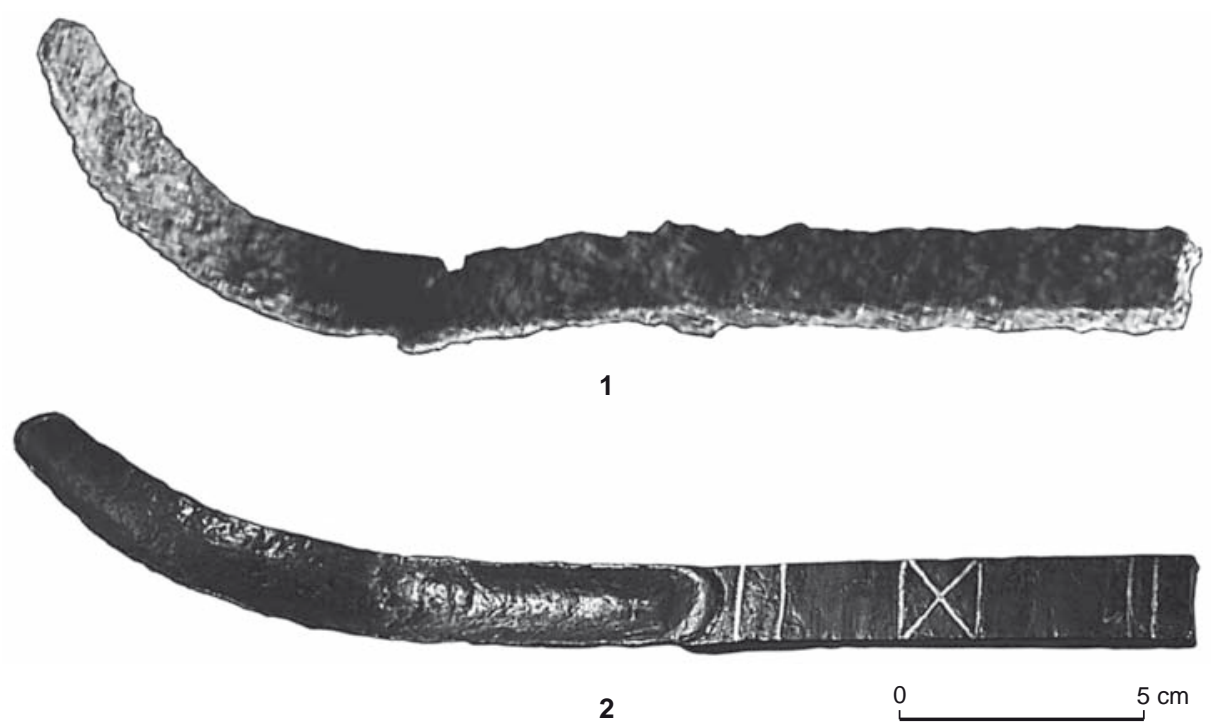

Fig. 4 - Le strigile de Charny : 1, avec corrosion ; 2, après restauration (clichés : $n^{o} 1, F$. Mallet, Inrap ; $n^{o} 2$, V. Brunet, Inrap).

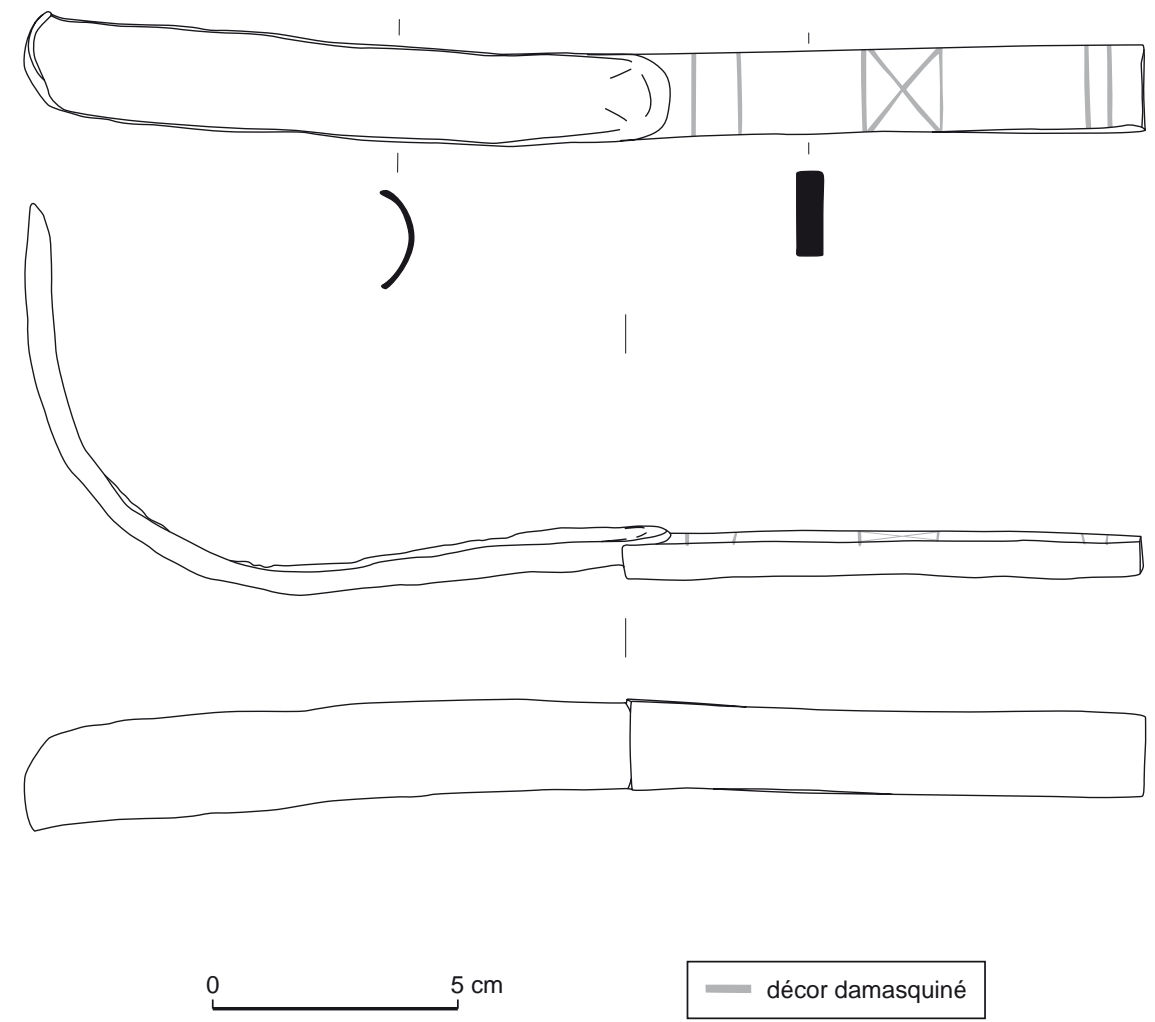

Fig. 5 - Dessin du strigile de Charny (DAO : P. Pihuit, Inrap). 
Fig. 6 - Détail de la damasquinure du manche du strigile de Charny (cliché : F. Mallet, Inrap).

Cette technique décorative a vu le jour en Orient et a été pratiquée par les Égyptiens, les Grecs $^{3}$ et les Romains. Ce fut surtout une pratique décorative caractéristique des Mérovingiens. En effet, peu utilisée jusqu'au $\mathrm{VI}^{\mathrm{e}}$ s. apr. J.-C. ${ }^{4}$, elle connut un essor remarquable à partir du VII ${ }^{\mathrm{e}}$ s. et produisit un très large éventail de chefs-d'œuvre où prédomine jusqu'au VIII ${ }^{\mathrm{e}} \mathrm{s}$. une damasquinure monochrome souvent en argent, avant d'être remplacée par une damasquinure bichrome argent-laiton. Elle est appliquée aux garnitures de ceinture de fer, à des pièces de harnachement et à des fibules. Ainsi, le fourreau damasquiné d'une épée a été découvert dans la tombe à incinération de La Tène finale de Notre-Dame-du-Vaudreuil dans l'Eure (Dechezleprêtre et al., 2005). Cette technique a, semblet-il, été utilisée sur un manche d'objet découvert dans le sanctuaire gallo-romain de Vaux-de-la-Celle à Genainville dans le Val-d'Oise ; il porte une inscription et est daté du troisième quart du III ${ }^{\mathrm{e}}$ s. apr. J.-C. (Mitard, 1993) ${ }^{5}$.

3. Des poignards damasquinés en or datés du $\mathrm{XV}^{\mathrm{e}} \mathrm{s}$. av. J.-C. ont été retrouvés à Mycènes.

4. Des instruments chirurgicaux, comme des scalpels ou des aiguilles, ont été découverts en contexte funéraire en Rhénanie pour le BasEmpire (Künzl, 1982).

5. En contexte indigène, la damasquinure est une technique décorative ancienne, comme en témoignent certains objets datés du IV ${ }^{\mathrm{e}} \mathrm{s}$. av. J.-C.
Le décor particulier du strigile de Charny est, sans nul doute, le témoignage d'une volonté de produire un objet très personnalisé et n'a certainement aucun autre rôle que celui de conférer un aspect esthétique particulier et unique. La spécificité du strigile de la villa des Champs-de-Choisy fait qu'il est le seul exemplaire connu en Gaule portant un décor de damasquinure. De fait, la présence d'un tel ustensile dans la villa de Charny est étonnante, car c'est une période où le balnéaire est absent, même dans les civitates proches de Iatinum et de Lutetia. Aussi, il semble judicieux de se poser la question de sa réelle utilité. Pour ce faire, il est utile de recourir à un panorama le plus exhaustif possible des découvertes de strigiles en Gaule et de mieux cerner l'histoire de cet ustensile d'origine méditerranéenne.

\section{APERÇU HISTORIQUE ET FONCTION DU STRIGILE}

$\mathrm{Au} \mathrm{I}{ }^{\mathrm{er}}$ s. apr. J.-C., Pétrone, dans le Satiricon, mentionne la rencontre entre Encolpe et Giton, ce dernier étant « appuyé contre le mur et muni des frottoirs et des racloirs de l'étuviste »(Pétrone, Satiricon, XCI). Ces objets sont des strigiles ou encore des étrilles qui servaient en Grèce et en Italie à enlever, en grattant, l'humidité et les corps étrangers (la soude, la cendre et l'huile) répandus à la surface de la peau, après les bains de vapeur ou les exercices pratiqués dans la palestre (Cicéron, De finibus bonorum et malorum, IV, 12 ; Suétone, Vie des douze Césars, Auguste, I, II, LXXX ; Perse, Satires, V, 126 ; Rich, 1995). Dès le IV e s. av. J.-C., l'utilisation du strigile avait inspiré à Lysippe sa statue de l'Apoxyomène (Pline l'Ancien, Histoire naturelle, XXXIV, 62), signe que l'objet lui-même et le geste lié à son utilisation symbolisaient à eux seuls l'univers de la palestre. Selon C. Dezobry, « ces frictions durent assez longtemps, et pour qu'elles ne deviennent pas douloureuses, il faut que le frictionneur soit doué d'une certaine habileté ». D'après cet auteur, il semble que ce traitement soit réservé aux personnes riches ou relativement aisées. En effet, « les pauvres se contentent d'une simple friction avec la main, ou bien d'une autre, plus économique encore, qu'ils s'administrent eux-mêmes, en s'aidant des murailles contre lesquelles ils se frottent les parties du corps que leurs mains ne sauraient atteindre facilement [...]»(Dezobry, 1875).

L'utilisation du strigile semble trouver ses origines chez les gymnastes grecs. La doctrine éducative élaborée par les

découverts sur l'oppidum de La Heuneburg (Allemagne), sur le Danube supérieur ou d'autres, encore, mis au jour en Espagne. 
Grecs au $V^{\mathrm{e}}$ s. comprenait la gymnastique militaire, la gymnastique médicale et la gymnastique sportive.

Le strigile utilisé dans les bains se distingue du strigile à usage médical. Ce dernier servait, entre autres fonctions, à introduire des lotions dans l'oreille et son nom est certainement dû au fait qu'il est traversé dans le sens de la longueur par un canal (Celse, De la médecine, VI, 7 ; Pline l'Ancien, Histoire naturelle, XXV, 103, 2). Pline indique également que les huiles médicamenteuses étaient élaborées en recueillant avec le strigile la sueur des athlètes mélangée aux onguents dont ils s'étaient recouverts. Ainsi, il est difficile de définir la limite entre l'utilisation habituelle (les soins du corps) et le cas particulier (l'intervention médicale). Il est important de ne pas confondre les deux types d'objets et, malheureusement, la distinction n'est pas toujours faite dans la littérature ; en l'absence d'illustration, il est parfois délicat de se prononcer pour l'un ou l'autre usage.

À l'époque romaine, la gymnastique était d'abord et surtout un moyen d'aguerrir les soldats des légions, mais également d'entraîner les gladiateurs (Thuillier, 1996). Puis la gymnastique finit par devenir une sorte d'hygiène conseillée par les médecins. La fréquentation des thermes est donc une activité incontournable qui imprègne la société et la culture, et à laquelle les jeunes enfants étaient confrontés relativement tôt (Bouet, Saragoza, 2008).

C'est au cours de la seconde moitié du $\mathrm{IV}^{\mathrm{e}} \mathrm{s}$. av. J.-C. que les strigiles se diffusent de façon importante en Italie centrale, même si quelques exemples antérieurs sont connus, le centre de diffusion initial étant certainement Praeneste, actuelle Palestrina, ancienne ville du Latium localisée à 37 km à l'est de Rome (Jolivet, 1995).

Très utilisé en Italie et en Grèce durant toute l'Antiquité, le strigile est présent à l'époque romaine en Narbonnaise, mais il est bien plus rare dans les autres provinces. Ainsi, à Ampurias, en Espagne, sur la nécropole de Bonjoan, deux strigiles datés du $\mathrm{III}^{\mathrm{e}}-\mathrm{II}^{\mathrm{e}} \mathrm{s}$. av. J.-C. ont été découverts dans deux incinérations (Almagro, 1953, vol. I, p. 163, p. 232, p. 282 et fig. 229-23). Des exemplaires sont aussi connus en Belgique, à Liberchies par exemple (Brulet, Demanet dir., 1997, p. 124, no 31 et p. 125) ou dans un tumulus à Penteville (Plumier, 1996, fig. 48 et 55, $\left.n^{\mathrm{o}} 26\right)$; en Allemagne, dans la tombe 2315 datée du $\mathrm{I}^{\mathrm{er}} \mathrm{s}$. apr. J.-C. de la nécropole de Wederath-Belginum, près de Trèves (Haffner, 1974 ; Kaiser, 2006), où quatre strigiles en fer ont été découverts ; ou encore en Angleterre dans la nécropole de Hod Hill, où un strigile en fer fut découvert au XIX ${ }^{\mathrm{e}} \mathrm{s}$. (Manning, 1985, p. 78, pl. 34) ; enfin, une nécropole hellénistique, fouillée en 1967 et 1968 à Casabianda en Corse, a livré 27 tombes, dont l'abondant et riche mobilier comprenait un strigile (Gallia, XXVII, 2, 1969, p. 459).

\section{PRÉSENTATION DU CORPUS DE GAULE ROMAINE}

Nous avons choisi de centrer le champ d'investigation sur la Gaule romaine en excluant volontairement une grande partie de la Gaule Belgique et la Germanie.

D’une façon générale, ces instruments, lorsqu'ils sont découverts en Gaule, ne font l'objet d'aucune étude spécifique et les publications étant rares, le nombre total d'exemplaires réellement découverts reste inconnu. À l'inverse, les publications sur les strigiles grecs ou romains sont plus nombreuses (Thuillier, 1989 par exemple).

Effectivement, seuls 158 strigiles, dont certains possèdent leur anneau de suspension, ont pu être répertoriés dans le cadre de la présente étude (fig. 7 et tabl. I). Les informations sont, d'une façon générale, dispersées et souvent incomplètes. Pour certains sites, le nombre de strigiles découverts n'est pas du tout mentionné, comme à Saint-Gervasy (Gard), à Belbèze-en-Comminges (Haute-Garonne), à Crézilles (Meurthe-et-Moselle) ou encore à Jouars-Pontchartrain (Yvelines). Pour certains, c'est le matériau qui n'est pas décrit (34 occurrences), pour d'autres, les contextes de découverte ne sont pas mentionnés (47 occurrences) et enfin, parfois, ni l'un ni l'autre ne sont indiqués (14 occurrences). De nombreuses découvertes ne précisent pas les dimensions des objets.

Dans bien des cas, il n'a pas été possible de revenir à la source et de vérifier les données, les publications étant parfois très anciennes. Enfin, nombre de strigiles dont les musées font état (dépôt, donation ou achat) ont une provenance inconnue, car il s'agit de découvertes et d'acquisitions anciennes qui, bien souvent, ont été faites hors contexte et pourraient bien, pour la plupart, provenir d'Italie ou de Grèce. C'est ainsi le cas, par exemple, d'un strigile en bronze, égyptien, phénicien ou grec, introduit frauduleusement dans le mobilier de la vaste villa des Baumelles à Saint-Cyr-sur-Mer, dans le Var (Brun, Borréani, 1999b, p. 648). De même, le musée archéologique de Nîmes dispose de nombreux strigiles dont la provenance est inconnue (Tendille, 1981, p. 69, fig. 5, $\mathrm{n}^{\text {os }}$ 29- 34). On peut également mentionner quatre strigiles en bronze que possède le cabinet des Médailles. Le premier, découvert en Gaule méridionale ou à proximité du limes, mesure 19,5 cm de longueur (Landes dir., 1994, p. 216 et p. 232, fig. 56). Le deuxième dispose d'une clausula dont l'extrémité est décorée d'une feuille de lierre, comme cela semble courant pour les strigiles hellénistiques (Landes dir., 1994, p. 216 et p. 232, fig. 57). Enfin, une paire de strigiles en bronze avec 


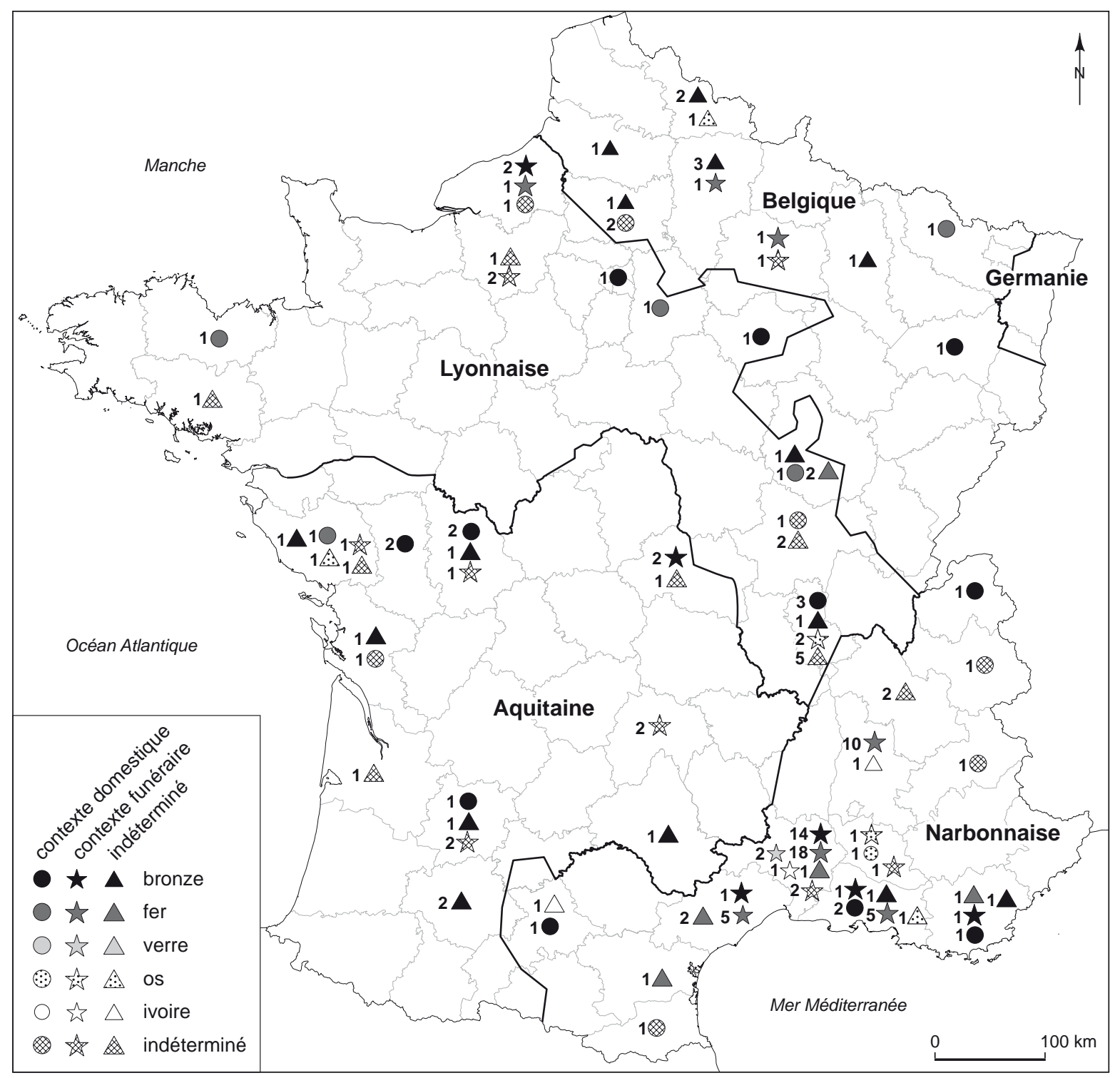

Fig. 7 - Carte de répartition des découvertes des strigiles en Gaule au $I^{\text {er }}$ s. (DAO : F. Mallet et P. Pihuit, Inrap).

anneau, mesurant chacun $21 \mathrm{~cm}$ de longueur (l'un est inventorié sous le numéro Frohner 381), présente une estampille (Landes dir., 1994, p. 215-216 et p. 231, fig. 55). Sur le premier, on peut lire dans le cartouche -C. Polii flanqué de deux motifs étoilés encadrés par deux lignes parallèles ; sur le second, le décor est le même, mais la marque est illisible. Les objets dateraient du $\mathrm{I}^{\mathrm{er}}$ s. av. J.-C.

Dans la grande majorité des cas, ces étrilles n'ont pas été retenues. De ce fait, il est délicat de synthétiser les données et d'en tirer des conclusions définitives, en particulier sur les dimensions des objets ou leurs décors, notamment sur les étrilles en fer qui, pour l'essentiel, n'ont pas été restaurées.
Néanmoins, au regard de la diffusion des strigiles en Gaule depuis la présence grecque à Marseille puis la conquête, il est possible de se faire une idée de la dimension sociale qu'a revêtue cet ustensile dans le monde romain et de l'évolution du symbolisme de cet objet. Le strigile de Charny apporte à ce sujet de nombreux éclaircissements.

\section{LES MATÉRIAUX DES STRIGILES}

Les strigiles sont avant tout reconnaissables à leur forme particulière, quel que soit leur matériau : une poignée prolongée d'une lame creuse recourbée. C'est pourquoi, 


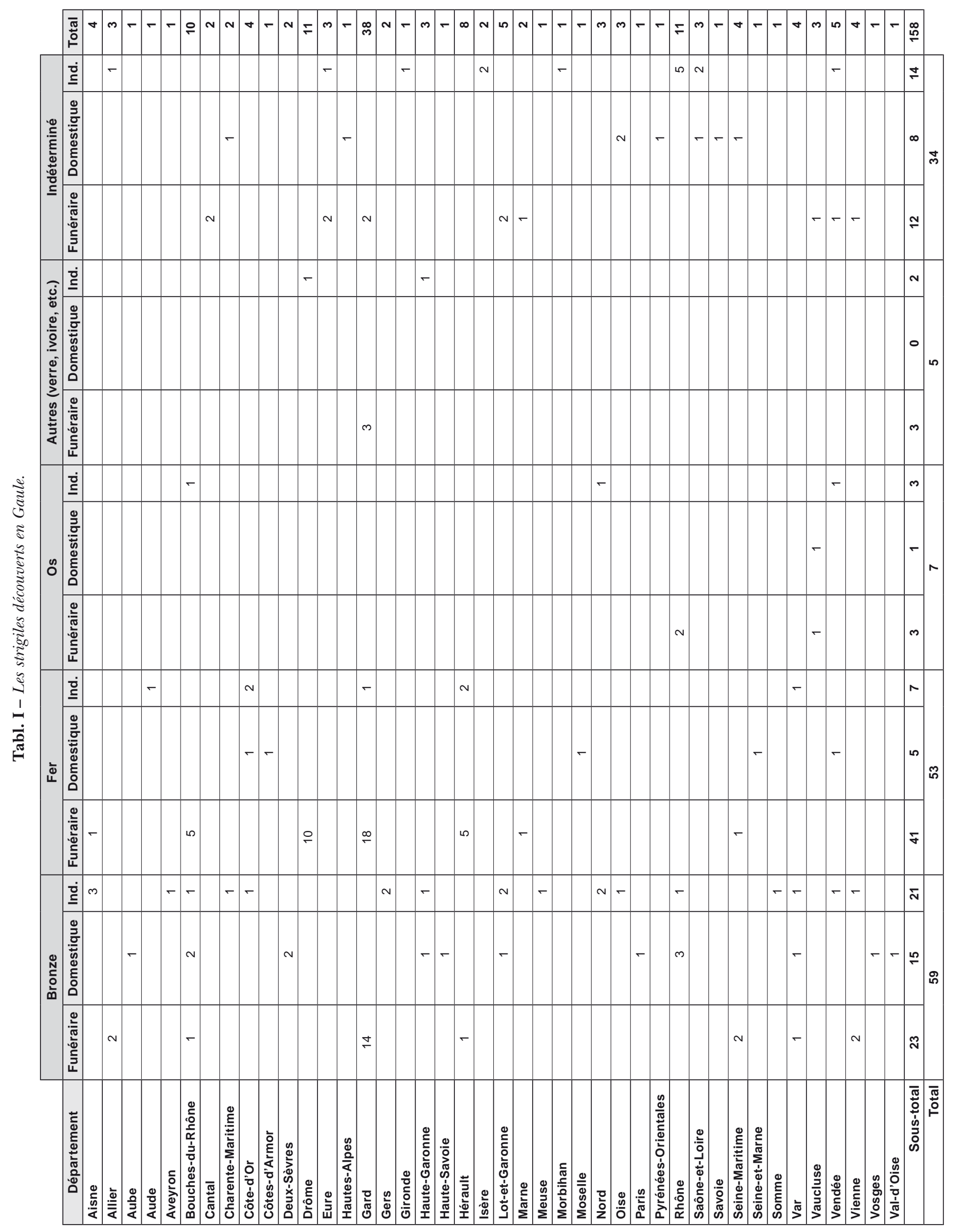


Tabl. II - Matériaux utilisés pour la fabrication des strigiles.

\begin{tabular}{|l|c|c|c|c|c|c|c|}
\hline \multicolumn{1}{|c|}{ Contexte } & Bronze & Fer & Verre & Os & Ivoire & Indéterminé & Total \\
\hline Funéraire & 23 & 41 & 2 & 3 & 1 & 12 & $\mathbf{8 2}$ \\
\hline Domestique & 15 & 5 & 0 & 1 & 0 & 8 & $\mathbf{2 9}$ \\
\hline Indéterminé & 21 & 7 & 0 & 3 & 2 & 14 & $\mathbf{4 7}$ \\
\hline Total & $\mathbf{5 9}$ & $\mathbf{5 3}$ & $\mathbf{2}$ & $\mathbf{7}$ & $\mathbf{3}$ & $\mathbf{3 4}$ & $\mathbf{1 5 8}$ \\
\hline
\end{tabular}

comme le précise J.-C. Béal, les strigiles en os répondent à la même fonction que ceux en métal même si, pour des raisons techniques, ils sont beaucoup moins arqués et munis d'un manche plus réduit, pris dans la masse (Béal, 1983).

Il peut paraître facile d'identifier ce type d'objets, particulièrement lorsqu'ils sont en bronze, même si la corrosion est importante et surtout s'ils sont découverts en contexte funéraire où ils sont régulièrement présents par paire. Il est cependant possible que des éléments métalliques, lorsqu'ils sont déposés sur les bûchers, viennent à fondre et soient rendus méconnaissables, comme cela est le cas dans la sépulture à incinération de Kerlan à Goulien, dans le Finistère (Chatelier, 1886). Quant aux strigiles en fer, ils peuvent parfois souffrir d'un état de corrosion tel que leur identification, pour peu que l'objet soit fragmenté ou incomplet, peut devenir très délicate, notamment lorsque le capulus ne dispose pas de poignée, comme cela est le cas à Charny. Ainsi, en contexte domestique, de nombreux crochets fortement corrodés pourraient être assimilés à des strigiles et de nombreux strigiles oxydés pourraient, par là même, être pris pour des crochets.

Les strigiles sont le plus couramment confectionnés en fer et/ou en bronze, rarement en argent (tabl. II). Le Louvre possède un strigile italique ( ${ }^{\circ} \mathrm{d}$ 'inv. $\mathrm{Bj}$ 2154), en argent doré, daté du I ${ }^{\mathrm{er}} \mathrm{s}$., et décoré d'une gravure de Vénus se coiffant debout sur une coquille. Il n'est pas exclu que les strigiles aient pu être façonnés dans du bois ou de la corne. Le Dictionnaire des Antiquités grecques et romaines mentionne ainsi des strigiles en électrum, en roseau, en or ou même en ébène, cités par des auteurs anciens (Daremberg, Saglio dir., 1877-1919, p. 1532-1534).

Plusieurs exemplaires en os sont répertoriés, notamment à Lyon (Béal, 1983, p. 245-246, pl. XLIII, nos 770 et 771 ; Le Mer, Chomer, 2007, p. 627 et p. 628, fig. 610) ou à Cambrai (Coulon, 1895a, p. 57-58 ; Delmaire dir., 1996, p. 159-160). Dans son catalogue lyonnais, J.-C. Béal en répertorie près de onze (auxquels viennent s'ajouter les deux exemplaires mis au jour sur la nécropole de Trion, à Lyon), dont seuls sept semblent avoir été certainement découverts en Gaule (Béal, 1983, p. 245-246). Dans le même ouvrage, cet auteur mentionne la présence de strigiles en os dont la provenance est inconnue : trois exemplaires appartiennent au musée archéologique de Nîmes, tandis qu'un exemplaire se trouve au musée de la Société archéologique de Montpellier. Enfin, il souligne l'existence d'un strigile en os dans le Cambrésis, mentionné par Coulon (Coulon, 1895b, p. 6 et p. 45, pl. III, no 3). Ces objets n'ont pas été comptabilisés dans notre étude.

Un strigile en ivoire aurait été découvert à Crest, dans la Drôme (Béal, 1983, p. 248, n. 5), et un autre a été mis au jour dans une urne cinéraire à Courbessac, dans le Gard (Béal, 1983, p. 248, n. 5 ; Béal, 1984, p. 65, no 259 ; Fiches, Veyrac, 1996, p. 474). Le manche d'un probable troisième exemplaire a été exhumé d'un remblai du $\mathrm{II}^{\mathrm{e}} \mathrm{s}$. à Toulouse (Haute-Garonne). À ce jour, seuls deux exemplaires en verre se trouvent à Nîmes (Manniez, 2005, p. 34-36).

Sur les cent cinquante-huit objets répertoriés cent douze sont en bronze ou en fer, soit $71 \%$ de l'ensemble. Cinquanteneuf strigiles $(37,7 \%$ de l'ensemble) mentionnés sont en bronze et cinquante-trois (soit $33 \%$ de l'ensemble) sont en fer. Trente-quatre sont dans un matériau qui n'a pas été mentionné. L'emploi du métal a donc été privilégié pour la fabrication des étrilles, mais il semble que l'on n'ait préféré ni le fer ni le bronze, même si certains exemplaires associent les deux, comme à Corseul (Côtes-d'Armor), où le bronze n'est qu'un élément décoratif.

\section{LES DIMENSIONS DES STRIGILES}

On se heurte ici à plusieurs écueils : manque de données et divergences dans la prise des mesures. La longueur des étrilles est souvent évoquée, mais la largeur du manche et/ou son épaisseur sont régulièrement absentes. Néanmoins, plusieurs artéfacts ont été décrits précisément. Les objets en os ou en ivoire sont généralement plus petits que leurs homologues en métal. Les plus petites pièces connues sont des répliques miniatures en verre, mises au jour dans une sépulture à incinération de l'avenue Jean-Jaurès à Nîmes (Manniez, 2005).

Malgré ces nombreuses lacunes, il est possible de présenter une illustration des principaux types de strigiles rencontrés (fig. 8 et 9) et des tableaux récapitulatifs des données métriques pour chacun des matériaux employés (tabl. III). La hauteur des objets, la largeur des capuli et celle des ligulae seront présentées. À quelques rares exceptions, la largeur des ligulae sera mentionnée.

Dans l'ensemble, et à l'exception des strigiles particuliers, la hauteur des objets ne varie guère. Elle va, pour les exemplaires en bronze, de $28 \mathrm{~cm}$ pour le plus grand, mis au jour à Étretat, Seine-Maritime (pavillon Lemaistre), à $15 \mathrm{~cm}$ pour 

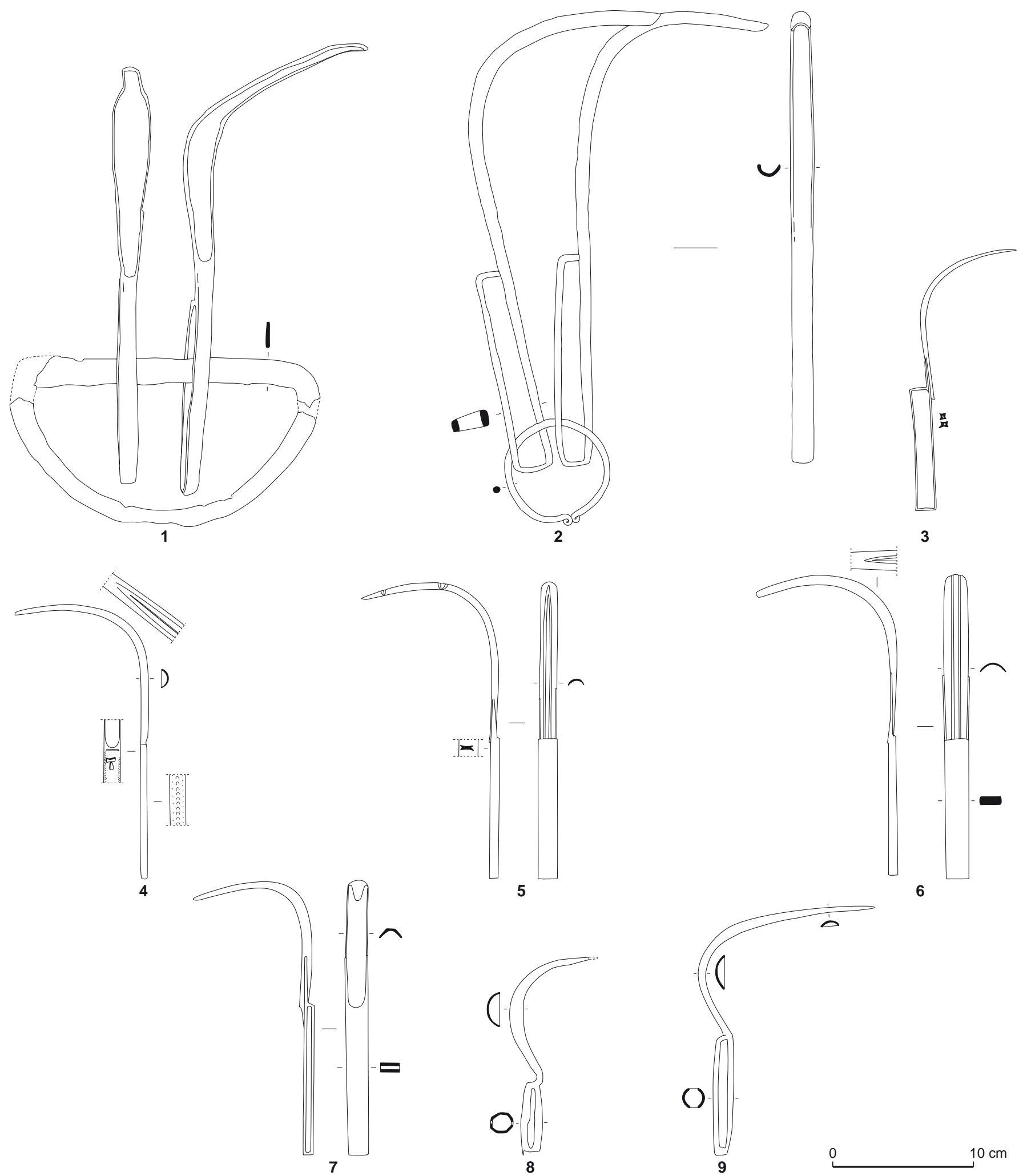

3

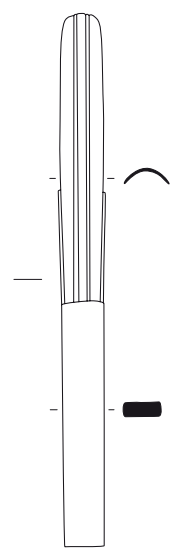

6

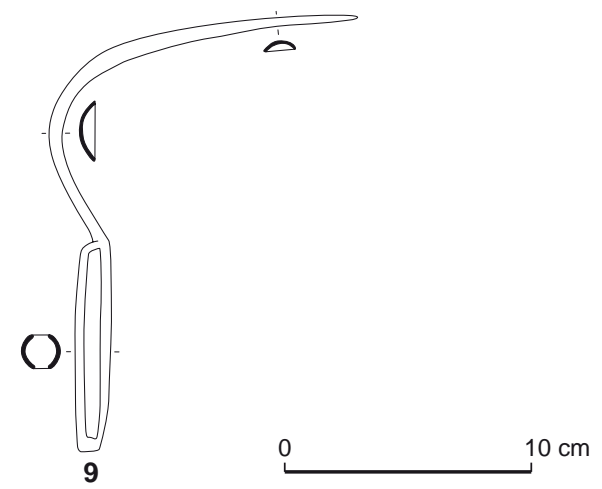

Fig. 8 - Différents types de strigiles en bronze : 1, strigiles sur leur anneau de la tombe 158 de la nécropole du Valladas à Saint-Paul-TroisChâteaux (Drôme) (d'après Bel, 2002) ; 2, paire de strigiles sur anneau de la tombe 226 du Mail de Nîmes (Gard) (d'après Feugère et al., 1995) ; 3, strigile estampillé du musée archéologique de Nîmes (d'après Tendille, 1981) ; 4, strigile estampillé de la place des Grands-Hommes à Bordeaux (Gironde) (d'après Feugère, 1997) ; 5, strigile provenant de Beaucaire portant une marque en creux (d'après Tendille, 1981) ; 6, 7, strigiles conservés au musée archéologique de Nîmes (d'après Tendille, 1981) ; 8, strigile de la tombe 158 de la nécropole du Valladas à Saint-Paul-Trois-Châteaux (d'après Bel, 2002); 9, strigile de la tombe 258 de la nécropole du Valladas à Saint-Paul-Trois-Châteaux (d'après Bel, 2002) (DAO : P. Pihuit, Inrap). 


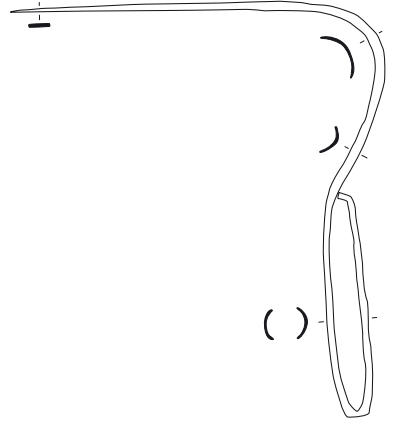

1

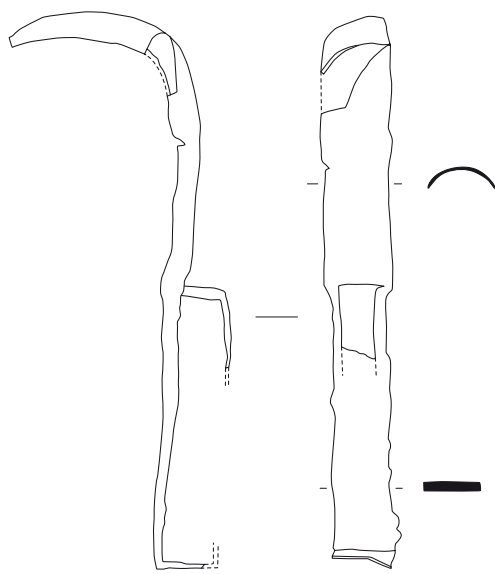

2

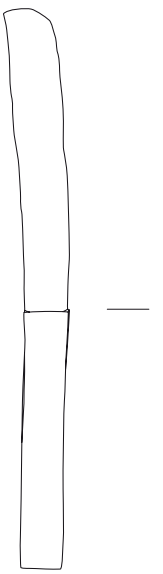

3

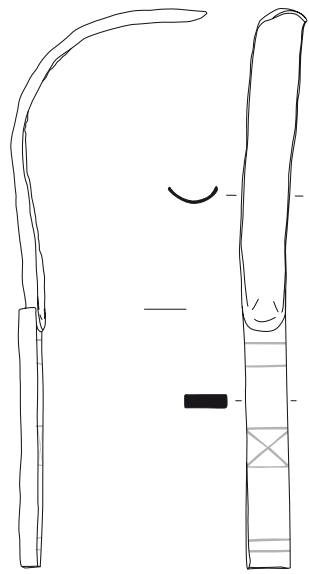
$10 \mathrm{~cm}$

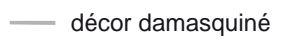

Fig. 9 - Différents types de strigiles en fer : 1, strigile du musée archéologique de Nîmes (Gard) (d'après Tendille, 1981); 2, strigile découvert dans la tombe 13 de la nécropole des Marronniers à Beaucaire (Gard) (d'après Tendille, 1981); 3, strigile mis au jour dans la villa augustéenne de Charny (Seine-et-Marne) (DAO : P. Pihuit, Inrap).

le plus petit, découvert à Villefranche-du-Queyran, Lot-etGaronne. Pour les objets en fer, le plus grand mesure $25 \mathrm{~cm}$, il a été trouvé à Saint-Paul-Trois-Châteaux dans la Drôme (le Valladas, tombe 158) et le plus petit atteint $14,4 \mathrm{~cm}$ (le Valladas, tombe 258). Quels que soient le contexte archéologique et la chronologie étudiés, il n'y a pas de différence pertinente dans la hauteur des objets, qu'ils aient été découverts dans des contextes de l'âge du Fer ou du Haut-Empire. À l'inverse, le manche des objets a des dimensions qui vont du simple au double. On peut observer que les strigiles effilés semblent présenter une lame recourbée à angle droit, à l'inverse des strigiles larges dont les lames sont recourbées en arc de cercle. L'idée de distinguer par leur largeur les étrilles utilisées par les hommes de celles utilisées par les femmes a même été évoquée (Feugère, Bel, 2002, p. 149).

Il semble bien que de nombreux exemplaires ne présentent pas de clausula, comme par exemple ceux mis au jour à Charny ou à Chassenard (Allier) .

Certaines hypothèses sur la chronologie de strigiles trouvés en Italie ont déjà été formulées (Palmer, 1964). Ainsi, les manches massifs, qui arborent les décors les plus soignés, dateraient du dernier quart du IV ${ }^{\mathrm{e}}$ s. av. J.-C., tandis que les strigiles à manche plus mince seraient postérieurs (Jolivet, 1995, p. 447). Cette réflexion a été menée sur quinze strigiles découverts en contexte archéologique et s'accompagne d'une étude de l'évolution des timbres disposés sur les capuli. Le manque de données en Gaule empêche de mener de telles enquêtes.

\section{LES DÉCORS ET LES INSCRIPTIONS}

Sur les étrilles en bronze, le décor est aisément identifiable car mieux conservé. En ce qui concerne les strigiles en fer, seule une restauration ou, le cas échéant, une radiographie peuvent permettre la reconnaissance de décors. À ce titre, le cas du strigile de Charny est exemplaire ; lors de sa découverte, l'état de corrosion de l'objet était si important que la présence de décor était indécelable.

L'existence d'un décor est commune sur ces objets. Certains exemplaires grecs ou italiques ont livré des gravures exceptionnelles. Ainsi, et à titre d'exemple, S. Reinach mentionne des strigiles italiques portant des marques diverses et parfois le nom du fabricant au génitif (Reinach, 1886). D’autres exemplaires possèdent des manches sculptés, comme celui mis au jour à Palestrina (Italie) représentant une danseuse nue tenant un petit strigile dans sa main gauche. Les gravures sont exceptionnellement rares. Certaines représentent un éphèbe nu, un nain pugiliste, des palmettes ou encore un Hermès.

De même, on peut mentionner le strigile provenant de l'auberge de Grabinianus à Pompéi, daté du I ${ }^{\text {er }}$ s. apr. J.-C. Il s'agit d'une étrille en bronze, de $19 \mathrm{~cm}$ de hauteur, dont le manche, large de 2,5 cm et recouvert d'étain, présente un Satyre dansant (Ciarallo, De Carolis dir., 2001, p. 198, fig. 252).

En Gaule, les décors se trouvent sur le revers de la ligula et sur le manche, particulièrement pour les objets en bronze, le métal se prêtant facilement à l'ornementation. Les ligulae 
Tabl. III - Dimensions des strigiles découverts en Gaule.

\begin{tabular}{|c|c|c|c|c|}
\hline Matière & Localisation & $\begin{array}{c}\text { Hauteur } \\
(\mathrm{mm})\end{array}$ & $\begin{array}{l}\text { Largeur } \\
(\mathrm{mm})\end{array}$ & $\begin{array}{l}\text { Épaisseur } \\
(\mathrm{mm})\end{array}$ \\
\hline \multirow{14}{*}{ Bronze } & Chassenard 1 (Allier) & 162 & 17 & 4 \\
\hline & Chassenard 2 (Allier) & 207 & 18 & 3 \\
\hline & Beaucaire, tombe 5 (Gard) & 165 & - & - \\
\hline & Beaucaire, tombe 13 (Gard) & 225 & 23 & - \\
\hline & Beaucaire, tombe 19-1 (Gard) & 215 & 20 & - \\
\hline & Beaucaire, tombe 19-2 (Gard) & 226 & 26 & - \\
\hline & Boissières 1 (Gard) & 195 & 13 & - \\
\hline & Boissières 2 (Gard) & 195 & 13 & - \\
\hline & Bordeaux (Gironde) & 212 & - & - \\
\hline & $\begin{array}{l}\text { Saint-Bertrand-de-Comminges } \\
\text { (Haute-Garonne) }\end{array}$ & 200 & - & - \\
\hline & $\begin{array}{l}\text { Villefranche-du-Queyran } \\
\text { (Lot-et-Garonne) }\end{array}$ & 150 & 25 & - \\
\hline & Amiens (Somme) & 230 & - & - \\
\hline & Antran, $\mathrm{n}^{\circ} 13$ (Vienne) & 188 & 19 & - \\
\hline & Antran, $\mathrm{n}^{\circ} 14$ (Vienne) & 195 & 19 & - \\
\hline \multirow{9}{*}{ Fer } & Braux (Côte-d'Or) & 180 & 22 & 3 \\
\hline & Corseul (Côtes-d'Armor) & 222 & - & - \\
\hline & $\begin{array}{l}\text { Valladas, Saint-Paul-Trois-Châteaux, } \\
\text { tombe } 258 \text { (Drôme) }\end{array}$ & 144 & 24 & - \\
\hline & \begin{tabular}{|l|} 
Valladas, Saint-Paul-Trois-Châteaux, \\
tombe 158 (Drôme)
\end{tabular} & 209 & 25 & - \\
\hline & \begin{tabular}{|l|} 
Valladas, Saint-Paul-Trois-Châteaux, \\
tombe 158 (Drôme)
\end{tabular} & 250 & - & - \\
\hline & Beaucaire, tombe 5-1 (Gard) & 195 & 14 & - \\
\hline & Beaucaire, tombe 5-2 (Gard) & 210 & 14 & - \\
\hline & Beaucaire, tombe 5-3 (Gard) & 222 & 16 & - \\
\hline & Charny (Seine-et-Marne) & 220 & 2 & 1 \\
\hline Ivoire & Courbessac (Gard) & 117 & - & 2 \\
\hline \multirow{3}{*}{ Os } & Cambrai (Nord) & 120 & - & - \\
\hline & Lyon, Trion, nº 770 (Rhône) & 156 & 15 & - \\
\hline & Lyon, Trion, n 771 (Rhône) & 105 & 16 & - \\
\hline \multirow{2}{*}{ Verre } & Nîmes, n 18 (Gard) & 84 & 5,5 & - \\
\hline & Nîmes, nº 19 (Gard) & 85,5 & 7,5 & - \\
\hline
\end{tabular}

présentent souvent des cannelures et les manches des lignes gravées sur le bord et la tranche. Certains exemplaires portent des ornementations plus complexes, comme le strigile mis au jour place des Grands-Hommes à Bordeaux (Gironde).

Cependant, il semble bien que ce soient les objets en fer qui montrent les décors les plus «sophistiqués ». L'emploi composite fer-bronze (comme à Corseul), l'emploi de nielle ${ }^{6}$ ou de la damasquinure pour les strigiles mis au jour à Chassenard sont exceptionnels. L'objet de Charny, damasquiné, fait ainsi partie des quatre exemplaires connus en Gaule qui présentent des décors élaborés.

6. C'est une incrustation décorative d'un sulfure métallique, du latin nigellum, encaustum nigrum; en italien niello.
Une clé en fer, au manche portant un décor de lignes damasquinées, a également été découverte hors contexte dans la cour de la villa de Charny (Mallet, 2006a, p. 45 ; Mallet et al., 2006, fig. 131, no 448-1 et fig. 132). Il est fort probable que cet objet puisse être rattaché à la phase augustéenne de l'occupation, même si les damasquinures présentent des compositions différentes. La clé et le strigile de Charny seraient, par conséquent, les plus anciens objets en fer à décor damasquiné connus en Gaule romaine.

Les rares objets en os sont parfois décorés. C'est le cas d'un des exemplaires découverts à Lyon, dans la nécropole de Trion.

À l'instar de ces décors, les inscriptions sur les étrilles sont peu communes. Seules six sont connues en France à Ébouleau (Aisne), à Boissières (Gard), à Cancon (Lot-etGaronne), au Mont-Beuvray (Saône-et-Loire), au Cannetdes-Maures (Var) et au musée Sainte-Croix à Poitiers (Vienne). Deux sont identifiées sur des strigiles en bronze et, à notre connaissance, aucune n'apparaît sur des strigiles en fer.

Les inscriptions sur ce type d'objets sont difficilement déchiffrables. Pour l'essentiel, il semble bien qu'il s'agisse de sobriquets. Par exemple VRBANVS, inscription découverte sur un strigile conservé au musée Sainte-Croix à Poitiers, peut ainsi faire référence à la fois à un surnom ${ }^{7}$ et à un nom de personne, comme cela est commun sur d'autres supports $^{8}$.

\section{LES CONTEXTES ET LES LIEUX DE DÉCOUVERTE}

Il faut, avant tout, garder à l'esprit que quarante étrilles ont été découvertes hors contexte ou dans un contexte non déterminé (soit 26,6\% du lot étudié).

Il ne semble pas utile de distinguer les découvertes faites en contexte domestique ou funéraire. En effet, ces objets sont comparables d'un point de vue typologique, mais surtout l'essentiel du mobilier des tombes a été, on peut le supposer, prélevé dans les accessoires appartenant aux défunts ou à son entourage, même si on ne peut exclure des dépôts effectués sans aucun lien avec la personne.

7. urbanus, a, um : à propos de la ville, de Rome ; ou poli, de bon goût, de bon ton ; ou civil, pacifique ; ou aimable, spirituel, ingénieux, enjoué ; ou plaisant, badin, railleur ; ou élégant, pur (style) ; ou arrogant, hardi, effronté, impudent ; ou, enfin à propos des plantes, cultivé, soigné.

8. Notamment les tegulae (Mallet, 2006b). 
Vingt-neuf strigiles ont été mis au jour dans des contextes domestiques, soit 18,2 \% des découvertes. Il s'agit d'exemplaires trouvés, par exemple, dans des villae, des domus ou d'autres parties de l'habitat, et toutes ces trouvailles peuvent laisser penser que les strigiles ont pu être utilisés en contexte thermal. C'est ainsi, par exemple, le cas des strigiles des agglomérations de Corseul (Kérébel, 2001), d'Auxon (Aube) et de la villa de la Côte du Rocquet à Ébouleau (Aisne), fouillée en 1859 (Pichon, 2003, p. 222). Dans le nord de la Gaule, l'essentiel des découvertes a été fait en milieu rural ou dans le cadre d'un habitat sans lien direct avec une structure balnéaire, même si celle-ci est avérée à proximité, comme par exemple à Genainville dans le Val-d'Oise. La majorité des strigiles mis au jour en contexte domestique est en bronze (15 ex. sur 29). Cinq exemplaires sont en fer tandis qu'un seul exemplaire en os a été découvert dans une insula à Vaison-la-Romaine (Sautel, 1942, p. 26 ; Béal, 1983, p. 245 et p. 248, n. 5). Parmi ces exemplaires connus, peu sont indubitablement en relation directe avec des thermes publics ou privés. On peut mentionner, à titre d'exemple, les strigiles des villae de la Croisée à Braux (Côtes-d'Or), de Crézilles (Meurthe-et-Moselle), de Tournus (Saône-et-Loire), du pavillon Lemaistre à Étretat (Seine-Maritime) ou de Noirmoutier (Vendée).

Bien plus nombreux sont les strigiles découverts en contexte funéraire. Ainsi, 82 d'entre eux, soit 51,2\% des trouvailles, ont été mis au jour dans des inhumations ou des incinérations, dont la majorité est localisée dans le sud-est de la France. Dans la plupart des cas, les strigiles sont trouvés isolés ou par paire, même si plusieurs découvertes présentent des lots plus importants. Parmi les 82 strigiles découverts en contexte funéraire, 23 sont en bronze et 41 sont en fer. Le ratio penche nettement en faveur du fer, tandis que les strigiles en verre, en os ou en ivoire, restent très minoritaires. Dans la majorité des cas, le strigile accompagne un mobilier abondant et riche. C'est le cas de ceux mis au jour dans une incinération à Chassenard (Allier), ou de ceux découverts dans la nécropole du Valladas à Saint-Paul-Trois-Châteaux (Drôme). Les exemplaires sont nombreux, notamment en Narbonnaise où 63 (soit $42 \%$ du total des découvertes) proviennent d'un contexte funéraire, ce qui représente $76 \%$ de strigiles mis au jour dans de tels contextes. L'abondance de ce type d'objets en contexte funéraire souligne assurément leur forte charge symbolique dans la Gaule du début du Principat.

Les strigiles semblent absents des sanctuaires même si, à Corent, un probable porte-strigiles peut témoigner de la présence d'étrilles sur les lieux. En effet, le fragment d'un porte-strigiles en bronze, à l'extrémité ornée d'une tête d'oiseau (un canard) ou de serpent, a été découvert dans le remplissage du fossé d'enclos du sanctuaire galloromain, daté du I ${ }^{\text {er }}$ s. av. J.-C. (Poux, 2002a, p. 27-28, fig. 16 ; Poux, 2002b, p. 27 et p. 28, fig. 19, no 364). Il est difficile d'être aussi affirmatif que l'auteur sur le fait que cet anneau orné soit réellement un porte-strigiles, même si le décor paraît s'inspirer d'étrilles fabriquées en Italie à la fin de l'époque républicaine (Poux, 2002a, p. 27). L'hypothèse de l'utilisation d'une spatule en fer comme strigile a aussi été évoquée dans le temple gallo-romain de Pédégas à Belbèze-de-Lauragais (Haute-Garonne), mais cela paraît peu probable car il semble avoir été mis au jour dans un contexte du premier âge du Fer (Manière, 2001, p. 52).

Cependant, il semble bien que le dépôt d'objets de toilette dans les temples ait été pratiqué à l'époque galloromaine.

La répartition géographique des découvertes permet d'émettre quelques réflexions (fig. 10). L'essentiel des objets mis au jour provient de la Narbonnaise (tabl. IV), région où la présence grecque est attestée dès le VII ${ }^{\mathrm{e}} \mathrm{s}$. av. J.-C. et foyer de romanisation précoce, il n'est donc guère étonnant que les étrilles y soient courantes. Ainsi, 84 exemplaires y ont été identifiés, soit près de $53 \%$ du total des découvertes. La Gaule Aquitaine (tabl. V) et la Gaule Belgique (tabl. VI) ont livré respectivement $17 \%$ et $19 \%$ de ces objets. Enfin, en Gaule lyonnaise on en a répertorié $19 \%$ (tabl. VII).

Même si le corpus est important, il est possible que ces chiffres ne reflètent pas la réalité. Ainsi, la faible quantité des objets découverts en Gaule Aquitaine peut paraître étonnante. La carte de répartition des découvertes permet d'évoquer le fait, déjà soupçonné, que les strigiles, après être apparus en Narbonnaise, ont connu une diffusion progressive dans le reste de la Gaule via les grands axes de communication et notamment les grands axes fluviaux, comme la vallée du Rhône.

\section{LA CHRONOLOGIE DES DÉCOUVERTES}

Les datations fournies sont peu nombreuses et de la plupart des découvertes anciennes n'indiquent aucun élément utile (tabl. VIII). Les chronologies sont données essentiellement par les contextes funéraires et ce majoritairement en Narbonnaise. Le strigile le plus ancien semble avoir été découvert à Lattes, dans une incinération du $\mathrm{VI}^{\mathrm{e}}$ s. av. J.-C. dans une amphore étrusque, alors que de nombreux exemplaires découverts à Marseille remontent à 


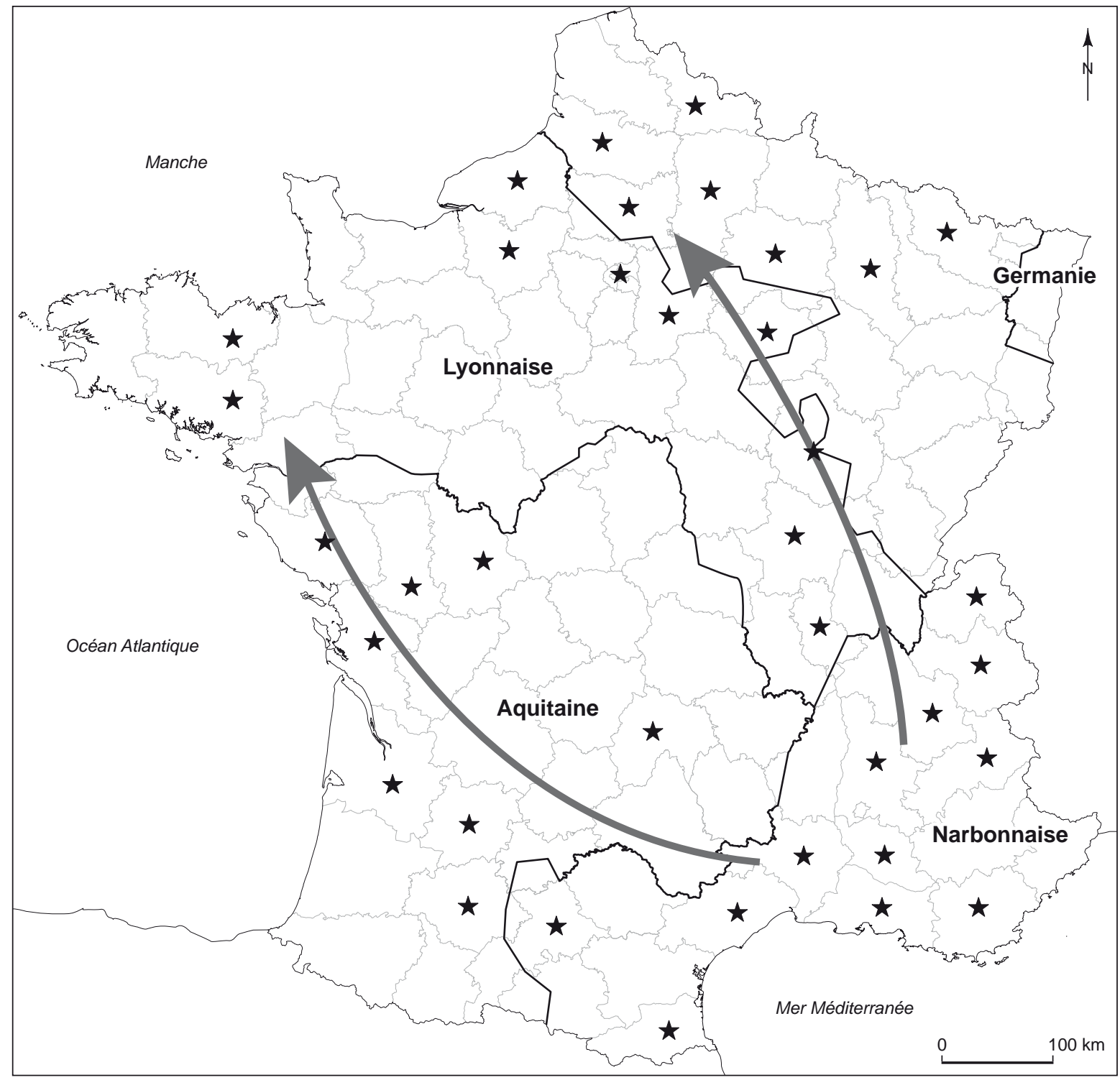

Fig. 10 - Carte de répartition des strigiles en Gaule (DAO : F. Mallet et P. Pihuit, Inrap).

l'occupation grecque : nécropole du Tapis Vert et de l'îlot Sainte-Barbe.

Dans le sud de la France, dans les départements du Gard et du Var, les strigiles semblent se multiplier au $\mathrm{I}^{\mathrm{er}}$ s. av. J.-C. à Boissières, Beaucaire et Courac (Gallia, XVI, 2, 1958, p. 437 ; Py, 1972 ; Dedet et al., 1978 ; Sudres, 1981).

En contexte domestique, la datation des objets est plus difficile, puisque la plupart sont issus de trouvailles anciennes ou ont été découverts hors contexte. On peut cependant noter que les strigiles mis au jour dans ces contextes ne sont guère antérieurs au $\mathrm{I}^{\mathrm{er}} \mathrm{s}$. apr. J.-C.
En tout état de cause, les chronologies fournies montrent que les strigiles découverts en Gaule datent, pour les plus précoces, du VI ${ }^{\mathrm{e}} \mathrm{s}$. av. J.-C. et, plus généralement, de la fin de l'âge du Fer (jusqu'aux environs de 50 av. J.-C. pour les strigiles de la nécropole de Beaucaire) et, pour les plus tardifs, de la seconde moitié du I ${ }^{\mathrm{er}}$ s. apr. J.-C., comme pour les objets de la tombe 5 de Castelnau-le-Lez (Hérault).

Une nouvelle fois, la carte de diffusion des strigiles fait coïncider la chronologie et la répartition des découvertes.

En l'état actuel des connaissances, il est difficile de connaître la part des strigiles fabriqués en Gaule et celle des objets qui pourraient provenir d'Italie. 
Tabl. IV - Les strigiles en Narbonnaise.

\begin{tabular}{|c|c|c|c|c|c|c|c|c|c|c|c|c|c|c|c|c|}
\hline \multirow[b]{2}{*}{ Département } & \multicolumn{3}{|c|}{ Bronze } & \multicolumn{3}{|c|}{ Fer } & \multicolumn{3}{|c|}{ Os } & \multicolumn{3}{|c|}{ Autres (verre, ivoire, etc.) } & \multicolumn{3}{|c|}{ Indéterminé } & \multirow[b]{2}{*}{ Total } \\
\hline & Funéraire & Domestique & Ind. & Funéraire & Domestique & Ind. & Funéraire & Domestique & Ind. & Funéraire & Domestique & Ind. & Funéraire & Domestique & Ind. & \\
\hline Aude & & & & & & 1 & & & & & & & & & & 1 \\
\hline Bouches-du-Rhône & 1 & 2 & 1 & 5 & & & & & 1 & & & & & & & 10 \\
\hline Hautes-Alpes & & & & & & & & & & & & & & 1 & & 1 \\
\hline Drôme & & & & 10 & & & & & & & & 1 & & & & 11 \\
\hline Gard & 14 & & & 18 & & 1 & & & & 3 & & & 2 & & & 38 \\
\hline Haute-Garonne & & 1 & 1 & & & & & & & & & 1 & & & & 3 \\
\hline Haute-Savoie & & 1 & & & & & & & & & & & & & & 1 \\
\hline Hérault & 1 & & & 5 & & 2 & & & & & & & & & & 8 \\
\hline Isère & & & & & & & & & & & & & & & 2 & 2 \\
\hline Pyrénées-Orientales & & & & & & & & & & & & & & 1 & & 1 \\
\hline Savoie & & & & & & & & & & & & & & 1 & & 1 \\
\hline Var & 1 & 1 & 1 & & & 1 & & & & & & & & & & 4 \\
\hline \begin{tabular}{|l|} 
Vaucluse \\
\end{tabular} & & & & & & & 1 & 1 & & & & & 1 & & & 3 \\
\hline Sous-total & 17 & 5 & 3 & 38 & 0 & 5 & 1 & 1 & 1 & 3 & 0 & 2 & 3 & 3 & 2 & 84 \\
\hline Total & & 25 & & & 43 & & & 3 & & & 5 & & & 8 & & \\
\hline
\end{tabular}

Tabl. V - Les strigiles en Gaule Aquitaine.

\begin{tabular}{|c|c|c|c|c|c|c|c|c|c|c|c|c|c|c|c|c|}
\hline \multirow[b]{2}{*}{ Département } & \multicolumn{3}{|c|}{ Bronze } & \multicolumn{3}{|c|}{ Fer } & \multicolumn{3}{|c|}{ Os } & \multicolumn{3}{|c|}{ Autres (verre, ivoire, etc.) } & \multicolumn{3}{|c|}{ Indéterminé } & \multirow[b]{2}{*}{ Total } \\
\hline & Funéraire & Domestique & Ind. & Funéraire & Domestique & Ind. & Funéraire & Domestique & Ind. & Funéraire & Domestique & Ind. & Funéraire & Domestique & Ind. & \\
\hline Allier & 2 & & & & & & & & & & & & & & 1 & 3 \\
\hline Aveyron & & & 1 & & & & & & & & & & & & & 1 \\
\hline Cantal & & & & & & & & & & & & & 2 & & & 2 \\
\hline Deux-Sèvres & & 2 & & & & & & & & & & & & & & 2 \\
\hline Charente-Maritime & & & 1 & & & & & & & & & & & 1 & & 2 \\
\hline Gers & & & 2 & & & & & & & & & & & & & 2 \\
\hline Gironde & & & & & & & & & & & & & & & 1 & 1 \\
\hline Lot-et-Garonne & & 1 & 2 & & & & & & & & & & 2 & & & 5 \\
\hline Vendée & & & 1 & & 1 & & & & 1 & & & & 1 & & 1 & 5 \\
\hline Vienne & 2 & & 1 & & & & & & & & & & 1 & & & 4 \\
\hline Sous-total & 4 & 3 & 8 & 0 & 1 & 0 & 0 & 0 & 1 & 0 & 0 & 0 & 6 & 1 & 3 & 27 \\
\hline Total & & 15 & & & 1 & & & 1 & & & 0 & & & 10 & & \\
\hline
\end{tabular}

Tabl. VI - Les strigiles en Gaule Belgique.

\begin{tabular}{|c|c|c|c|c|c|c|c|c|c|c|c|c|c|c|c|c|}
\hline \multirow[b]{2}{*}{ Département } & \multicolumn{3}{|c|}{ Bronze } & \multicolumn{3}{|c|}{ Fer } & \multicolumn{3}{|c|}{ Os } & \multicolumn{3}{|c|}{ Autres (verre, ivoire, etc.) } & \multicolumn{3}{|c|}{ Indéterminé } & \multirow[b]{2}{*}{ Total } \\
\hline & Funéraire & Domestique & Ind. & Funéraire & Domestique & Ind. & Funéraire & Domestique & Ind. & Funéraire & Domestique & Ind. & Funéraire & Domestique & Ind. & \\
\hline Aube & & 1 & & & & & & & & & & & & & & 1 \\
\hline Côte-d'Or & & & 1 & & 1 & 2 & & & & & & & & & & 4 \\
\hline Côtes-d'Armor & & & & & 1 & & & & & & & & & & & 1 \\
\hline Eure & & & & & & & & & & & & & 2 & & 1 & 3 \\
\hline Morbihan & & & & & & & & & & & & & & & 1 & 1 \\
\hline Paris & & 1 & & & & & & & & & & & & & & 1 \\
\hline Rhône & & 3 & 1 & & & & 2 & & & & & & & & 5 & 11 \\
\hline Saône-et-Loire & & & & & & & & & & & & & & 1 & 2 & 3 \\
\hline Seine-Maritime & 2 & & & 1 & & & & & & & & & & 1 & & 4 \\
\hline Seine-et-Marne & & & & & 1 & & & & & & & & & & & 1 \\
\hline Val-d'Oise & & 1 & & & & & & & & & & & & & & 1 \\
\hline Sous-total & 2 & 6 & 2 & 1 & 3 & 2 & 2 & 0 & 0 & 0 & 0 & 0 & 2 & 2 & 9 & 31 \\
\hline Total & & 10 & & & 6 & & & 2 & & & 0 & & & 13 & & \\
\hline
\end{tabular}


Tabl. VII - Les strigiles en Lyonnaise.

\begin{tabular}{|c|c|c|c|c|c|c|c|c|c|c|c|c|c|c|c|c|}
\hline \multirow[b]{2}{*}{ Département } & \multicolumn{3}{|c|}{ Bronze } & \multicolumn{3}{|c|}{ Fer } & \multicolumn{3}{|c|}{ Os } & \multicolumn{3}{|c|}{ Autres (verre, ivoire, etc.) } & \multicolumn{3}{|c|}{ Indéterminé } & \multirow[b]{2}{*}{ Total } \\
\hline & Funéraire & Domestique & Ind. & Funéraire & Domestique & Ind. & Funéraire & Domestique & Ind. & Funéraire & Domestique & Ind. & Funéraire & Domestique & Ind. & \\
\hline Aisne & & & 3 & 1 & & & & & & & & & & & & 4 \\
\hline Marne & & & & 1 & & & & & & & & & 1 & & & 2 \\
\hline Meuse & & & 1 & & & & & & & & & & & & & 1 \\
\hline Moselle & & & & & 1 & & & & & & & & & & & 1 \\
\hline Nord & & & 2 & & & & & & 1 & & & & & & & 3 \\
\hline Oise & & & 1 & & & & & & & & & & & 2 & & 3 \\
\hline Somme & & & 1 & & & & & & & & & & & & & 1 \\
\hline Vosges & & 1 & & & & & & & & & & & & & & 1 \\
\hline Sous-total & 0 & 1 & 8 & 2 & 1 & 0 & 0 & 0 & 1 & 0 & 0 & 0 & 1 & 2 & 0 & 16 \\
\hline Total & & 9 & & & 3 & & & 1 & & & 0 & & & 3 & & \\
\hline
\end{tabular}

Tabl. VIII - Chronologie des découvertes en Gaule.

\begin{tabular}{|c|c|c|c|}
\hline \multicolumn{3}{|c|}{ Localisation } & \multirow{2}{*}{ Datation } \\
\hline Lieu-dit & Commune & Département & \\
\hline La Céreirède & Lattes & Hérault & IVe s. av. J.-C. \\
\hline La Plaine Saint-Michel & Marseille & Bouches-du-Rhône & IVe ou III s. av. J.-C. \\
\hline Rue du Tapis-Vert & Marseille & Bouches-du-Rhône & 430 av. J.-C. \\
\hline Îlot Saint-Barbe & Marseille & Bouches-du-Rhône & 400-150 av. J.-C. \\
\hline Les Marronniers, tombe 19 & Beaucaire & Gard & 75 av. J.-C. \\
\hline Les Marronniers, tombe 13 & Beaucaire & Gard & 50 av. J.-C. \\
\hline Les Marronniers, tombe 21 & Beaucaire & Gard & 50-25 av. J.-C. \\
\hline Les Marronniers, tombe 5 & Beaucaire & Gard & 10 av. J.-C. / 10 apr. J.-C. \\
\hline Les Marronniers, tombe 18 & Beaucaire & Gard & 10 av. J.-C. / 10 apr. J.-C. \\
\hline Place des Grands-Hommes & Bordeaux & Gironde & 20-10 av. J.-C. \\
\hline Mail Romain & Nîmes & Gard & fer s. av. J.-C. \\
\hline \multirow[t]{2}{*}{ Rue Dagobert } & Nîmes & Gard & Ier s. av. J.-C. \\
\hline & Boé & Lot-et-Garonne & fin $I^{\text {er }}$ S. av. J.-C. \\
\hline La Croix-Verte & Antran & Vienne & fin ler s. av. J.-C. \\
\hline \multirow[t]{2}{*}{ Les Champs-de-Choisy } & Charny & Seine-et-Marne & 10 av. J.-C. / 10 apr. J.-C. \\
\hline & Auch & Gers & Haut-Empire \\
\hline Avenue Jean-Jaurès & Nîmes & Gard & Haut-Empire \\
\hline Épave Port-Vendres 2 & Port-Vendres & Pyrénées-Orientales & jer s. apr. J.-C. \\
\hline Navitau, tombe 5 & Castelnau-le-Lez & Hérault & fin ler s. apr. J.-C. \\
\hline Le Valladas, tombe 258 & Saint-Paul-Trois-Châteaux & Drôme & 100-150 apr. J.-C. \\
\hline Le Valladas, tombe 158 & Saint-Paul-Trois-Châteaux & Drôme & 150-200 apr. J.-C. \\
\hline Blaïs 7 & Le Cannet-des-Maures & Var & $\mathrm{I}^{\mathrm{er}}-\mathrm{II}^{\mathrm{e}}$ s. apr. J.-C. \\
\hline Courac I & Tresques & Gard & |er-II s. apr. J.-C. \\
\hline \multirow[t]{2}{*}{ Le Grand Lou I } & La Rocquebrussanne & Var & fin $I^{\mathrm{e}} \mathrm{s}$. apr. J.-C. \\
\hline & Le Bernard & Vendée & fin II ${ }^{\mathrm{e}}$ s. apr. J.-C. \\
\hline Les Vaux-de-la-Celle & Genainville & Val-d'Oise & fin Ile s. apr. J.-C. \\
\hline Rue Sainte-Anne & Toulouse & Haute-Garonne & fin II $\mathrm{e}$ s. apr. J.-C. \\
\hline Place des Célestins & Lyon & Rhône & $\mathrm{II}^{\mathrm{e}}-\mathrm{II}^{\mathrm{e}}$ s. apr. J.-C. \\
\hline Rue Pierre-Leca & Marseille & Bouches-du-Rhône & $\mathrm{III}^{\mathrm{e}}$ s. apr. J.-C. \\
\hline \multirow[t]{2}{*}{ La Source Chomel } & Vichy & Allier & III e s. apr. J.-C. \\
\hline & Eslettes & Seine-Maritime & Haut Moyen Âge \\
\hline
\end{tabular}




\section{DE L'UTILITÉ DU STRIGILE À SON "PARAÎTRE À LA ROMAINE »}

Le strigile découvert à Charny ne comporte aucun aménagement particulier à l'extrémité du manche et surtout il ne présente pas de clausula, ce dernier élément étant essentiel pour suspendre l'étrille ou la porter à la ceinture grâce à un anneau. L'étrille est alors accompagnée d'un puisoir et d'un flacon d'huile, comme le montrent de nombreux exemplaires italiques ou gaulois. Comme celui de Charny, de nombreux strigiles mis au jour ne possèdent pas de clausula, ce qui pose le problème de savoir si certains de ces objets ont pu réellement servir ou pas. Cependant, certains exemplaires disposent d'aménagements particuliers, comme celui découvert à Noyon (Oise) pour lequel le manche présente une fente à l'extrémité, permettant d'y glisser des liens pour suspendre l'objet. Les strigiles en bronze du musée Saint-Croix à Poitiers disposent d'une clausula fermée dont la fente ne dépasse guère $2 \mathrm{~mm}$. Même si la clausula n'est pas indispensable pour se servir de l'objet (certains ne possèdent pas de manche arrondi pour faciliter la préhension mais un petit creux à la jonction du capulus et de la ligula, pour y placer le pouce), il semble évident que, lorsqu'elle n'est pas suffisamment large, elle rend difficile, du fait de la sueur se dégageant des corps, une prise en main efficace du manche (ou de l'objet). Cette absence semble dès lors poser un problème d'ordre technique et fonctionnel non seulement pour les manches qui mesurent moins de 1,5 cm de largeur, mais surtout pour ceux dont l'épaisseur est faible, à l'instar de l'objet de Charny. Cette étrille trouve des comparaisons directes avec de nombreuses autres étrilles en fer, dont certaines de Chassenard, mais également avec des exemplaires en os, notamment ceux mis au jour dans une incinération de la nécropole du Trion à Lyon dont les manches relativement courts et peu épais ne disposent d'aucun moyen de suspension et ne permettent pas de préhension efficace ${ }^{9}$. D'autres objets montrent des manches apparemment inadaptés, comme par exemple l'étrille mise au jour à Blossac (commune de Saint-Hilaire, Vienne), dont le manche est cylindrique. Cela ne paraît guère pratique pour une prise ferme en cours d'utilisation. Néanmoins, il faut garder à l'esprit que la copie romaine de l'Apoxyomène de Lysippe semble bien tenir aisément un strigile au manche de section carrée ne disposant pas de clausula! Il faut imaginer cependant que de nombreux strigiles ont été utilisés par une tierce personne, notamment dans les thermes où ces soins étaient prodigués par des esclaves.

9. À moins qu'il ne faille voir définitivement dans ces objets en os que des strigiles à usage médical ?
La morphologie de l'étrille de Charny et des quelques autres objets mentionnés semble donc peu compatible avec leur utilisation dans une sphère thermale. Cela est d'autant plus plausible que la villa des Champs-de-Choisy, selon toute vraisemblance, ne dispose pas d'une zone balnéaire à l'époque augustéenne ; même si seule la partie septentrionale de la villa et plus particulièrement de la pars urbana a été mise au jour, il paraît peu probable que des bains aient existé à cette époque dans les parties détruites dans les années 1970. Il semble bien, en effet, que ce confort public ou privé soit inconnu dans les habitats précoces fouillés en Île-de-France, comme ceux de Meaux (Iatinum) ou de Paris (Lutetia), par exemple. En Aquitaine, c'est vers 15-10 av. J.-C. qu'est mis en place le balnéaire public antérieur à la domus de la rue des Bouquets à Périgueux, en Dordogne (Bouet, 2001, p. 242). En Narbonnaise, les thermes apparaissent un peu plus tôt, comme ceux de Glanum (Saint-Rémy-de-Provence, Bouches-du-Rhône), mis en place vers 40-20 av. J.-C. (Bouet, 2004, vol. II, p. 237-239), d'autres sont plus tardifs, comme ceux de Montfau à Magalas, dans l'Hérault, mis en place vers 15-40 apr. J.-C. (Bouet, 2004, vol. II, p. 151-154). En Lyonnaise, seuls les thermes de la Croix-Saint-Charles à Alésia (Alise-Sainte-Reine, Côte-d'Or) pourraient éventuellement remonter à l'époque augustéenne (Espérandieu, 1912) ou julio-claudienne (Grenier, 1960). Enfin, d'une manière générale, les balnéaires ne semblent pas se développer en nombre dans le sud-ouest de la Gaule avant le tout début du $\mathrm{I}^{\mathrm{er}}$ s. apr. J.-C. Ainsi, par exemple, les thermes publics mis au jour sur dans l'agglomération antique de Saint-Jean-le-Vieux (Pyrénées-Atlantiques), datés aux environs de 20 apr. J.-C., sont un des premiers témoignages de la pratique du balnéaire dans le sud-ouest (Bouet, Tobie, 2003).

Peut-on alors imaginer que le strigile de Charny et de nombreux autres aient eu une autre fonction que de servir à se racler la peau au sortir des bains ?

C'est certainement au travers de la découverte de tels objets dans les sépultures que l'on peut imaginer l'évolution particulière qu'a pu avoir le strigile en Gaule entre le $\mathrm{V}^{\mathrm{e}}$ s. av. J.-C. et la fin du Haut-Empire.

La découverte en Gaule de strigiles dans les tombes à incinération dès le $\mathrm{VI}^{\mathrm{e}} \mathrm{s}$. av. J.-C. semble bien participer d'une tradition empruntée strictement à la culture méditerranéenne dans laquelle le strigile a sa place en tant qu'objet personnel.

Le dépôt d'objets liés à l'hygiène corporelle, ayant éventuellement servi pour la toilette du mort, se retrouve régulièrement dans les tombes. Ces objets y sont déposés sans doute comme des accessoires ayant appartenu au défunt. 
Le strigile, à l'instar des rasoirs ou des miroirs, ne doit pas déroger à cette règle. Il ne paraît donc pas étonnant que certaines incinérations puissent contenir de nombreux strigiles, comme la tombe 5 de la nécropole des Marronniers à Beaucaire (Gard) ou celle de Boissières (Gard) qui en recélaient chacune quatre. En tout état de cause, il semble acquis que le mobilier déposé dans les tombes a appartenu au défunt et, qu'en ce sens, il rappelle le mode de vie et les fonctions qu'il a occupées de son vivant. Le strigile apparaît donc comme un élément fort de la panoplie personnelle du défunt.

L'objet ne semble être présent qu'à partir de la conquête romaine. En effet, lorsque la Provincia (ce n'est pas encore la Narbonnaise) est conquise par Rome, elle voit l'installation de vétérans et l'émergence de notables indigènes qui adoptent rapidement les signes extérieurs d'un mode de vie romanisé.

Dès lors, le strigile devient un des objets important dans les signes de la romanisation. Cependant, il a dû revêtir des aspects symboliques bien différents selon qu'il a appartenu à un vétéran, à un colon ou à un notable gaulois.

En effet, en Gaule méridionale, où l'objet est très courant dans les sépultures à incinération, il semble bien perpétuer directement les traditions grecques et romaines antérieures : il s'agit peut-être alors, dans ces cas précis, de sépultures de vétérans ou de colons.

Même si ces objets ne sont pas présents dans toutes les tombes et s'ils ne sont pas les seuls symboles de la romanité, ils sont cependant un marqueur fort de l'influence italique. Dès avant le règne d'Auguste, ces influences méditerranéennes ont fortement marqué le domaine funéraire. Nous sommes alors dans un cadre chronologique qui tend à privilégier l'incinération, où le dépôt d'offrandes, sur le bûcher, et/ou au-dessus de la tombe, est la norme. Or, le strigile, à l'instar de nombreux autres objets de toilette, ne peut être considéré comme une offrande. Objet ayant appartenu au défunt de son vivant, il renvoie davantage au statut social du défunt. À ce titre, rares sont les publications précisant que les strigiles portaient les traces d'un passage au feu. En effet, la disposition des offrandes sur le bûcher, dites primaires, ou sur la tombe, dites secondaires, pourrait ne pas avoir la même portée symbolique.

Dans les Trois Gaules, il semble que le strigile, même s'il est un exemple de tradition romaine, a pu constituer dans certains cas un symbole d'aptitude à exercer un pouvoir particulier, indicateur du statut social de celui qui le possède. En effet, à cette période, il paraît douteux que de tels objets soient acquis durant l'enfance et participent de l'éducation, et qu'ils aient jamais servi en milieu thermal, le balnéaire étant absent à l'aube de notre ère. De même, les strigiles découverts ne semblent pas avoir appartenu à des vétérans ou à des colons, même si cela ne peut pas être exclu.

L'objet découvert à Charny permet d'apporter des éclaircissements sur l'aspect symbolique des strigiles. Cette étrille a été mise au jour avec des restes mobiliers exceptionnels : un buste anthropomorphe en calcaire (fig. 11), la partie sommitale d'un bétyle (fig. 12), une monnaie gauloise en argent ${ }^{10}$, des militaria (trois clous de caligae, un fragment de résille en bronze ayant orné la face avers du fourreau d'une arme de poing, un petit élément de harnachement circulaire possédant un rivet), un fragment de miroir en argent, des fibules et de la céramique indiquant un niveau de vie aisé (Séguier et al., 2005). De plus, une clé en fer au décor de lignes damasquinées, trouvée hors contexte, pourrait très bien avoir appartenu à la phase précoce de l'occupation au regard de son traitement décoratif (fig. 13). Tous ces éléments indiquent la position sociale du propriétaire de l'établissement et précisent, en définitive, que le strigile de Charny est gaulois.

Ce dernier a pu appartenir à un membre de l'élite foncière gauloise en voie de romanisation. Cette aristocratie encore armée, comme à la fin de l'âge du Fer, est assimilée à la classe des equites et occupera des charges dans l'administration de la civitas. Il est admis que ces élites sont à l'origine de la mise en place d'un premier réseau de villae autour desquelles s'organiseront les réseaux d'exploitations rurales à la période gallo-romaine précoce. Si c'est le cas, il est probable que ces élites aient eu besoin d'afficher leur statut et leur position sociale. Les éléments mobiliers mis au jour à Charny semblent le confirmer. Ainsi, la quantité importante de sigillée de type italique distingue nettement Charny des autres établissements augustéens de la région, mais se rapproche de ce que l'on observe à Lutèce. Les amphores vont également dans le même sens puisque certains des vins présents sont réputés être des crus de qualité.

Le strigile de Charny a-t-il jamais servi ? À l'instar des strigiles en verre mis au jour dans la sépulture 1113 de

10. Il s'agit du type BN 5762 (La Tour, pl. XVII). Vallée du Rhône. Argent. 1,75 g : D/tête casquée à droite, imitée de celle de Rome ; devant la face, le pied des lettres vers l'extérieur, la légende en caractère latin (DVR) NACOS. R/Cavalier armé d'une lance chargeant à droite, son manteau flottant sur l'épaule. Au-dessous, la légende AVSCROCOS. Cette monnaie qui a beaucoup circulé appartient au groupe IV des monnaies au cavalier, suivant le classement défini par Antonin Deroc (Deroc, 1983). Il situe les premières frappes de ce monnayage au cavalier vers 75 av. J.-C. et les dernières au moment de la conquête. 

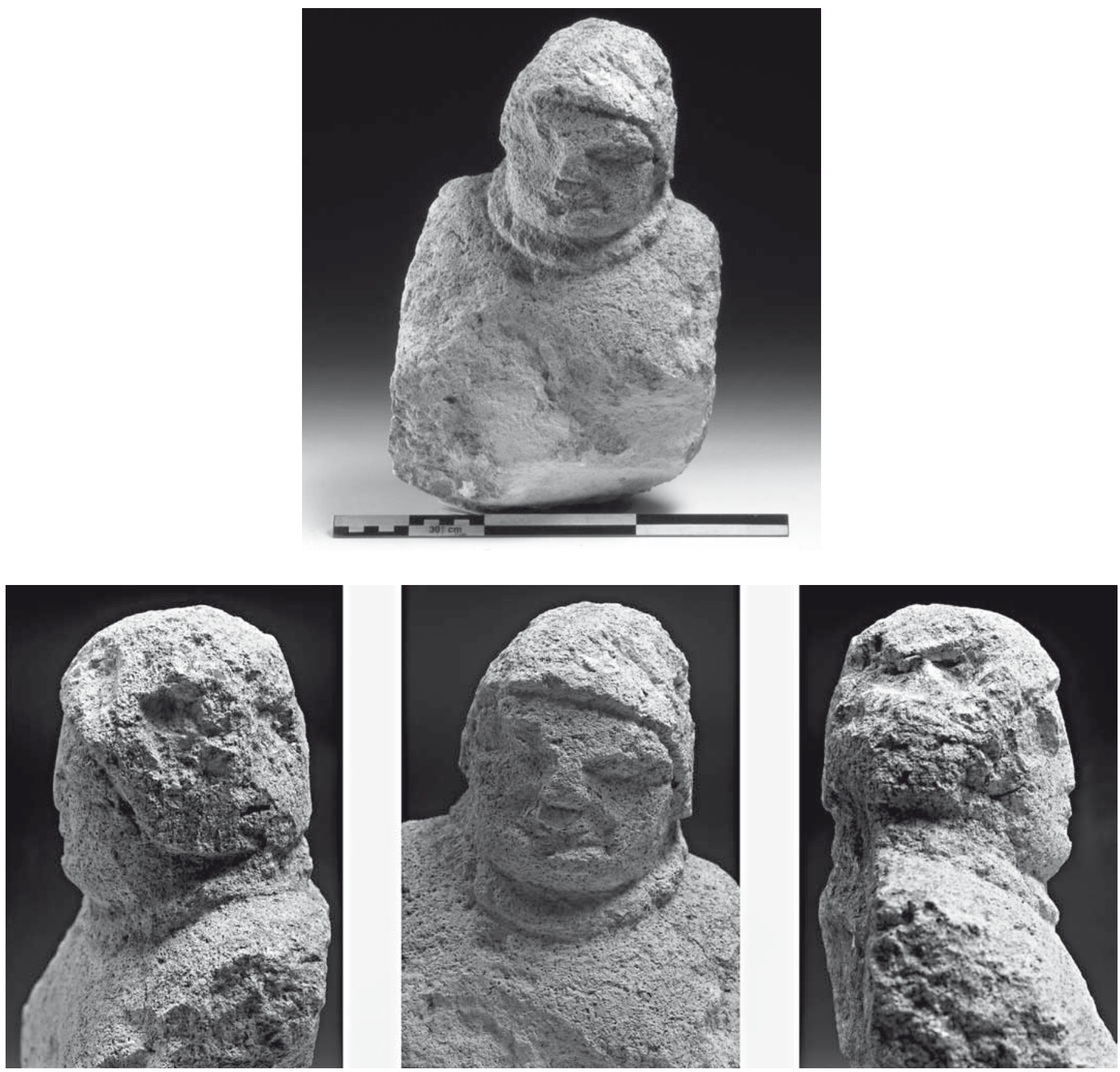

Fig. 11 - Buste anthropomorphe en calcaire découvert à Charny (cliché : V. Brunet, Inrap).

l'avenue Jean-Jaurès à Nîmes, peut-être n'a-t-il eu qu'une fonction ostentatoire. On sait que les étrilles mises au jour dans les tombes en Gaule romaine sont les témoignages de la «romanité » de leur propriétaire ou d'une volonté de paraître romain. De même, l'utilisation de la damasquinure dans la décoration de ce strigile est le reflet de la volonté manifeste de personnaliser cet objet.
De nombreux autres objets de toilette présents dans les tombes pourraient avoir pour but d'affirmer la romanité du défunt, comme cela a déjà été évoqué (Feugère, 1993).

Au-delà du I ${ }^{\text {er }}$ s. apr. J.-C., il est difficile de savoir si le strigile continue d'être un symbole de romanité dans le nord de la Gaule et, d'une façon plus générale, dans l'ensemble de la Gaule, même si en Belgique actuelle, une étrille 

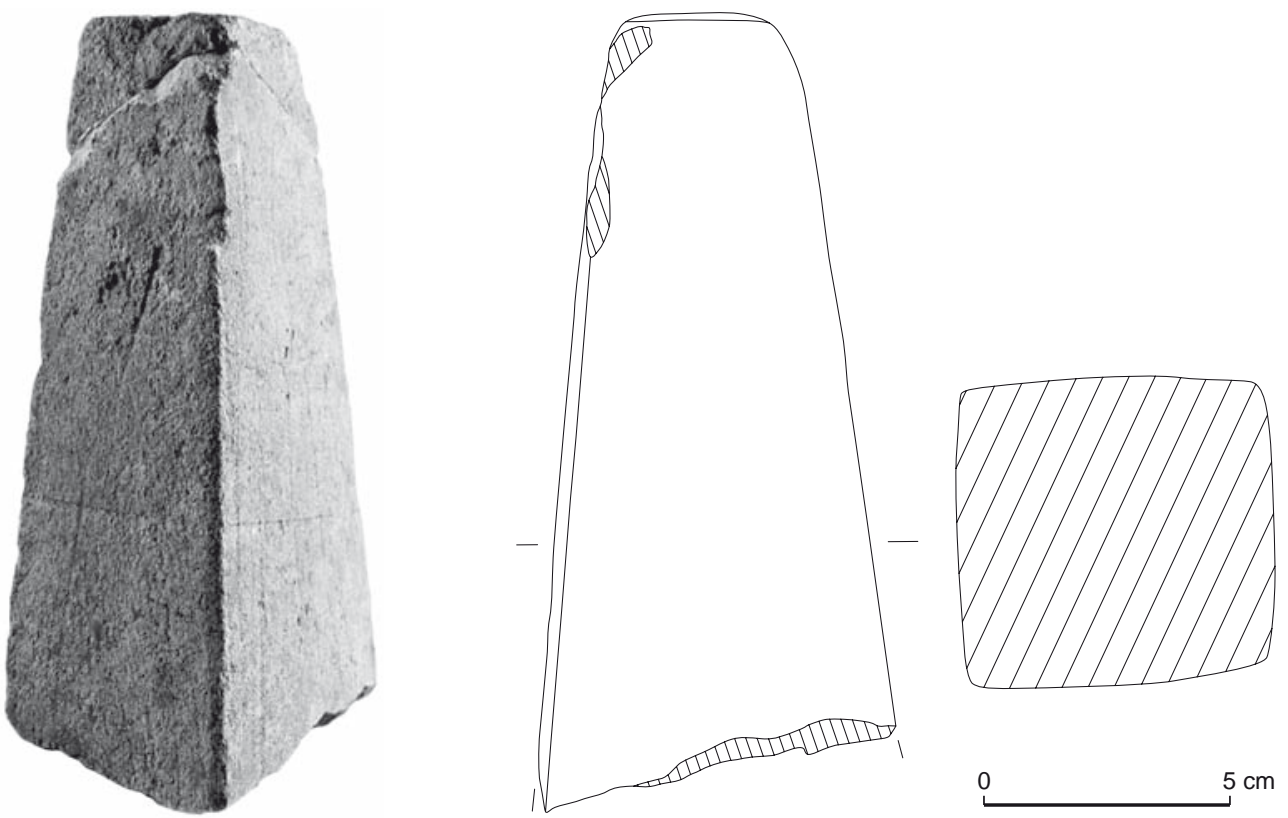

Fig. 12 - Fragment de bétyle découvert à Charny (cliché : V. Brunet, Inrap; dessin : P. Pihuit, Inrap).

a été découverte en contexte funéraire pour le dernier tiers du $\mathrm{II}^{\mathrm{e}}$ s. apr. J.-C. (Plumier, 1996). Peu de villae livrent des étrilles aux $\mathrm{II}^{\mathrm{e}}$ et $\mathrm{III}^{\mathrm{e}}$ s., alors que le balnéaire devient un confort relativement commun. Ainsi, on peut s'étonner de l'absence de cet objet dans toutes les grandes villae disposant d'un confort thermal développé, comme celles de Montmaurin, en Haute-Garonne (Fouet, 1983), de Chasseylès-Montbozon, en Haute-Saône (Barbet, Gandel dir., 1997), ou encore de Champion à Hamois en Belgique (Van Ossel, Defgnée, 2001), ou de Champ Madame à Beaumont dans le Puy-de-Dôme (Alfonso, Blaizot dir., 2004). À l'inverse, cet objet est découvert dans l'établissement plus modeste de la Croisée à Braux en Côte-d'Or (Farine, 1999, p. 287, fig. 219, $\mathrm{n}^{\circ} 57$ ). Ces villae, disposant d'un confort imposant et faisant montre d'un certain luxe, ont été la propriété de personnes aisées. Le strigile n'y a cependant pas le rôle ostentatoire qu'il a pu avoir antérieurement.

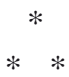

\section{DU FONCTIONNEL AU SYMBOLIQUE}

Le strigile a longtemps eu en Gaule un aspect très symbolique, depuis sa présence dans les tombes grecques de Marseille jusqu'à son apparition à l'aube de notre ère en Gallia comata, mais il semble que sa portée sociale ait évolué avec le temps, à mesure que sa diffusion en Gaule gagnait les provinces septentrionales.

On l'a vu, les strigiles mis au jour dans les tombes grecques de Marseille, datées entre le $\mathrm{V}^{\mathrm{e}}$ et le $\mathrm{II}^{\mathrm{e}} \mathrm{s}$. av. J.-C., semblent perpétuer une tradition : en effet, que l'on soit un homme ou une femme, on se fait incinérer et accompagner d'un objet personnel acquis depuis le plus jeune âge. Cet objet fait alors partie de la panoplie de la vie quotidienne de l'adulte depuis l'adolescence et participe de l'épanouissement de l'individu.

En Gaule, à partir de la conquête romaine, l'étrille rappelle différents aspects de la vie quotidienne à la romaine. Parmi les Gaulois promus à des fonctions administratives, le strigile a pu, très vite, représenter le statut social de son propriétaire et éventuellement son rôle politique plutôt que d'avoir eu un rôle purement fonctionnel, particulièrement dans les provinces où les thermes sont encore absents. Ainsi, le strigile est un objet que l'on s'est approprié pour en faire le symbole d'une réussite sociale, réunissant à la fois les notions de pouvoir et d'otium.

Cela a dû être le cas pour l'étrille de Charny. Dans la villa des Champs-de-Choisy, de nombreux autres témoins mobiliers manifestent que les propriétaires des lieux vivaient à la mode romaine. Plusieurs éléments peuvent être liés à la position économique et à l'affichage social des occupants, à l'instar de bien d'autres marqueurs (consommation carnée, mobilier métallique, type de vin) qui pourraient désigner 


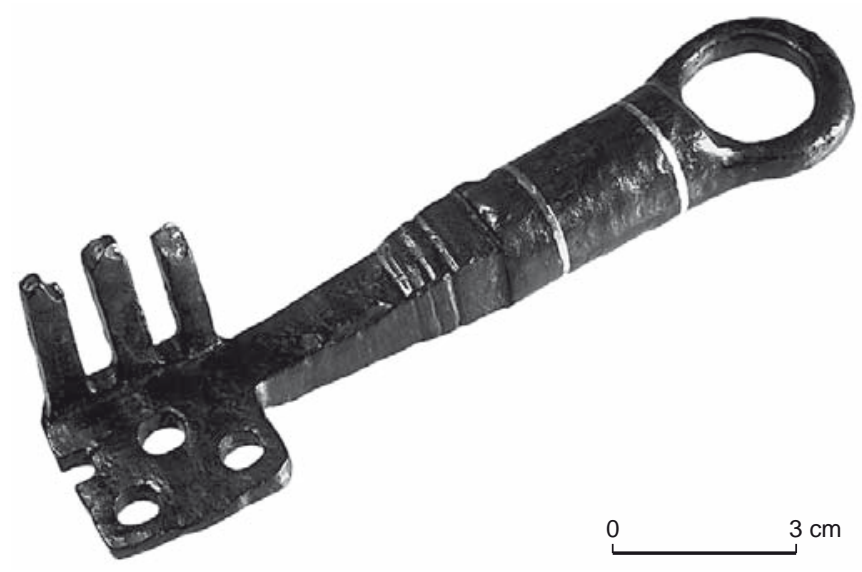

Fig. 13 - Clé damasquinée mise au jour à Charny (cliché : V. Brunet, Inrap).

les occupants comme des héritiers de l'aristocratie gauloise, jouissant d'un statut éminent (Séguier et al., 2005). On peut néanmoins s'étonner de ne pas avoir découvert l'étrille de Charny en contexte funéraire ; sa présence dans le remblai d'un fossé d'enclos soulève de nombreuses interrogations.

Le fossé est un lieu important : localisé à proximité du bâtiment résidentiel, il matérialise non seulement la limite de l'espace habité mais également un lieu de transition. Le comblement de nombreux fossés gaulois a ainsi des origines cultuelles. Peut-on voir dans le rassemblement de tant d'objets atypiques à Charny la volonté de faire une offrande aux divinités protectrices ? L'ensemble du mobilier a été découvert dans une petite portion du fossé nord de l'enclos précoce. De ce point de vue, l'ensemble des vestiges mobiliers ne devrait donc rien à une volonté de combler les fossés de détritus. Dans ce cas, l'enfouissement du strigile dans le fossé d'enclos avec de nombreux objets ostentatoires soulève alors des questions, non seulement sur les éventuels bouleversements qui ont pu avoir lieu dans la villa à la fin de l'époque augustéenne, mais également sur le futur rôle social du propriétaire des lieux. Or, la villa trouve un nouvel épanouissement dans le courant des $\mathrm{II}^{\mathrm{e}}$ et $\mathrm{III}^{\mathrm{e}} \mathrm{s}$. avec un bâtiment résidentiel qui se développe, notamment par l'adjonction d'une annexe thermale, de nombreuses pièces disposant de peintures murales et un important mobilier qui témoigne une nouvelle fois de l'aisance des habitants des lieux (Mallet, 2006a ; Mallet et al., 2006). Dès lors, il ne paraît guère possible d'envisager que les vestiges rejetés dans les fossés précoces puissent être seulement mis sur le compte d'un bouleversement de l'occupation et par la même du statut des propriétaires. L'hypothèse d'un dépôt volontaire, probablement associé à la sphère cultuelle, en contexte domestique, pourrait donc trouver ici toute sa logique, même si cette fonction est marginale dans les contextes que nous avons préalablement évoqués. Le strigile, instrument au symbolisme culturel et social fort, objet de romanité par excellence, trouve ainsi parfaitement une place de choix parmi le riche mobilier qui lui est associé ${ }^{11}$.

\section{ANNEXE I}

\section{INVENTAIRE DES DÉCOUVERTES}

\section{AISNE : 4 objets}

\section{Ébouleau, Goudelancourt-lès-Pierrepont, la Côte du Rocquet : 3 en bronze.}

Trois strigiles passés dans un anneau portant l'estampille VASNVS (CIL, XIII, 10027, 184) ont été découverts en 1859 à l'endroit d'une probable villa. Le dessin des objets montre que les strigiles disposent chacun d'une ligula décorée et d'un manche avec une clausula permettant de les glisser dans leur anneau (Fleury, 1877-1878, vol. I, p. 213 ; Pichon, 2003, p. 222, fig. 255). Les objets en bronze semblent avoir été ramassés à l'occasion d'une prospection pédestre. De fait, le contexte de leur découverte est inconnu, même s'il semble domestique.

Soissons, les Longues Raies : 1 en fer.

La fouille d'une nécropole, menée en 1897, a permis la découverte de plusieurs inhumations et de rares incinérations datées entre la fin du I ${ }^{\mathrm{er}}$ s. et le $\mathrm{IV}^{\mathrm{e}} \mathrm{s}$. apr. J.-C. Parmi le riche mobilier mis au jour, un strigile en fer a été découvert (Vauvillé, 1911, p. 300-304 ; Pichon, 2003, p. 451-452). On peut regretter que l'objet ne soit pas dessiné dans l'ouvrage de Boulanger (Boulanger, 1902-1905).

11. L'auteur tient à remercier tout particulièrement Michel Feugère, pour son aide précieuse et ses nombreux conseils. 


\section{ALLIER : 3 objets}

Chassenard : 2 en bronze.

Deux strigiles en bronze niellé ont été découverts dans une sépulture à incinération en 1874, près de Digoin (Beck, Chew, 1991, p. 81-83). Le premier mesure $16,2 \mathrm{~cm}$ de longueur, 1,7 cm de largeur et présente une épaisseur de $0,4 \mathrm{~cm}$. Il est décoré d'une forme végétale se rapprochant du lierre et d'un décor de lunules. Le second mesure 20,7 cm de longueur, $1,8 \mathrm{~cm}$ de largeur et présente une épaisseur de $0,5 \mathrm{~cm}$. Les deux objets se trouvent au musée de SaintGermain-en-Laye et ont été acquis en 1904. Les étrilles étaient accompagnées d'un important ensemble mobilier, notamment quatre coins monétaires, un glaive avec son cingulum, une cotte de mailles, un casque à visage et un torque qui laisse à penser que le défunt était un soldat et qu'il a dû avoir un rôle officiel confié par l'administration romaine (Feugère, 2002, p. 35-36). La date d'enfouissement est estimée à 40 apr. J.-C.

Vichy, la source Chomel : 1 dont le matériau est indéterminé.

En 1944, un strigile a été mis au jour lors de la fouille d'un puits de captage romain comblé dans le courant du III $^{\text {e }}$ s. apr. J.-C. Cet objet mesure 22 cm (Morlet, 1957, p. 32 et fig. 13 ; Corrocher et al., 1989, p. 143).

\section{AUBE : 1 objet}

Auxon : 1 en bronze.

Un strigile en bronze a été découvert à l'emplacement de l'agglomération antique. L'objet a été déposé au musée de Troyes en 1882 (Denajar, 2005, p. 240).

\section{AUDE : 1 objet}

Mailhac, le Cayla : 1 en fer.

Une fouille menée en septembre 1936 à Mailhac a livré un strigile en fer possédant une clausula. L'objet est conservé au musée de Mailhac (comm. pers. M. Feugère).

\section{AVEYRON : 1 objet}

Rodez, Ouest-le-Château : 1 en bronze.

Un strigile en bronze, dont il ne manque que l'extrémité de la ligula a été découvert à Rodez. L'objet présente une clausula dont l'extrémité en forme de cuillère reprend le galbe de la lame recourbée (comm. pers. M. Feugère).

\section{BOUCHES-DU-RHÔNE : 10 objets}

Arles, musée Réatu : 1 en os.

Le musée Réatu d'Arles conserve dans ses collections un strigile en os (inv. 250) dont la provenance serait locale (Béal, 1983, p. 248, n. 5).

Arles, thermes de Constantin, égouts des cryptoportiques : 1 en bronze.

Ce strigile en bronze est conservé au musée de l'Arles et de la Provence antique (Sintès dir., 1996 ; Heijmans, 2003). Marseille, îlot Sainte-Barbe : 4 en fer.

Une nécropole grecque et romaine a été fouillée au début des années 1990. Parmi les cent-cinq tombes d'époque grecque (66 inhumations et 29 incinérations), dont les datations s'échelonnent entre 400 et 150 av. J.-C., les tombes 99 et 19 ont livré quatre strigiles en fer (Moliner dir., 1993, p. 16-25 et 2003 ; Moliner, 1999, p. 107-120 ; Rothé, Tréziny, 2005, p. 575). Trois des strigiles datent de la première moitié du $\mathrm{IV}^{\mathrm{e}} \mathrm{s}$., tandis que le quatrième est attribué à la première moitié du II ${ }^{\mathrm{e}}$ s. av. J.-C. (Feugère, 2003, p. 163).

Marseille, musée d'Histoire : 1 en bronze.

Le musée d'Histoire de Marseille détient sous le $\mathrm{n}^{\mathrm{o}} \mathrm{d}$ 'inv. 15041, un strigile en bronze portant un décor de stries sur le revers de la ligula dont il manque le bout. L'objet a semble-t-il été mis au jour à Marseille (ministère de la Culture, base Joconde).

Marseille, la Plaine Saint-Michel : 1 en fer.

Lors des travaux menés pour la réalisation du métro en 1981, deux sépultures grecques ont été mises au jour. L’une contenait un jeune adulte accompagné de trois objets dont un strigile en fer disposés au niveau des jambes. Les tombes sont datées du $\mathrm{IV}^{\mathrm{e}} \mathrm{s}$. ou du III ${ }^{\mathrm{e}}$ s. av. J.-C. (Rothé, Tréziny, 2005, p. 679).

Marseille, rue Pierre-Leca : 1 en bronze.

La construction d'un immeuble a révélé de nombreux vestiges dont un établissement thermal établi dans le courant du troisième quart $d u \mathrm{IV}^{\mathrm{e}} \mathrm{s}$. av. J.-C., une maison hellénistique et une maison romaine qui s'est développée du milieu du I ${ }^{\mathrm{er}}$ s. av. J.-C. jusqu'au milieu du III $^{\mathrm{e}}$ s. apr. J.-C. C'est dans les couches de démolition du III $^{\mathrm{e}}$ s. qu'a été mis au jour un strigile en bronze. L'objet présente une ligula courte mais très large et un manche massif avec clausula (Rothé, Tréziny, 2005, p. 480, fig. 539).

Marseille, rue du Tapis-Vert : 1 en bronze.

La nécropole antique de la rue du Tapis-Vert a été découverte à l'occasion du creusement d'une cave en 1953. Parmi les tombes grecques mises au jour, un sarcophage a livré un strigile en bronze de $22 \mathrm{~cm}$ de longueur accom- 
pagnant les squelettes d'un homme et d'une femme. Le dépôt, qui comprenait plusieurs autres objets, est datable de 430 av. J.-C. environ (Gallia, XII, 2, 1954, p. 428-429, fig. 7 ; Rothé, Tréziny, 2005, p. 600-601, fig. 819).

\section{CANTAL : 2 objets}

Arpajon-sur-Cère, le Bourg-nord : 2 dont le matériau est indéterminé.

En 1842, J.-B.-A. Dubuisson publiait le mobilier mis au jour pendant les fouilles effectuées dans l'une des nécropoles gallo-romaines du vicus d'Arpajon-sur-Cère. Parmi les nombreux objets, deux strigiles, dont les dimensions et les matériaux ne sont pas mentionnés ont été découverts (Provost, Vallat, Vinatié, 1996, p. 69).

\section{CHARENTE-MARITIME : 2 objets}

Saintes, rue Saint-Macoult : 1 en bronze.

Un strigile en bronze est mentionné par G. Le Cloirec (Le Cloirec, 2001, p. 154).

Saintes, Saint-Vivien : 1 dont le matériau est indéterminé.

I. Bertrand mentionne la découverte, dans les habitations antiques du cimetière Saint-Vivien, d'une lame de strigile conservée au musée archéologique de Saintes sous le $\mathrm{n}^{\mathrm{O}} \mathrm{d}^{\prime}$ inv. 743405 (Bertrand, 2003, p. 101).

\section{CôTE-D'OR : 4 objets}

Braux, la Croisée : 1 en fer.

Un strigile en fer peu oxydé a été découvert dans l'us 278(B), non datée, dans une villa disposant de bains et occupée de 40-30 av. J.-C. à la fin du deuxième tiers du III $^{\mathrm{e}}$ s. apr. J.-C. La partie active de l'étrille est en forme de spatule courbe qui va en s'amincissant à hauteur du manche. La tige de section carrée a pu supporter un manche en bois, le retour servant à bloquer le manche. L'objet mesure $18 \mathrm{~cm}$ de longueur, 2,2 $\mathrm{cm}$ de largeur et l'épaisseur atteint 0,30 cm au centre (Farine, 1999, p. 287, fig. 219, objet 57, p. 293).

Dijon : 1 en fer et 1 en bronze.

Deux strigiles sont conservés au musée de Dijon. L’un est en fer, l'autre en bronze.

Vertault, musée de Châtillon-sur-Seine : 1 en fer.

Un strigile en fer, conservé au musée du Châtillonnais (vitrine 14, $\mathrm{n}^{\circ}$ 2), mesure $17,5 \mathrm{~cm}$ de longueur pour $9 \mathrm{~cm}$ de largeur. La clausula est fermée (Hofmann, 1985, pl. XXXIX, no 33, p. 82-83).

\section{CôTES-D'ARMOR : 1 objet}

Corseul, Monterfil II : 1 en fer.

Un strigile en fer, dont le manche de section carrée est incomplet, a été mis au jour dans le « secteur commercial » de l'agglomération antique de Monterfil II (us 41) perturbé par les labours. Long de 22,2 cm, il présente dans sa partie médiane deux plaques de bronze décoratives de forme trapézoïdale séparant le manche de la ligula. La partie haute du manche présente des moulurations marquées. Des traces de ficelles ont également été identifiées (Kérébel, 2001, p. 203 et p. 214, fig. 157, no 166 ; Le Cloirec, 2001, p. 57 et 59, fig. 15, $\mathrm{n}^{\mathrm{o}} 35$ ). Plusieurs domus sont présentes mais aucune ne semble disposer du confort thermal. L'ensemble est occupé de l'époque augustéenne jusqu'au III ${ }^{\mathrm{e}}$ s. apr. J.-C.

\section{DEUX-SÈVRES : 2 objets}

Rom : 2 en bronze.

Deux strigiles, probablement en bronze, ont été trouvés à l'occasion de la fouille d'une domus couvrant une superficie de près de $2500 \mathrm{~m}^{2}$ et possédant un balnéaire privé (Pouhet, 1890, p. 74-380 ; Hiernard, Simon-Hiernard, 1996, p. 281).

\section{DRÔME : 11 objets}

Crest : 1 en ivoire.

Cet objet est mentionné par J.-C. Béal (Long, 1849 ; Béal, 1983, p. 248, n. 5).

Saint-Paul-Trois-Châteaux, le Valladas : 10 en fer.

Plusieurs strigiles ont été découverts dans deux incinérations de la première moitié $\mathrm{du} \mathrm{II}^{\mathrm{e}} \mathrm{s}$ (tombes 158 et 258), mais également dans un ustrinum d'époque claudienne.

Tombe 258 : trois strigiles en fer, brûlés, étaient déposés au fond de la fosse, disposés sur leur anneau de suspension et accompagnés d'un rasoir en fer. La tombe est datée entre 100 et 150 apr. J.-C. Seul un strigile est pratiquement intact : il mesure 14,4 cm de longueur. Les trois strigiles présentent un manche court de $5 \mathrm{~cm}$ dont les deux faces sont arrondies pour faciliter la préhension. Les lames sont réduites, larges de $2,3 \mathrm{~cm}$ à $2,5 \mathrm{~cm}$, mais profondes, et sont recourbées en arc de cercle. L'anneau est en forme de D (Bel, 2002, p. 435, fig. 513, objets 14-16).

Tombe 158 : quatre strigiles en fer accompagnés d'un balsamaire en bronze et d'une autre paire de strigiles déposée après la crémation avec deux balsamaires en verre. La tombe est datée entre 140-150 et 200 apr. J.-C. Les quatre 
strigiles sont identiques et mesurent $20,9 \mathrm{~cm}$ de longueur. Les manches sont arrondis pour faciliter la préhension et la ligula est large, comprise entre 2,4 cm et 2,6 cm. L'anneau, incomplet, est en forme de D.

La paire de strigiles supplémentaire montre deux objets au manche étroit $(0,8 \mathrm{~cm})$ formé d'une même plaque repliée sur elle-même. La ligula s'élargit jusqu'à $1,7 \mathrm{~cm}$ dans le creux du coude. Les étrilles mesurent $23,5 \mathrm{~cm}$ et $25 \mathrm{~cm}$ de longueur et étaient disposées dans un anneau en forme de D (Bel, 2002, p. 465, fig. 552, objets 3-5, p. 466, fig. 553, objets 12-16, p. 467, fig. 554).

\section{EURE : 3 objets}

Aizier, hameau de Flacq : 2 en bronze.

Deux strigiles ont été découverts à Aizier, dans une urne cinéraire, accompagnés de 657 objets autorisant une datation du deuxième tiers du $\mathrm{II}^{\mathrm{e}} \mathrm{s}$. Les strigiles sont conservés au musés d'Évreux (Fauduet, 1992, n ${ }^{\text {os }} 916$ et 916bis ; Cliquet, 1993, p. 228).

Pîtres : 1 dont le matériau est indéterminé.

Un objet strigiliforme a été découvert au XIX ${ }^{\mathrm{e}}$ s. à Pîtres. L'objet a été recueilli sans provenance précise (Fauduet, 1992, p. 12).

\section{GARD : 38 objets}

Beaucaire, nécropole des Marronniers : 5 en bronze et 7 en fer.

Plusieurs strigiles ont été découverts dans des incinérations disposées dans des coffres faits de dalles posées sur chant.

La tombe 5, augustéenne, était disposée dans un coffre monolithique fermé par une dalle et abritait, parmi un abondant mobilier (miroir, balsamaires, patères à vernis noir), trois strigiles en bronze et un en fer. L'objet en fer, entier, mesure $16,5 \mathrm{~cm}$ de hauteur. La spatule a un profil en angle droit et le manche est replié afin de former une clausula. Le premier strigile en bronze mesure 19,5 cm de hauteur. Il possède une ligula à profil arqué, dont le dos présente trois facettes. Le manche double est constitué d'un ruban replié sur lui-même. Les deux autres strigiles sont identiques. Le dos des ligulae est orné de moulures : il s'agit de quatre sillons longitudinaux se rejoignant en ogive et de deux groupes de trois et quatre sillons transversaux se rejoignant au bord de la spatule. Les manches sont pleins. Le premier, qui mesure $21 \mathrm{~cm}$ de hauteur porte une marque en creux illisible sur le capulus et le second, qui mesure 22,2 cm, porte deux estampillages (Dedet et al., 1978 , p. $101-107$, fig. $65, \mathrm{n}^{\text {os }} 4-5$ et fig. $76, \mathrm{n}^{\text {os }} 1-2$, infra, pl. 2 , fig. 1-2 ; Tendille, 1981, p. 69, fig. $5, \mathrm{n}^{\text {os }} 25,26,27 \mathrm{a}$ et $27 \mathrm{~b}$; Bessac et al., 1987a et b, p. 36, fig. 32 ; Provost et al., 1999, p. 212, fig. $180, \mathrm{n}^{\text {os }} 3$ et 4 ).

La tombe 13, datée de 50 av. J.-C., comprenait, parmi les onze objets mis au jour, deux strigiles en fer. L'un des strigiles, dont la ligula est ébréchée, mesure $22,5 \mathrm{~cm}$ de hauteur et sa largeur est de $0,23 \mathrm{~cm}$ pour le manche et $0,26 \mathrm{~cm}$ pour la spatule. Le manche, à l'origine double, est brisé (Dedet et al., 1978 ; Tendille, 1981, p. 67, fig. 4, no 23 ; Provost et al., 1999, p. 196, fig. 160, nº 5).

La tombe 18, d'époque augustéenne, a livré près de dix-huit objets empilés dans un petit caisson cubique dont deux strigiles en fer (Provost et al., 1999, p. 212).

La tombe 19, datée de 75 av. J.-C. a livré deux strigiles en fer sur leur anneau. Les deux objets sont fragmentaires, l'extrémité des spatules étant cassée. Les objets mesurent $21,5 \mathrm{~cm}$ et 22,6 $\mathrm{cm}$ et sont larges de $0,20 \mathrm{~cm}$ et $0,26 \mathrm{~cm}$. Chacune des étrilles présente un manche double à l'origine, constitué d'un ruban de métal de section rectangulaire, replié sur lui-même et venant se raccorder à la base du dos de la spatule pour former une clausula. L'un des objets présente une ligula arquée renforcée par une côtelure triangulaire (Dedet et al., 1978 ; Tendille, 1981, p. 67, fig. 4).

La tombe 21, datée entre 50 et 25 av. J.-C. a livré un strigile en bronze (Provost et al., 1999, p. 198).

Un strigile en bronze a également été mis au jour dans la nécropole mais hors tombe. L'objet est complet et mesure 20,7 cm de hauteur. Le manche, orné sur le côté d'un sillon longitudinal joignant deux petits cercles, mesure $1,6 \mathrm{~cm}$ de largeur et la ligula, $1,8 \mathrm{~cm}$. Le dos de la spatule est orné de moulures : il s'agit de trois sillons qui encadrent deux nervures plus larges et plus profondes (Tendille, 1981, p. 69, fig. $5, \mathrm{n}^{\mathrm{o}} 28$ ).

Boissières : 2 dont le matériau est indéterminé et 2 en bronze.

Deux strigiles en bronze associés par paire ont été découverts dans une riche tombe à incinération comprenant près de 60 pièces de mobilier funéraire (Py, 1972, p. 75-88 ; Tendille, 1981, p. 69, fig. 4, no 24 ; Provost et al., 1999, p. 249). Les strigiles étaient reliés par un anneau torsadé. Les dos des strigiles sont décorés d'une palme et leur manche présente deux marques poinçonnées disposées dans des cartouches : un personnage ailé et une silhouette de dauphin. Une seconde paire de strigiles a disparu; elle aurait porté la marque SALVI dans un cartouche (CIL, XII, 5698, 13 ; Aurès, 1875, p. 43-94). Les objets mesurent 
$19,5 \mathrm{~cm}$ de hauteur et les manches sont larges de 1,3 cm. La datation proposée va de 30 av. à 10 apr. J.-C. (Py, 1972).

Bouillargues, Mas de Bourges : 2 dont le matériau est indéterminé.

Deux strigiles en bronze incomplets ont été découverts en 1883 dans la tombe 226, qui comprenait une urne cinéraire en verre. Seules les ligulae sont conservées ; elles présentent sur leur dos un décor de lignes godronnées. Ces strigiles sont conservés au musée archéologique de Nîmes sous le no 909-9-2 et 3 (Goudard, 1883, p. 115-117 ; Fiches, Veyrac, 1996, p. 500 ; Provost et al., 1999, p. 253).

Courbessac : 1 en fer et 1 en ivoire.

Un strigile en fer a été mis au jour, mais le contexte de découverte est inconnu.

Un strigile en ivoire, dont le manche est brisé, provient de Courbessac. Conservé au musée archéologique de Nîmes ( $\mathrm{n}^{\mathrm{o}}$ inv. 866-4-2), il mesure 11,7 cm de longueur pour $2 \mathrm{~cm}$ d'épaisseur et a été mis au jour en 1865 dans la tombe 202 qui contenait une petite urne cinéraire accompagnée de plusieurs offrandes (Béal, 1983, p. 248, n. 5 et 1984, p. 65, no 259 ; Fiches, Veyrac, 1996, p. 474).

Nîmes, avenue Jean-Jaurès : 2 en verre, 2 en bronze et 2 en fer.

Des travaux menés sur l'avenue en 1871 ont permis la découverte de plusieurs sépultures. Parmi elles, la tombe à incinération 99 disposait de deux strigiles en bronze dont l'un était passé dans un anneau (Germer-Durand, 1872, p. 92 ; Fiches, Veyrac, 1996, p. 434-435). La tombe 100, une autre incinération proche de la précédente, a livré deux strigiles en fer (Germer-Durand, 1872, p. 94 ; Fiches, Veyrac, 1996, p. 435).

L'incinération 1113, datée du Haut-Empire, a livré un riche mobilier (deux balsamaires en verre, un flacon en verre, une amulette en cristal de roche, une fibule en bronze à figure de Méduse) comprenant deux strigiles en verre, version miniature des étrilles en bronze ou en fer. Le strigile $\mathrm{n}^{\circ} 18$ mesure $8,4 \mathrm{~cm}$ de longueur pour $0,55 \mathrm{~cm}$ de largeur. Il présente une baguette en gouttière à renfort externe, coudée d'un côté et repliée de l'autre dans le sens opposé, de manière à imiter au mieux l'ustensile de métal et son attache. Les extrémités sont bouletées. Le strigile $\mathrm{n}^{\circ} 19$ mesure $8,55 \mathrm{~cm}$ de longueur pour $0,75 \mathrm{~cm}$ de largeur et est similaire au précédent (Manniez, 2005, p. 34-36).

Nîmes, chemin de la Lampèze et rue Rouget-de-Lisle : 1 en fer.

Les travaux effectués sur une ligne de chemin de fer ont permis la découverte de la tombe 175 à incinération. La tombe était couverte d'une dalle calcaire et contenait une amphore à l'intérieur de laquelle était disposée l'urne.
Parmi les objets déposés sur les ossements se trouvait un strigile en fer (Fiches, Veyrac, 1996, p. 458).

Nîmes, Mail romain : 2 en fer.

En 1867, deux strigiles en fer sur leur anneau de bronze ont été découverts dans la sépulture $n^{\circ} 68$ à proximité de la porte d'Arles et de Beaucaire. La tombe serait datée du $\mathrm{I}^{\mathrm{er}}$ s. av. J.-C. (Fiches, Veyrac, 1996, p. 413-414).

Nîmes, route d'Avignon : 1 en fer.

Un objet en fer, qui pourrait être un strigile, a été découvert dans la tombe $\mathrm{n}^{0} 55$ à incinération trouvée vers 1840. L'urne cinéraire en plomb comprenait quelques autres objets (Fiches, Veyrac, 1996, p. 408).

Nîmes, 94 route de Beaucaire : le nombre d'objets et les matériaux sont indéterminés.

Une sépulture à incinération a été recueillie en 1958 à cette adresse. La tombe $n^{\circ} 33$ contenait des strigiles dont le matériau et les dimensions sont inconnus (Lassalle, 1958 ; Gallet de Santerre, 1959, p. 470 ; Fiches, Veyrac, 1996, p. 394).

Nîmes, route de Beaucaire : 2 en fer.

En 1850, sur la voie antique Nîmes/Ugernum, plusieurs sépultures ont été découvertes. Parmi elles, la tombe 42 à inhumation a livré les fragments d'un strigile en fer. La tombe 44 à incinération a également livré un strigile en fer. Les strigiles étaient accompagnés d'un riche mobilier (Espérandieu, 1934, p. 43 ; Fiches, Veyrac, 1996, p. 399-400, fig. 310).

Nîmes, rue Dagobert et rue du Cirque-Romain : 2 en fer.

La fouille menée en 1988-1989 a révélé un ensemble funéraire comprenant deux tombes à incinération, disposées l'une à côté de l'autre et datées du deuxième quart du $\mathrm{I}^{\mathrm{er}} \mathrm{s}$. av. J.-C. La tombe $\mathrm{n}^{\mathrm{o}} 8$ a livré un important mobilier funéraire, dont une paire de strigiles en fer reliés par un anneau (Feugère et al., 1995 ; Fiches, Veyrac, 1996, p. 193-194, fig. 97).

Nîmes, Tour Magne : 1 en bronze.

Un strigile en bronze a été découvert en 1840 dans une sépulture (Le Cloirec, 2001).

Nîmes, Saint-Baudille : 2 en bronze.

Les deux strigiles en bronze ont été découverts dans une sépulture du Haut-Empire à proximité de l'église SaintBaudille (Le Cloirec, 2001).

Saint-Gervasy : le nombre des objets et les matériaux sont indéterminés.

Des strigiles ont été découverts en 1912 dans une tombe à incinération comprenant une auge cylindrique en pierre couverte d'une dalle et abritant une urne cinéraire. Ils étaient associés à un riche mobilier, dont une bague en or, une pyxide en os et son couvercle, deux lampes en bronze avec trépied, 
un miroir circulaire en argent, une boucle en bronze avec ardillon, une anse de vase en bronze, une anse de coupe en argent et une patère en bronze (Provost et al., 1999, p. 613).

Tresques, Courac I : 1 en fer.

La fouille de la nécropole en 1965 a permis la mise au jour de sept tombes à incinération datées des $\mathrm{I}^{\mathrm{er}}$-II ${ }^{\mathrm{e}} \mathrm{s}$. apr. J.-C. et de trois tombes à inhumation du $\mathrm{III}^{\mathrm{e}} \mathrm{s}$. apr. J.-C. Le strigile en fer a été découvert dans l'incinération $\mathrm{n}^{\circ} 6$, comprenant près de 35 offrandes (Sudres, 1981, p. 17-24 et 1983, p. 3-14 ; Sudres, 1983, p. 3-14; Provost et al., 1999, p. 704).

\section{GERS : 2 objets}

Auch : 1 en bronze.

La pointe d'un strigile en bronze a été découverte dans un contexte inconnu. La datation estimée est le HautEmpire (Feugère, 1997, p. 121, n. 7).

Seysses-Savès, Labarthe : 1 en bronze.

Le strigile en bronze découvert à Seysses-Savès présente à l'extrémité du capulus une petite excroissance percée au bout de laquelle était disposé un petit anneau. Le manche de l'objet, qui ne dispose pas de clausula, est plein (Costes et al., 1988).

\section{GIRONDE : 1 objet}

Bordeaux, place des Grands-Hommes : 1 dont le matériau est indéterminé.

Un strigile a été découvert dans l'us 11001 qui a été datée entre 20 av. J.-C. et 10 apr. J.-C. L'objet mesure 21,2 cm de longueur et possède un manche massif. Le dos de la ligula est décoré de lignes convergentes gravées et le sommet du manche, côté interne, présente deux estampilles illisibles placées dans des cartouches rectangulaires, disposés perpendiculairement l'un à l'autre, ainsi qu'une série de hachures obliques le long des bords. Enfin, l'autre côté du capulus montre une rangée médiane de petits cercles ouverts, estampés, qui sont placés entre deux lignes de points espacés (Feugère, 1997, p. 125-126 et fig. 3, no 25).

\section{HAUTE-Garonne : plus de 3 objets}

Auterive, le Purgatoire : 1 en bronze.

Les fouilles menées en 1968 et 1969 sur la parcelle 28 du site du Purgatoire ont livré un ensemble gaulois de La Tène finale et un bâtiment gallo-romain du $\mathrm{I}^{\mathrm{er}}$ s. apr. J.-C. Des sondages effectués à proximité ont révélé des " couches détritiques " recelant un important mobilier, dont un strigile en bronze (Gallia, XXVIII, 1970, 2, p. 405).
Belbèze-en-Comminges, temple de Belbèze-Pédégas : le nombre des objets et les matériaux sont indéterminés.

À l'occasion des fouilles menées sur le sanctuaire galloromain de Belbèze-Pédégas, découvert par G. Manière en 1965, plusieurs strigiles auraient été découverts dans le comblement d'un bassin interprété comme un pédiluve (Manière, 2001, p. 38 ; Sablayrolles, Beyrie, 2006, p. 26). Le sanctuaire aurait été en activité de la fin du $\mathrm{I}^{\mathrm{er}} \mathrm{s}$. au $\mathrm{IV}^{\mathrm{e}}$ s. apr. J.-C. G. Manière décrit également une spatule à manche courbe en fer, découverte dans une couche hallstattienne du replat du temple, qui pourrait avoir joué le rôle de strigile (Manière, 2001, p. 52).

Saint-Bertrand-de-Comminges, thermes du Nord : 1 en bronze.

À l'occasion des fouilles de Saint-Bertrand-deComminges, de nombreux vestiges mobiliers ont été mis au jour sans que ne soit précisée leur position spatiale et stratigraphique. Parmi ces objets, un strigile en bronze, d'une longueur de $20 \mathrm{~cm}$ a été découvert dans les thermes du Nord (Sablayrolles, Beyrie, 2006, p. 383).

Toulouse, rue Sainte-Anne : 1 en ivoire.

Le manche d'un probable strigile a été découvert à Toulouse dans un remblai de démolition daté de la fin du $\mathrm{II}^{\mathrm{e}}$ s. apr. J.-C. L'objet est en ivoire d'éléphant et présente un décor très élaboré : il s'agit d'une frise de trois masques (un jeune homme imberbe et deux personnages chevelus et barbus) séparés, d'un canthare renversé et d'un probable thyrse. Chaque masque est surmonté d'un pilastre cannelé portant un chapiteau orné d'un personnage dansant. L'extrémité du manche représente un centaure assis jouant de la lyre : il s'agit de Chiron, le précepteur d'Achille. Cette décoration somptueuse est exceptionnelle (Cazes, 1995).

\section{HAUTES-AlPeS : 1 objet}

La Bâtie-Montsaléon : 1 dont le matériau est indéterminé.

Un fragment de strigile, visible au musée départemental de Gap (collection Tournier), portant des caractères grecs effacés, provient de Mons Seleucus, agglomération secondaire connue depuis le XVII ${ }^{\mathrm{e}}$ s. (Béraud, 1982, p. 105 ; Ganet, 1995, p. 80).

\section{HAUTE-SAVOIE : 1 objet}

Thonon-les-Bains : 1 en bronze.

À l'occasion de travaux menés sur le port, en 1861-1862, un strigile en bronze a été découvert à l'emplacement d'un habitat possédant une pièce sur hypocauste et un 
portique, laissant présager une fonction thermale du lieu. Les monnaies mises au jour couvrent les règnes d'Auguste à Constance (Bertrandy et al., 1999, p. 281).

\section{HÉRAULT : 8 objets}

Castelnau-le-Lez, Navitau : 1 en fer.

En 1985, une fouille de sauvetage a permis la mise au jour de cinq incinérations gallo-romaines. Un strigile en fer a été découvert dans la tombe 5, datée de la seconde moitié du I ${ }^{\mathrm{er}}$ s. av. J.-C. (Ramonat, Sahuc, 1988 ; Vial, 2003, p. 151). Lattes, la Céreirède : 1 en bronze.

Un strigile en bronze a été découvert dans une incinération placée dans une amphore étrusque. Le dépôt est daté du $\mathrm{VI}^{\mathrm{e}}$ s. av. J.-C. L'étrille semble être également d'origine étrusque (fouille V. Bel, 2003 ; information : site Inrap).

Murviel-lès-Montpellier, quartier de Redon : 2 en fer.

Deux strigiles en fer ont été mis au jour.

Pignan, la Garonne : 4 dont le matériau est indéterminé.

La tombe 1887 aurait livré un lot de quatre strigiles, dont il ne restait que les débris (Bonnet, 1905, p. 241, nº 4). La mention a été reprise par M. Feugère (1993, p. 131 et 1996, p. 130).

\section{ISÈRE : 2 objets}

Vienne : 2 dont le matériau est indéterminé.

Deux strigiles sont connus mais les dimensions et les matériaux utilisés ne sont pas mentionnés (Le Cloirec, 2001, p. 57-59).

\section{LOT-ET-GARONNE : 5 objets}

Boé : 2 dont le matériau est indéterminé.

La tombe à char de Boé, datée du dernier quart du $\mathrm{I}^{\mathrm{er}}$ s. av. J.-C., est une tombe fastueuse mise au jour en 1859 , dont la fouille a été reprise en 1990 et qui a livré un mobilier riche et abondant. Les offrandes étaient nombreuses et, parmi elles, les fragments d'une paire de strigiles ont été découverts (Schönfelder, 1996 ; Schönfelder et al., 2000).

Cancon, le Barrou : 1 en bronze.

Un strigile en bronze a été trouvé au $\mathrm{XIX}^{\mathrm{e}} \mathrm{s}$. dans le puits d'une villa gallo-romaine occupée au Haut-Empire. Il portait l'inscription ASEROS (CIL, XIII, 10027, 172 ; Fages, 1995, p. 183 ; Bertrand, 2003, p. 101).

Le Mas-d'Agenais : 1 en bronze.

La pointe d'un strigile en bronze a été découverte à l'occasion de prospections pédestres menées par J.-P. Noldin (comm. pers. M. Feugère).
Villefranche-du-Queyran, Grand-Saint-Pé : 1 en bronze.

Le strigile en bronze, long de $15 \mathrm{~cm}$ et large de $2,5 \mathrm{~cm}$, découvert de façon fortuite, est incomplet, tordu et très corrodé. L'objet est conservé au musée de Sainte-Bazeille sous le no 1254/1852 (Schönfelder, 1996 ; Schönfelder et al., 2000).

MARNE : 2 objets ou plus

Prosnes, les Charbons : 1 dont le matériau est indéterminé. La fouille d'un cimetière d'animaux de l'époque romaine par M. Jorssen aurait livré un « possible » strigile (Jorssen, 1963, p. 11-17 ; Chossenot et al., 2004, p. 580-581).

Villeseneux, l'Homme-Mort : 1 en fer.

Un strigile en fer a été découvert dans une sépulture, accompagné de bagues et de céramique métallescente (Chossenot et al., 2004, p. 741).

MEURTHE-ET-MOSELLE : nombre d'objets indéterminé

Crézilles, Au Quart des Thermes : le nombre des objets est indéterminé.

La fouille ancienne de thermes privés, appartenant à une probable villa, a permis la mise au jour de nombreux objets métalliques dont d'éventuels strigiles en bronze (Olry, 1862, p. 286-287 ; Hamm, 2004, p. 164).

MEUSE : 1 objet

Verdun, musée de Verdun : 1 en bronze.

Bien qu'il soit difficile d'être affirmatif, il semble bien que le strigile en bronze, enregistré sous le no d'inv. 94.103 [s.m.] au musée de Verdun ait bien été découvert dans le département de la Meuse (Mourot, 2002, p. 595).

\section{MORBIHAN : 1 objet}

Vannes : 1 dont le matériau est indéterminé.

G. Le Cloirec mentionne la présence d'un strigile à Vannes dans une carte de répartition des strigiles en Gaule (Le Cloirec, 2001, p. 154).

MOSELLE : 1 objet

Rouhling, les Maisons païennes : 1 en fer.

La villa mise au jour et fouillée au lieu-dit Heidenhaueser (les Maisons païennes) par E. Huber entre 1890 et 1891 à Rouhling a permis la découverte d'un strigile en fer (Huber, Grenier, 1904, p. 259-292 ; Flotté, Fuchs, 2004, p. 677). 


\section{NORD : 3 objets}

\section{Cambrai : 1 en os.}

Un strigile en os, d'une longueur de $12 \mathrm{~cm}$, aurait été mis au jour à l'emplacement de l'ancienne cathédrale et de l'ancienne manufacture Legrand en 1852-1853 à l'occasion de travaux d'adduction d'eau (Delmaire dir., 1996, p. 159-160 ; Coulon, 1895b, p. 57-58 et 1895c).

Fressain : 2 en bronze.

Deux strigiles en bronze ont été découverts en 1885 à l'occasion des travaux du chemin de fer de Somain à Aubigny (Coulon, 1895b, p. 58 ; Delmaire dir., 1996, p. 255).

\section{OISE : 3 objets}

Cuignières, les Fonds : 2 dont le matériau est indéterminé.

La fouille du vicus et de ses nombreuses caves a permis la mise au jour d'un riche mobilier archéologique parmi lequel sont mentionnés un outil strigiliforme et un strigile, ce dernier ayant été découvert dans une cave, accompagné d'un important mobilier dont trente-deux monnaies d'Auguste-Tibère à Gratien (Jacquinez, 1972, p. 39-57 ; Woimant, 1995, p. 236).

Noyon, îlot des Deux Bornes : 1 en bronze.

Un strigile en bronze a été mis au jour rue de l'Évêché, dans l'îlot des Deux Bornes, pendant les fouilles menées dans les années 1980 (Woimant, 1995, p. 471). Le strigile a la particularité de posséder un manche décoré et une extrémité à tête d'aigle. Le manche dispose d'une ouverture par laquelle devait passer un anneau d'accroche (Lacroix dir., 2004, p. 4).

\section{PARIS : 1 objet}

Rues Le Goff, Malebranche, Gay-Lussac, Royer-Collard : 1 en bronze.

Les fouilles menées de 1889 à 1891 ont mis au jour une occupation gallo-romaine, éventuellement précoce. Parmi le mobilier exhumé, on note la présence de nombreux objets en bronze dont un strigile (Toulouze, 1890 et 1892 ; Busson, 1998, p. 215). Cette découverte n'est cependant pas présentée par P. Velay dans son ouvrage consacré aux bronzes antiques de Paris (Velay dir., 1989).

\section{PyrénÉES-ORIENTALES : 1 objet}

Port-Vendres, épave Port-Vendres 2 : 1 dont le matériau est indéterminé.
La fouille d'une épave sur la côte sud de l'avant-port de Port-Vendres, conduite entre 1974 et 1984, a permis de mettre au jour une cargaison importante de lingots et d'amphores. Une inscription sur un lingot d'étain permet de dater l'épave du milieu du $\mathrm{I}^{\mathrm{er}}$ s. apr. J.-C. Parmi les objets personnels découverts, se trouvait un strigile (source Internet).

RHÔNE : 11 objets

Lyon : 1 en bronze et 4 dont le matériau est indéterminé.

Cinq strigiles du Haut-Empire ont été découverts à Lyon. L'un d'entre eux est en bronze, le matériau des autres est inconnu.

Lyon, nécropole de Trion : 2 en os.

Une multitude d'objets a été découverte à l'occasion de la fouille de la nécropole de Trion, à Lyon. Parmi eux, deux strigiles en os ont été reconnus. Le premier $\left(\mathrm{n}^{\circ} 770\right)$ est fragmenté mais complet. Il mesure $15,6 \mathrm{~cm}$ de longueur. La ligula mesure $8,8 \mathrm{~cm}$ de longueur pour $1,5 \mathrm{~cm}$ de largeur. L'extrémité du manche présente un décor de deux gorges convergentes soulignées de trois autres gorges transversales. Le second $\left(\mathrm{n}^{\circ} 771\right)$ est incomplet, le manche étant brisé et l'extrémité de la ligula endommagée. La longueur conservée est de 10,5 cm. La ligula mesure $6,6 \mathrm{~cm}$ de longueur et $1,6 \mathrm{~cm}$ de largeur. Aucun décor n'est visible sur la partie conservée de l'objet (Béal, 1983, p. 245-246, pl. XLIII, n ${ }^{\text {os }} 770-771$; Le Mer, Chomer, 2007, p. 627-628, fig. 610).

Lyon, place des Célestins : 1 en bronze, cuivre et nacre.

Les travaux de voirie menés sur la place des Célestins à partir de 1876 ont mis au jour une domus. À la fin du II $^{\mathrm{e}} \mathbf{s}$. ou au début du $\mathrm{III}^{\mathrm{e}} \mathrm{s}$., l'habitat a subi de nombreux réaménagements et c'est dans les niveaux datés de cette période qu'a été mis au jour un strigile en bronze, cuivre et nacre (Le Mer, Chomer, 2007, p. 363-364).

Lyon, rue du Colonel-Chambonnet : 1 en bronze.

Des sondages archéologiques menés en 1996 au no 1 de la rue ont permis la mise au jour d'une occupation antique qui débute à l'époque augustéenne. Par la suite, une domus est édifiée mais elle semble être abandonnée, puis détruite par incendie pendant la période sévérienne, à la fin du $\mathrm{II}^{\mathrm{e}} \mathrm{s}$. ou au début du $\mathrm{III}^{\mathrm{e}} \mathrm{s}$. Parmi les nombreux objets mis au jour, un strigile en bronze a été découvert (Le Mer, Chomer, 2007, p. 375).

Lyon, le Verbe Incarné : 1 dont le matériau est indéterminé.

À hauteur du temple octastyle, de nombreux vestiges mobiliers ont été découverts dans les remblais de com- 
blement du cryptoportique, dont un fragment de strigile (Le Mer, Chomer, 2007, p. 533).

\section{SAÔNE-ET-LOIRE : 3 objets}

Autun : 1 en bronze.

Un strigile dont les dimensions et le matériau sont inconnus (Pinette dir., 1985, p. 168, no 299bis ; Kérébel, 2001, p. 203).

Mont-Beuvray : 1 dont le matériau est indéterminé.

Un strigile, long de 0,27 m et portant la marque VICCIVS, a été mis au jour (CIL, XIII, 10027, 186).

Tournus, En Belnay : 1 dont le matériau est indéterminé.

Une vaste villa gallo-romaine, occupée du I ${ }^{\mathrm{er}} \mathrm{s}$. au IV ${ }^{\mathrm{e}} \mathrm{s}$, a livré, à l'occasion de fouilles anciennes, une grande quantité de mobilier archéologique, dont un strigile. La villa était dotée d'un ensemble thermal bien identifié.

SAVOIE : 1 objet

Aix-les-Bains, parc de Verdure : 1 dont le matériau est indéterminé.

Une fouille menée en 1868-1869 a mis au jour plusieurs bâtiments gallo-romains groupés. Parmi le mobilier, un strigile fut découvert (Mouxy de Loche, 1899, p. 313 ; Rémy et al., 1996, p. 107).

\section{SeINE-MARITIME : 4 objets}

Eslettes : 1en fer.

À l'occasion de la construction du chemin de fer de Dieppe, une nécropole gallo-romaine et mérovingienne a été mise au jour. Plusieurs incinérations gallo-romaines côtoyaient douze sarcophages du haut Moyen Âge. Deux d'entre eux contenaient un important mobilier dont un strigile en fer (Rogeret, 1998, p. 239).

Étretat, la Côte-du-Mont : 1 dont le matériau est indéterminé.

En 1830, une villa possédant un balnéaire a été découverte. L'une des salles dégagées a livré « une sorte de strigile» (Rogeret, 1998, p. 243).

Étretat, pavillon Lemaistre : 2 en bronze.

Non loin de la villa de la Côte-du-Mont, une incinération datée du $\mathrm{II}^{\mathrm{e}} \mathrm{s}$. ou du début du $\mathrm{III}^{\mathrm{e}} \mathrm{s}$. a livré un mobilier important et exceptionnel. Plus de quarante objets ont été répertoriés, dont une paire de strigiles en bronze, longs de $28 \mathrm{~cm}$, aux manches pleins accompagnée d'une anse (anneau) pour les suspendre (Rogeret, 1998, p. 364).
SEINE-ET-MARNE : 1 objet

Charny, les Champs-de-Choisy : 1 en fer.

Un strigile en fer au manche décoré de damasquinure a été mis au jour dans le comblement d'un fossé d'enclos d'époque augustéenne, enserrant un bâtiment résidentiel (Mallet, 2006a ; Mallet et al., 2006). L'objet était accompagné d'un mobilier particulièrement riche (buste anthropomorphe en calcaire, partie sommitale d'un bétyle, fragment de miroir en argent, fibules, céramique sigillée italique, amphores italiques) qui suggère que le propriétaire des lieux pouvait avoir eu un statut particulier (Séguier et al., 2005).

SOMME : 1 objet

Amiens, musée de Picardie : 1 en bronze.

Un strigile en bronze de $23 \mathrm{~cm}$ de longueur, décoré de cannelures au revers de la gouge, présente des lignes gravées sur le bord et la tranche du manche (source Internet).

\section{VAL-D'OISE : 1 objet}

Genainville, les Vaux-de-la-Celle : 1 en bronze.

Les fouilles menées au lieu-dit les Vaux de la Celle par le Centre archéologique du Vexin ont permis la mise au jour d'un bâtiment gallo-romain sur hypocauste au sol de ciment rose (Gallia, XXVIII, 2, 1970, p. 246-250). Dans une couche de remblais, attribuable à la fin du $\mathrm{II}^{\mathrm{e}} \mathrm{s}$. apr J.-C., un strigile en tôle de bronze a été découvert (Gallia, XXX, 2, 1972, p. 310 ; Mitard, 1993, p. 442 ; Wabont et al., 2006, p. 283 et fig. 255).

VAR : 4 objets

\section{Le Cannet-des-Maures, Blaïs 7 : 1 en bronze.}

D'anciens travaux effectués sur la N7, entre Vidauban et Le Cannet-des-Maures, ont révélé les vestiges d'une agglomération antique mais également une nécropole à incinération. Le Blaïs 7 semble avoir été un vaste ustrinum utilisé du milieu du $\mathrm{I}^{\mathrm{er}}$ s. au milieu du $\mathrm{II}^{\mathrm{e}}$ s. apr. J.-C., d'où a été tiré un strigile en bronze à manche plat portant la marque M/ DDI, accompagné d'un balsamaire en verre (Gallia, XIV, 2, 1956, p. 232 ; Aubert et al., 1957 ; Gallia, XVI, 2, 1958, 2, p. 436-437 ; Brun, Borréani, 1999a, p. 305).

Fréjus, les Aiguières : 1 en bronze et 1 en fer.

Deux strigiles ont été mis au jour à Fréjus. Du premier, en bronze, ne subsiste qu'un fragment de la ligula (longueur 
de $6,1 \mathrm{~cm}$ et largeur de $1,9 \mathrm{~cm})$. Le second strigile en fer est également incomplet, puisque seule une partie du manche et de la ligula est conservée. L'ensemble mesure $10,5 \mathrm{~cm}$ de longueur et $1,5 \mathrm{~cm}$ à $1,7 \mathrm{~cm}$ de largeur. Il est possible que la pointe d'un strigile en fer ait pu appartenir à ce dernier objet (Feugère, à paraître).

La Rocquebrussanne, le Grand Lou I/le Sam Buc : 1 en bronze.

La villa du Grand Lou I, fouillée entre 1978 et 1983, est une vaste villa viticole disposant de nombreux bâtiments dont des thermes. Parmi les vestiges de la seconde moitié du $\mathrm{II}^{\mathrm{e}}$ s. apr. J.-C., un strigile en bronze a été mis au jour (Brun, Borréani, 1999b, p. 625).

Saint-Cyr-sur-Mer, les Baumelles : 1 bronze.

Un strigile est cité dans la Carte archéologique de la Gaule, 83/2, mais il n'est pas décrit (Brun, Borréani, 1999b, p. 648).

VAUCLUSE : 3 objets

Apt, quartier de la Madeleine : 1 dont le matériau est indéterminé.

Plusieurs incinérations gallo-romaines ont été mises au jour en 1876 à l'occasion de l'élargissement de la route de Sisteron. Le mobilier, riche et abondant, comprenait un strigile dont les dimensions et le matériau sont inconnus (Barruol, 1968, p. 119-120 ; Provost, Meffre, 2004, p. 152).

Vaison-la-Romaine : 2 en os.

Le premier objet est mentionné par J.-C. Béal. Conservé au musée Calvet, à Avignon, il ressemble fortement à l'objet n 770 découvert sur la nécropole de Trion à Lyon (Béal, 1983, p. 245 et 248, n. 5). Le second objet est conservé au musée de Vaison-la-Romaine et a été découvert en 1932 dans une insula (Sautel, 1942, p. 26, no 3473).

\section{VENDÉE : 4 objets}

\section{Le Bernard : 1 en os.}

Cet objet en os est mentionné par J.-C. Béal et daterait de la seconde moitié du II $^{\mathrm{e}}$ s. apr. J.-C. (Baudry, Ballereau, 1873, p. 155, fig. 2 ; Béal, 1983, p. 246).

Le Bernard : 1 dont le matériau est indéterminé.

Un strigile a été mis au jour dans l'ancien cimetière à l'occasion des fouilles menées par l'abbé Baudry en 18591860, non loin d'une villa possédant des thermes et d'un aqueduc cimenté (Baudry, 1861 ; Provost et al., 1996, p. 73). Des fouilles menées en 1987 ont révélé la présence, au même endroit, d'inhumations attribuées à l'époque romaine
(Hiernard, Simon-Hiernard, 1996, p. 223). Il est donc difficile de dire si le strigile a appartenu à une tombe ou s'il a été utilisé dans la villa.

Le Langon, les Ouches : 1 en bronze et 1 dont le matériau est indéterminé.

Les fouilles menées par E. Bernard en 1885 sur la commune du Langon, au lieu-dit les Ouches, ont permis la mise au jour d'un fragment de strigile en bronze. Il s'agit d'une partie de ligula présentant un décor rainuré. Lobjet appartenait à un ensemble daté de la seconde moitié du $\mathrm{I}^{\mathrm{er}} \mathrm{s}$. apr. J.-C. M. Feugère mentionne l'existence d'un deuxième strigile découvert dans un contexte attribuable à la seconde moitié du $\mathrm{I}^{\mathrm{er}}$ s. apr. J.-C. (Feugère, 1997, p. 121, n. 7).

Noirmoutier-en-île : 1 en fer.

Des fouilles effectuées en 1863 et 1864, sur le plateau de Saint-Hilaire dans l'île de Noirmoutier, ont permis la mise au jour du balnéaire d'une villa gallo-romaine. Parmi les nombreux objets recueillis, un strigile en fer a été découvert (Piet, 1864 ; Provost et al., 1996, p. 164).

\section{VIENNE : 5 objets}

Antran, la Croix-Verte : 2 en bronze.

Deux strigiles en bronze, inégalement conservés, ont été mis au jour sur l'ensemble aristocratique de la Croix-Verte d'Antran, daté de la fin du $\mathrm{I}^{\mathrm{er}}$ s. av. J.-C. ou du début du $\mathrm{I}^{\mathrm{er}}$ s. apr. J.-C. (Bertrand, 2003, p. 101). Les deux strigiles sont décorés de trois paires de stries et d'un trait incisé sur chaque bord. Les manches sont faits d'une plaque repliée, mais l'un des objets présente une ligula incomplète et déformée. Le strigile $\mathrm{n}^{\circ} 13$ mesure $18,8 \mathrm{~cm}$ de longueur pour $1,9 \mathrm{~cm}$ de largeur, le manche ayant une longueur de $6,5 \mathrm{~cm}$. Le strigile $\mathrm{n}^{\mathrm{o}} 14$ mesure $19,5 \mathrm{~cm}$ de longueur pour $1,9 \mathrm{~cm}$ de largeur, le manche ayant une longueur de $8,8 \mathrm{~cm}$ (Pautreau dir., 1999, p. 47, n ${ }^{\text {os }} 13$ et 14, fig. 69-71 ; Bertrand, 2003, pl. XXIX, n ${ }^{\text {os }} 1$ et 2 et fig. 131, p. 136).

Poitiers, Blossac-Saint-Hilaire : 1 dont le matériau est indéterminé

Un strigile à manche cylindrique, aujourd'hui disparu, a été mis au jour dans la nécropole de Blossac-Saint-Hilaire (Simon-Hiernard, 1990, p. 96, no 72).

Poitiers, musée Sainte-Groix : 1 en bronze.

Le musée Sainte-Croix à Poitiers possède un strigile en bronze incomplet, auquel il manque une grande partie de la ligula, décorée de cannelures, semblable au type Riha Striegel B (Riah, 1986, p. 23-26, fig. 7, no 62). Le manche dispose sur chaque côté de la poignée fermée l'inscription VRBANVS (Bertrand, 2003, p. 114, pl. XXIX, nº 3). 


\section{VOSGES : 1 objet}

Plombières-les-Bains : 1 en bronze.

Un strigile en bronze, conservé au musée d'Épinal, provient des fouilles menées en 1857 sur la commune. On ne connaît pas la localisation de l'objet, mais les vestiges mis au jour ont révélé un vaste ensemble thermal antique ayant capté des sources d'eaux chaudes (Michtlet, 2005, p. 268).
YVELINES : nombre d'objets indéterminé

Jouars-Pontchartrain : le nombre d'objets et les matériaux sont indéterminés.

Des strigiles auraient été découverts à Diodurum. Leur nombre et le matériau dans lequel ils ont été fabriqués sont inconnus (Blin et al., 2001, p. 37).

Franck MALLET

\section{ANNEXE II}

\section{ÉTUDE MÉTALLOGRAPHIQUE DE LA DAMASQUINURE}

\section{EXPERTISE DE LA GLÉ}

Le fil de damasquinure sortant légèrement de la gorge de la clé, un prélèvement de $3,7 \mathrm{mg}$ a pu être effectué. Celui-ci a été mis en solution au moyen d'acide minéraux concentrés (2,5 $\mathrm{ml}$ d'acide nitrique, puis $1 \mathrm{ml}$ d'acide chlorhydrique), la solution ainsi obtenue étant limpide.

La solution échantillon a ensuite été caractérisée par spectrométrie d'émission atomique à source plasma à couplage inductif (ICP-AES : Inductively Coupled PlasmaAtomic Emission Spectrometry) ${ }^{12}$.

Par cette technique d'analyse élémentaire, l'échantillon est introduit dans le plasma du spectromètre sous la forme d'un aérosol produit par un nébuliseur. L'énergie du plasma est transférée à l'aérosol, provoquant successivement l'évaporation du liquide, sa dissociation en atomes, puis leur excitation et/ou ionisation. La lumière, émise au cours du processus de retour à des niveaux énergétiques inférieurs par les éléments présents dans l'échantillon, est diffractée sur un réseau dont le rôle est de séparer les différentes longueurs d'onde. L'intensité du signal émis à une longueur d'onde donnée est caractéristique de l'élément à doser. Elle est quantifiée au moyen d'un capteur CCD, la concentration des différents éléments étant fonction de l'intensité de comptage correspondante. Pour un échantillon donné, les concentrations sont déterminées après étalonnage de l'instrument par des solutions synthétiques certifiées. L’appareil

12. Nous remercions M. Jean-Claude Birolleau, du Laboratoire d'expertises chimiques et physico-chimiques du CEA/Le Ripault (Indre-et-Loire), pour avoir réalisé cette caractérisation. utilisé pour cette analyse est un spectromètre JOBIN-YVONHORIBA Activa ${ }^{\mathrm{TM}}$.

Les résultats obtenus sont regroupés dans le tableau IX ${ }^{13}$.

La damasquinure utilisée pour la clé a donc été réalisée au moyen d'un fil de bronze (alliage de cuivre et d'étain), avec une teneur en étain de $11,5 \%$ qui confère à l'alliage une couleur jaune or (fig. 14, $n^{\circ} 1$ ). La couleur des bronzes varie en effet suivant leur teneur en étain : ils sont rouges jusqu'à $5 \%$ masse d'étain, puis jaunes de plus en plus clair jusqu'à $25 \%$ masse. Ils évoluent ensuite vers le blanc et enfin le gris (Pascal, 1963, p. 91).

\section{EXPERTISE DU STRIGILE}

Contrairement à la clé, il n'a pas été possible de réaliser un prélèvement au niveau de la damasquinure du strigile sans risque d'abîmer l'objet. De ce fait, une analyse par microscopie électronique à balayage couplée à la spectrométrie d'émission X dispersive en énergie (MEB-EDS) a été préférée ${ }^{14}$.

Cette technique de microanalyse, " non destructive ", permet en effet de renseigner tant sur la morphologie des matériaux à l'échelle du micromètre que sur la composition

13. Les éléments à analyser par ICP-AES ont été déterminés par une analyse préalable en fluorescence X, réalisée par M. Vincent Frotté, du Laboratoire d'expertises chimiques et physico-chimiques du CEA/ Le Ripault. Cette méthode permet en effet de réaliser une analyse élémentaire $(Z \geq 11)$ qualitative, rapide et " non destructive ».

14. Nous remercions $M^{\text {me }}$ Evelyne Estrade, du Laboratoire microstructure et comportement du CEA/Le Ripault (Indre-et-Loire), pour avoir mené à bien cette caractérisation. 
Tabl. IX - Tableau des spectres du cuivre et de l'étain présents dans la damasquinure de la clé : *, les concentrations ont été normalisées à $100 \%$ pour faire abstraction des éléments exogènes (oxygène par exemple); les incertitudes de mesures sont comprises en $5 \%$ et $10 \%$ relatifs en fonction des éléments; $\mathrm{Cu}$, cuivre; $\mathrm{Sn}$, étain ; $\mathrm{Pb}$, plomb; $\mathrm{Zn}$, zinc; Fe, fer.

\begin{tabular}{|l|c|c|c|c|c|}
\hline Élément & $\mathrm{Cu}$ & $\mathrm{Sn}$ & $\mathrm{Pb}$ & $\mathrm{Zn}$ & $\mathrm{Fe}$ \\
\hline Longueur d'onde d'analyse (nm) & 223,008 & 242,949 & 217,000 & 206,191 & 259,940 \\
\hline Concentration (\% masse) * & 87,3 & 11,5 & $<0,1$ & 0,02 & 0,2 \\
\hline
\end{tabular}
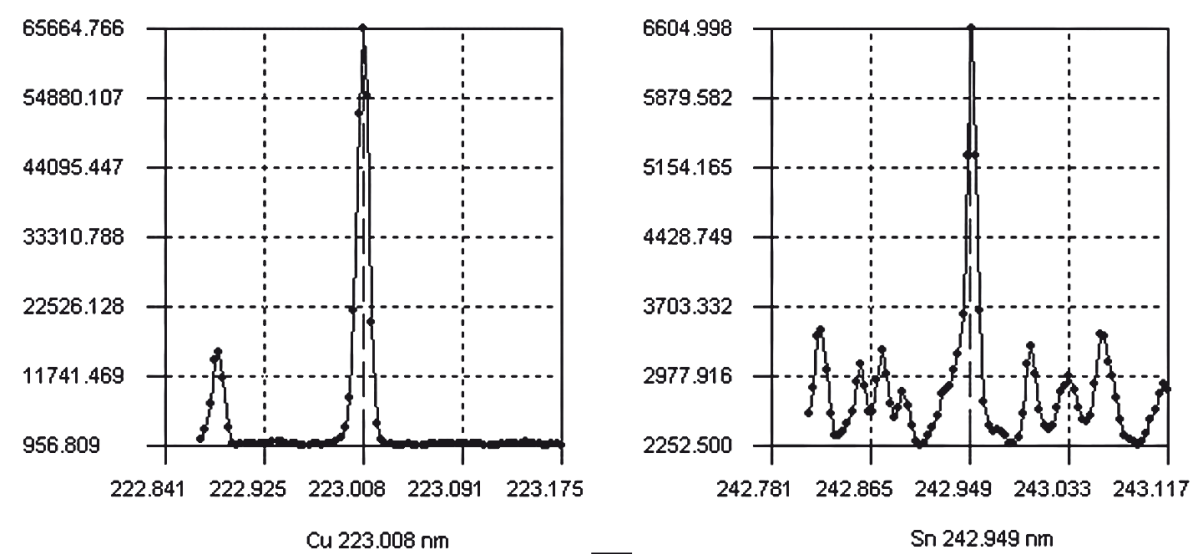

1

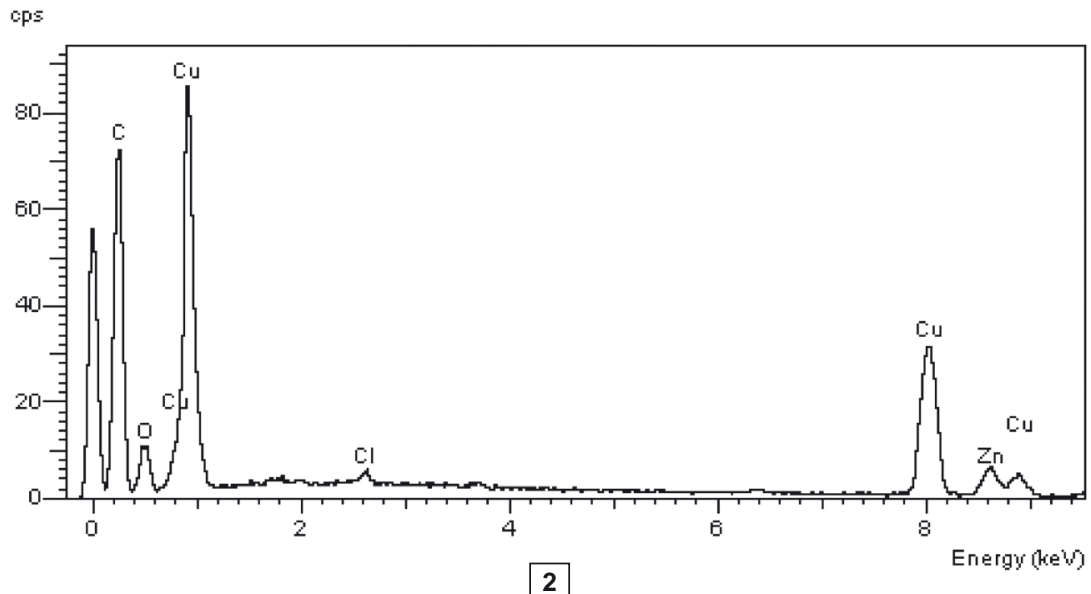

Fig. 14 - Spectres : 1, ICP-AES du cuivre $(\mathrm{Cu})$ et de l'étain $(\mathrm{Sn})$ présents

dans la damasquinure de la clé; 2, MEB-EDS de la damasquinure du strigile (F. Pilon). 
chimique, ce qui nous intéressait ici. Pratiquement, un faisceau d'électrons est envoyé sur l'échantillon à expertiser. Les interactions matière-particules permettent alors d'obtenir une image en électrons secondaires, qui fournit l'information topographique sur l'échantillon. Le spectre d'émission de rayons $\mathrm{X}$ donne, quant à lui, accès à la composition chimique de l'objet.

L'appareil utilisé est un microscope LEO 435 VPI. L'analyse par MEB-EDS montre la présence du cuivre et du zinc en éléments majeurs (fig. 14, nº 2). Le fil métallique employé pour réaliser la damasquinure du strigile est donc en laiton. Compte tenu des conditions d'acquisition du spectre, seule une analyse qualitative a pu être réalisée. Les proportions respectives des deux éléments d'alliage n'ont donc pas pu être déterminées.

\section{CONCLUSION}

Les damasquinures de la clé et du strigile, pourtant d'aspects très similaires (couleur, mode opératoire), s'avèrent au final différentes par la nature chimique des fils métalliques utilisés : le bronze dans le cas de la clé ; le laiton dans le cas du strigile.

Le choix opéré par l'artisan ne semble toutefois reposer que sur le critère esthétique - la couleur du fil (identique dans les deux cas, indépendamment de l'alliage) - et sur la disponibilité de tel ou tel fil métallique lors de sa préparation. Du reste, le rôle exclusivement décoratif de la damasquinure exclut la recherche d'une propriété physique particulière (mécanique par exemple), donc le choix d’un métal particulier.

Fabien PILON 


\section{BIBLIOGRAPHIE}

$\begin{array}{ll}\text { AFAN } & \text { Association pour les fouilles archéologiques nationales. } \\ \text { ALPARA } & \text { Association lyonnaise pour la promotion de l'archéologie en Rhône-Alpes. } \\ \text { ALUB } & \text { Annales littéraires de l'université de Franche-Comté. } \\ \text { ARALO } & \text { Association pour la recherche archéologique en Languedoc oriental. } \\ \text { BSR } & \text { Bulletin du service regional de l'archéologie. } \\ \text { CAG } & \text { Carte archéologique de la Gaule. } \\ \text { CIG } & \text { Corpus Inscriptiones Graecae. } \\ \text { CIL } & \text { Corpus Inscriptionum Latinarum. } \\ \text { CTHS } & \text { Comité des travaux historiques et scientifiques. } \\ \text { DAF } & \text { Documents d'archéologie française. } \\ \text { DARA } & \text { Documents d'archéologie en Rhône-Alpes et en Auvergne. } \\ \text { DFS } & \text { Document final de synthèse. } \\ \text { MSH } & \text { Maison des sciences de l'homme. } \\ \text { RA } & \text { Revue archéologique. } \\ \text { RAN } & \text { Revue archéologique de Narbonnaise. } \\ \text { SFECAG } & \text { Société française d'étude de la céramique antique en Gaule. } \\ \text { SRA } & \text { Service régional de l'archéologie. }\end{array}$

\section{APUlÉE}

Florides, II, 9, 2, texte établi et traduit par P. Vallette, Paris, Les Belles Lettres (coll. CUF), 1971.

CELSE

De la médecine, VI, 7, texte établi et traduit par G. Serbat, Paris, Les Belles Lettres (coll. CUF), 1995.

\section{CICÉRON}

De finibus bonorum et malorum, V, editor L. D. Reynolds, Oxford, Oxford University Press (coll. Oxford Classical Text), 1998.

ABAZ B.

1991 : Vingt ans de recherche de la Marmandais, Guide illustré du musée archéologique de Sainte-Bazeille, Sainte-Bazeille.

\section{ALFONSO G., BLAIZOT F. (DIR.)}

2004 : La Villa de Champ Madame à Beaumont (Puy-de-Dôme) : habitat et ensemble funéraire de nourrissons, Lyon, ALPARA (coll. DARA, 27).

\section{SOURCES ANTIQUES}

\section{HÉRODOTE}

Histoires, I, XXV, texte établi et traduit par P. E. Legrand, Paris, Les Belles Lettres (coll. CUF), 1958.

PERSE

Satires, V, 126, texte établi et traduit par A. Cartault, Paris, Les Belles Lettres (coll. CUF), 1966.

\section{PÉtRone}

Satiricon, XCI, texte établi et traduit par A. Ernout, Paris, Les Belles Lettres (coll. CUF), 1990.

\section{BIBLIOGRAPHIE GÉNÉRALE}

\section{Almagro M.}

1953 : Las necrópolis de Ampurias, I, Barcelona.

\section{Aubert G., Boyer R., FÉVRIER P.-A.,} TAXIL A.

1957 : «Évolution de la grande transversale des Alpes-Maritimes au Rhône ", in Histoire locale, Société française des historiens locaux, IX, 29-32, p. 2-14.

\section{PLINE L'ANCIEN}

Histoire naturelle, XXV, CIII, 2, texte établi et traduit par J. André, Paris, Les Belles Lettres (coll. CUF), 1974.

Histoire naturelle, XXXIV, 62, texte établi et traduit par H. Le Bonniec, Paris, Les Belles Lettres (coll. CUF), 1953

\section{SUÉTONE}

Vie des douze Césars, Auguste, I, II, LXXX, texte établi et traduit par A. Ailloud, Paris, Les Belles Lettres (coll. CUF), 1967.

\section{AURÈs A.}

1875 : "Marques de fabrique du musée de Nîmes ", in Mémoire de l'Académie du Gard 1875 (1876), p. 43-94.

\section{BARBET G., GANDEL P. (DIR.)}

1997 : Chassey-lès-Montbozon (Haute-Saône) : un établissement rural gallo-romain, Paris (coll. ALUB, 627, série archéologie, 42), $315 \mathrm{p}$. 
BARRUOL G.

1968 : «Essai sur la topographie d'Apta Julia », RAN, 1, p. 101-158.

\section{BAUDRY F.}

1861 : «Fouilles archéologiques du Bernard, cimetière chrétien ", Annuaire de la Société vendéenne, 8, p. 157-180, pl. V.

\section{BAUDRY F., BALLEREAU L.}

1873 : Puits funéraires gallo-romains du Bernard (Vendée), La Roche-sur-Yon, Imprimerie L. Gasté, 359 p.

BÉAL J.-C.

1983 : Catalogue des objets de tabletterie du musée de la Civilisation gallo-romaine de Lyon, Lyon, CNRS Éditions et De Boccard.

1984 : Les Objets de tabletterie antique du musée archéologique de Nîmes, Nîmes, Musée archéologique de Nîmes (coll. Cahiers des musées et monuments de Nîmes, 2), 150 p., 22 pl., 27 ill.

\section{BECK F., CHEW H.}

1991 : Masque de fer : un officier romain $d u$ temps de Caligula, Catalogue d'exposition, musée des Antiquités nationales, Saint-Germain-en-Laye, 6 nov. 19914 févr. 1992, Paris, éd. Réunion des Musées nationaux, $175 \mathrm{p}$.

BEL V.

2002 : Pratiques funéraires du Haut-Empire dans le Midi de la Gaule : la nécropole galloromaine du Valladas à Saint-Paul-TroisChâteaux (Drôme), Lattes, CNRS Éditions (coll. Monographies d'archéologie méditerranéenne, 11).

BÉRAUD I.

1982 : Recherches sur le site archéologique de La Bâtie-Montsaléon, mémoire de Maîtrise, Université d'Aix-en-Provence, 296 p.

\section{BERTRAND I.}

1995 : « Les objets de toilette et de parure de Saint-Pierre-les-Églises (fouilles 1971, 1978-1984) ", Bulletin de liaison et d'information, Association archéologique de PoitouCharentes, 24, p. 42-51.

2003 : Objets de parure et de soins du corps d'époque romaine dans l'est picton (DeuxSèvres, Vienne), Poitiers, Société archéologique de Chauvigny (coll. Mémoire de l'Association des publications chauvinoises, XXIII), 236 p., 133 fig., 36 pl.

\section{Bertrandy F., Chevrier M.,} SERRALONGUE J.

1999 : La Haute-Savoie, Paris, éd. de la MSH (coll. $C A G, 74), 412$ p., 384 fig.
Bessac J.-C., Christol M., Fiches J.-L., GASCO Y., JANON M., MICHELOZZI A., RAYNAUD C., ROTH CONGÈs A., TERRE D.

1987a : Ugernum, Beaucaire : le Beaucairois à l'époque romaine, I, Caveirac, ARALO (coll. Travaux du Centre Camille-Jullian, 2 ; cahier de l'ARALO, 15), $120 \mathrm{p}$.

1987b : Ugernum, Beaucaire : le Beaucairois à l'époque romaine, II, Caveirac, ARALO (coll. Travaux du Centre Camille-Jullian, 2 ; cahier de l'ARALO, 16), 128 p.

BLIN O., GILIGNY F., MARTIEL E.

2001 : Cent mille ans d'histoire sous la déviation de la RN12, de Jouars-Pontchartrain à Méré, Archéologie préventive en région Île-deFrance, Afan, DRAC Île-de-France, DDE des Yvelines.

BONNET E.

1980 : Antiquités et monuments du département de l'Hérault : géographie générale du département de l'Hérault, III, 2, Marseille, Laffite, p. 205-296.

\section{Bouet A.}

2001 : « Les bâtiments thermaux et sportifs en Aquitaine ", in « Amoenitas urbium: les bienfaits de la ville en Gaule et dans les provinces occidentales ", Caesarodunum, 35-36, p. 57-75.

2004 : Les Thermes privés et publics en Gaule Narbonnaise, Rome, l'École française de Rome (coll. de l'École française de Rome, 320), 2 vol., 381 p. et 416 p.

\section{Bouet A., Saragoza F.}

2008 : "Thermes et pratiques balnéaires dans le chef-lieu de cité des Parisii", Gallia, 65, p. 355-403.

\section{BOUET A., TOBIE J.-L.}

2003 : « Les thermes d'Imus Pyrenaeus (SaintJean-le-Vieux, Pyrénées-Atlantiques) », Aquitania, XIX, p. 155-179.

\section{BOULANGER C.}

1902-1905 : Le Mobilier funéraire gallo-romain et franc en Picardie et en Artois, Paris, Foulard, $150 \mathrm{p}$.

BRULET R., DEMANET J.-C. (DIR.)

1997 : Liberchies 3, vicus gallo-romain: les thermes et zone d'habitat au nord de la ville antique, Louvain-la-Neuve, Université catholique de Louvain (coll. Publication d'histoire de l'art et archéologie de l'université catholique de Louvain, XCIV), 399 p.

BRUN J.-P., BORRÉANI M.

1999a : Le Var, Paris, éd. de la MSH (coll. $C A G, 83 / 1), 488$ p., 530 fig. 1999b : Le Var, Paris, éd. De la MSH (coll. $C A G, 83 / 2)$, p. 491-984.

BUSSON D.

1998 : Paris, Paris, éd. de la MSH (coll. CAG, 75), 609 p., 398 fig.

Canat de Chizy P.

1895 : «Rapport sur les fouilles de Belnay », Mémoires de la Société d'archéologie de Chalonsur-Saône, VIII, p. 87-89.

\section{CAZES Q.}

1995 : «Ivoire sculpté au centaure ", in Archéologie toulousaine, Catalogue d'exposition, Toulouse, Musée Saint-Raymond, Toulouse.

\section{Chatelier P. DU}

1886 : «Excursion dans la presqu'île du Cap : le tumulus de Kerlan-en-Goulien (Finistère) ", RA, $3^{\mathrm{e}}$ série, VIII, p. 221-232.

Chossenot R., Charpy J.-J.,

Chossenot M., Chossenot S.

2004 : La Marne, Paris, éd. de la MSH (coll. $C A G, 51 / 1)$.

Ciarallo A., De Carolis E. (DIR.)

2001 : Pompéi : nature, sciences et techniques, Milan, Electa.

\section{Cliquet D.}

1993 : L'Eure, Paris, Académie des inscriptions et belles-lettres (coll. CAG, 27), 284 p., 128 fig.

Corrocher J., Piboule M., Hilaire M. 1989 : L'Allier, Paris, éd de la MSH (coll. CAG, 03), 216 p., 65 fig.

COSTES A. ET AL.

1988 : " Les sites archéologiques du canton de Samatan (Gers) ", Archéologie en Savès, 13 mars 1988, p. 47.

\section{COULON H.}

1895a : «De l'usage des strigiles dans l'Antiquité ", Mémoires de Cambrai, 50, p. 15-58. 1895b : De l'usage des strigiles dans l'Antiquité, Cambrai, Régnier Frères, 47 p. et 3 grav.

DAREMberg C., SAGLIO E. (DIR.)

1877-1919 : Dictionnaire des Antiquités grecques et romaines, t. IV, vol. 2, Paris, Hachette.

\section{Dechezleprêtre T., Pernet L.,}

\section{MERLUZZO P.}

2005 : «L'ensemble funéraire de Notre-Damedu-Vaudreuil (Eure) : la Coulinière ", Antiquités nationales, 37, p. 113-127. 
Dedet B., Michelozzi A., PY M., RAYNAUd C., TENDILle C.

1978 : Ugernum : Protohistoire de Beaucaire, Caveirac, ARALO (coll. Travaux du Centre Camille-Jullian ; cahier de l'ARALO, 6), p. 101-107.

DELMAIRE R. (DIR.)

1996 : Le Nord, Paris, éd. de la MSH (coll. $C A G, 59), 492$ p., 175 fig.

DENAJAR L.

2005 : L'Aube, Paris, éd. de la MSH (coll. CAG, 10), 704 p., 528 fig.

\section{DEROC A.}

1983 : Les Monnaies gauloises d'argent de la vallée du Rhône : études numismatiques celtiques, Paris, Les Belles Lettres, 115 p.

\section{DEZOBRY C.}

1875 (4 éd.) : Rome au siècle d'Auguste : voyage d'un Gaulois à Rome à l'époque du règne d'Auguste et pendant une partie du règne de Tibère, Paris, Delagrave, 4 vol.

ESPÉRANDIEU E.

1912 : « Fouilles de la Croix-Saint-Charles au Mont-Auxois (Alésia) : rapport sur les fouilles de 1910 », Bulletin archéologique du CTHS, 19/2, 1, p. 34-59.

1934 : Répertoire archéologique du département du Gard, période gallo-romaine, Montpellier, Fédération historique du Languedoc méditerranéen et du Roussillon, 93 p., 8 fig., 1 carte.

FAGES B.

1995 : Le Lot-et-Garonne, Paris, éd. de la MSH (coll. $C A G, 47$ ), 365 p., 227 fig.

\section{FARINE B.}

1999 : Le Site gallo-romain de la Croisée à Braux (Côte-d'Or) : 12 années de recherches (19851996), DRAC de Bourgogne, APESSAB, $334 \mathrm{p}$.

FAUDUET I.

1992 : Les Bronzes gallo-romains du musée d'Évreux: Instrumentum, Musée d'Évreux, Collections archéologiques, Argentonsur-Creuse, Le Trépan, 172 p.

\section{FEUGÈRE $M$.}

1993 : « L'évolution du mobilier non céramique dans les sépultures antiques de Gaule méridionale ( $\mathrm{II}^{\mathrm{e}}$ s. av. J.-C.début du V $\mathrm{V}^{\mathrm{e}}$ s. apr. J.-C.) ", in STUCK M. (DIR.), Romerzeitliche Gräber als Quellen zu Religion, Bevölkerungsstruktur und Sozialgeschichte, Mainz, Universität Mainz (coll. Archäologische Schriften des
Instituts für Vor- und Frühgeschichte der Johannes Gutenberg Universität, 3) p. 119-165.

1996 : «Pignan, La Garonne », BSR du Languedoc-Roussillon, 1996, p. 130.

1997 : " Le petit mobilier ", in SIREIX C. (DIR.), Les Fouilles de la place des GrandsHommes à Bordeaux, Bordeaux, CNRS et Ministère de la Culture (coll. Pages d'archéologie et d'histoire girondines, 3), p. 117-137.

2002: Les Armes des Romains, de la République à l'Antiquité tardive, Paris, éd. Errance.

2003 : «Le petit mobilier d'époque romaine», in MOLINer M. (DIR.), La Nécropole Sainte-Barbe à Marseille (IV s. av. J.-C.-II e s. apr. J.-C.), Aix-en-Provence, Édisud (coll. Etudes massaliètes, 8), p. 166-180.

À paraître : "Les petits objets du site Les Aiguières à Fréjus ", in GOUDINEAU C., BRENTCHALOFF D. (DIR.), Recherches sur le camp de la flotte à Forum Iulii : fouilles du quartier des Aiguières à Fréjus, Paris, éd. Errance.

FEUGÈre M., BEL V.

2002 : "Petit mobilier et matériel divers ", in BEL V. (DIR.), Pratiques funéraires du Haut-Empire dans le Midi de la Gaule : la nécropole gallo-romaine du Valladas à SaintPaul-Trois-Châteaux (Drôme), Lattes, CNRS Éditions (coll. Monographies d'archéologie méditerranéenne, 11), p. 146-160.

FeUGÈre M., GARDEISEn A., MANNieZ Y., MONTEIL M. et collab.

1995 : « Un espace funéraire du deuxième quart du I ${ }^{\text {er }}$ siècle av. J.-C. », Gallia, 52, p. $165-204$.

FICHES J.-L., VeYRAC A.

1996 : Nîmes, Paris, éd. de la MSH (coll. CAG, 30/1), 633 p., 388 fig., 32 pl.

FLEURY C.

1877-1878 (réimpr. 1999) : Antiquités et monuments du département de l'Aisne, Paris, Le Livre d'Histoire-Lorisse, 4 vol.

FlotTÉ P., FUCHS M.

2004 : La Moselle, Paris, éd. de la MSH (coll. $C A G, 57 / 1), 893$ p., 516 fig.

Fouet G.

1983 : La Villa gallo-romaine de Montmaurin (Haute-Garonne), Paris, éd. du CNRS (coll. Suppl. à Gallia, XX).

\section{GALleT DE SANTERRE $\mathbf{H}$.}

1954 : « Informations archéologiques », Gallia, XII, 2, p. 128-129 et p. 428-429.

1958 : « Informations archéologiques ", Gallia, XVI, 2, p. 436-437.
1959 : « Informations archéologiques », Gallia, XVII, 2, p. 469-474.

1969 : « Informations archéologiques ", Gallia, XXVII, 2, p. 459-461.

1970 : « Informations archéologiques ", Gallia, XXVIII, 2, p. 403-405.

1972 : « Informations archéologiques ", Gallia, XXX, 2, p. 310.

GANET I.

1995 : Les Hautes-Alpes, Paris, éd. de la MSH (coll. CAG, 05), 188 p., 107 fig.

GERMER-DURAND E.

1872 : «Découvertes archéologiques faites à Nîmes et dans le Gard pendant l'année 1871 ", in Mémoire de l'Académie du Gard, $1^{\mathrm{er}}$ semestre 1872, p. 67-156.

\section{GINOUX N.}

2001 : Charny, le Diable-aux-Forts (carrière R.E.P.), DFS, AFAN, SRA Île-de-France.

2002 : " Au fond du puits de Charny ", Archeologia, 273, mai 2002, p. 84.

GOUDARD A.-C.

1883 : «Découverte d'un tombeau galloromain ", Bulletin de l'Académie de Nîmes, 1883, p. 115-117.

\section{GRENIER A.}

1960 : Manuel d'archéologie gallo-romaine -IVLes Monuments des eaux -I- Aqueducs et thermes -2-Villes d'eaux et sanctuaires de l'eau, Paris, Picard.

\section{HAFFNER A.}

1974 : Das keltisch-römische Gräberfeld von Wederath-Belginum -II- Gräber 429-883, Ausgegraben 1956-1957, Mainz, Philipp von Zabern (coll. Trier Grabungen und Forschungen, VI-2), 76 p., 100 pl., 4 dépliants.

HAMM G.

2004 : La Meurthe-et-Moselle, Paris, éd. de la MSH (coll. CAG, 54).

\section{HeijMans M.}

2003 : Les Thermes de Constantin d'Arles, Miniguide, Arles, Service du patrimoine, fascicule illustré en couleur.

HIERNARd J., SIMON-HIERNARD D.

1996 : Les Deux-Sèvres, Paris, éd. de la MSH (coll. $C A G, 79$ ), 400 p., 269 fig.

HIRSCHFELD O., ZANGEMEISTER C. (DIR.)

1906 : CIL, Inscriptiones Trium Galliarum et Germaniae Latinae-XIII, 3.2- Instrumentum domesticum, 2, Berlin. 


\section{HOFMANN B.}

1985 : Inventaire de quincaillerie antique, Guiry-en-Vexin, Centre de recherches archéologiques du Vexin français (coll. Cahier archéologique, 5).

Huber E., Grenier A.

1904 : « La villa de Rouhling », Annales de la Société historique et archéologique de Lorraine, 16, p. 259-292.

JACQUINEZ R.

1972 : « Un habitat gallo-romain à Cuignières (Oise) », Revue archéologique de l'Oise, 2, p. 39-57.

\section{JOLIVET V.}

1995 : « Un foyer d'hellénisation en Italie centrale et son rayonnement $\left(\mathrm{IV}^{\mathrm{e}}-\mathrm{III}^{\mathrm{e}}\right.$ s. av. J.-C.) : Préneste et la diffusion des strigiles inscrits en grec ", in ARCElin P., BATS M., Garcia D., MARCHAND G., SCHWALlER M. (DIR.), Sur les pas des Grecs en Occident, Hommages à André Nickels, Paris/Lattes, éd. Errance/ ADAM (coll. Études massaliètes, 4), p. $445-457$

\section{JORSSEN M.}

1963 : « Un cimetière gallo-romain d'animaux à Prosnes (Marne) ", Mémoires de la Société de la Marne, LXXVIII, p. 11-17.

\section{KAISER M.-S.}

2006 : Das keltisch-römische Gräberfeld von Wederath-Belgium -6-Die Aschengruben und Aschenflächen, Ausgegraben 1954-1985, Trier, Rheinisches Landesmuseum, VII (coll. Trierer Grabungen und Forschungen, 6), 216 p., pl. h. t., plan h. t.

\section{KÉRÉBEL H.}

2001 : Corseul (Côtes-d'Armor), un quartier de la ville antique: les fouilles de Monterfil II, Paris, éd. de la MSH (coll. DAF, 88).

\section{LACROIX M.-C. (DIR.)}

2004 : Archéologie en Picardie, Noyon (Oise) : les abords de la cathédrale, Plaquette Archéologie en Picardie, Inrap, DRAC Picardie.

\section{LAFFAY G., MARTIN J.}

1919 : «Fouilles archéologiques de la villa gallo-romaine de Belné près Tournus : catalogue des objets et des monnaies recueillis par M.-P. Marle ", Mémoires de la Société des amis des arts et des sciences de Tournus, XIX, p. 137-159.

LANDES C. (DIR.)

1994 : Le Stade romain et ses spectacles,
Catalogue d'exposition, Lattes, Musée Henri-Prades, Imago, éd. Musée archéologique Henri-Prades.

LASSALLE V.

1958 : Nimes et ses environs en 1958, Rapport du SRA de Languedoc-Roussillon, Montpellier.

\section{LE CLOIREC G.}

2001 : Les Bronzes antiques de Corseul (Côtesd'Armor), Montagnac, Monique Mergoil (coll. Monographies Instrumentum, 18), $173 \mathrm{p}$.

LE Mer A.-C., CHOMER C.

2007 : Lyon, Paris, éd. de la MSH (coll. CAG, 69/2), 885 p., 889 fig.

\section{LONG J.-D.}

1849 : Recherches sur les Antiquités romaines du pays des Voconciens, Mémoires présentées par divers savants à l'Académie des inscriptions et belles-lettres, $2^{\mathrm{e}}$ série, t. II (coll. Antiquités de France), Paris.

\section{MALLET F.}

2006a : «Charny (77) : une grande villa galloromaine ", Archeologia, 433, p. 42-52.

2006b : " Les tuiles estampillées de Charny (77), les Champs-de-Choisy : quelques réflexions sur trois estampilles sur tuiles découvertes en Île-de-France, VICTORIS, BARONI et CORNUTI ", in Rivet L., SAUlnier S. (DIR.), Productions, approvisionnements et usages de la vaisselle en Languedoc du I er au IV siècle apr. I.-C., Actes du congrès de la SFECAG, Pézenas, 25-28 ma 2006, Marseille, SFECAG, p. 589-598.

MALLET F. ET AL.

2006 : Charny, les Champs-de-Choisy (Seine-etMarne, Île-de-France), Rapport final d'opération de fouille, Saint-Denis, SRA Îlede-France, 3 vol., 400 p., 166 ill.

\section{MANIÈRE G.}

2001 : «Archéologie des petites Pyrénées (Ausseing-Roquefort-Belbèze-Cassagne) : le temple gallo-romain de BelbèzePédégas », Mémoires de la Société archéologique du Midi de la France, LXI, p. 35-58.

\section{MANNIEZ Y.}

2005 : " Essai d'interprétation d'un lot de mobilier d'offrande issu d'une tombe nîmoise du $I^{\text {er }}$ siècle de notre ère ", Instrumentum, 21, p. 34-36.

\section{MANNING W.-H.}

1985 (rééd. 1989) : Catalogue of the RomanBritish Iron Tools, Fittings and Weapons in the British Museum, London, British Museum Publications.

MARWITZ H.

1979 : « Ein strigilis », Antike Kunst, 22, p. 72-81.

\section{MARYON H.}

1960 : « Pattern and Damascening of SwordBlades -2- The Damascene Process ", Studies in Conservation, 5, 2, p. 52-60.

\section{MichtLeT M.}

2005 : Les Vosges, Paris, éd. de la MSH (coll. $C A G, 88), 426$ p., 454 fig.

\section{MITARD P.-H.}

1993 : Le Sanctuaire gallo-romain des Vaux-dela-Celle à Genainville (Val-d'Oise), Guiryen-Vexin, Centre de recherches archéologiques du Vexin français.

\section{MOLINER M.}

1999 : « La nécropole de Sainte-Barbe : des sépultures de Massaliètes au temps de Marseille grecque et romaine ", in Hesnard A. ET aL. (DIR.), Parcours de villes, Marseille..., Aix-en-Provence, Édisud, p. 107-120 et p. 161-163.

MOLINER M. (DIR.)

1993 : "Une nécropole gréco-romaine " Archeologia, 290, p. 16-25.

2003: La Nécropole Sainte-Barbe à Marseille (IV s s av. J.-C.-II ${ }^{e}$ s. apr. J.-C.), Aix-en-Provence, Edisud (coll. Etudes massaliètes), 496 p.

\section{MORLET A.}

1957 : Vichy gallo-romain, Mâcon, éd. BuguetComptour, $303 \mathrm{p}$

MOUROT F.

2002 : La Meuse, Paris, éd. de la MSH (coll. $C A G, 55), 652$ p., 500 fig.

\section{MOUXY DE LOCHE J. DE}

1899 : « Monuments et objets antiques d'Aixles-Bains ", Mémoire de l'Académie de Savoie, $4^{\mathrm{e}}$ série, 7, p. 253-413.

OLRY E.

1862: « Sur des objets en bronze découverts à Crézilles ", Journal de la Société archéologique de Lorraine, 1862, p. 286-287.

PALMer H.

1964 : "Strigils ", in BLEgEN C. W. ET AL. (EDS), Corinth XIII. The North Cemetery, Princeton, p. 91-95.

\section{PASCAL P.}

1963 : Nouveau traité de chimie minérale -XX, 2 Alliages métalliques, Paris, Masson. 
PAUTREAU J.-P. (DIR.)

1999 : Antran (Vienne) : un ensemble aristocratique du premier siècle, Poitiers, Musées de Poitiers, p. 47, fig. 70 et 71 .

PICHON B.

2003 : L'Aisne, Paris, éd. de la MSH (coll. $C A G, 02), 598$ p., 698 fig.

PIET J.

1864 : « Fouilles archéologiques à Noirmoutier ", Annuaire de la Société vendéenne, $1^{\text {re }}$ série, 10, p. 207-230, pl. I-IV h. t.

PINeTTE M. (DIR.)

1985 : Autun-Augustodunum, capitale des Éduens, Catalogue d'exposition, Musée d'Autun, Autun, Hôtel de Ville.

\section{Plumier J.}

1996 : « Tumuli belgo-romains de la Hesbaye occidentale : Séron, Hanret, Bois de Buis, Penteville ", in Musée archéologique de Namur, Documents inédits relatifs à l'archéologie de la région namuroise, 2, Namur, Publication extraordinaire de la Société archéologique de Namur, p. 71-95.

\section{PROUheT D.}

1890 : « L'exposition de la Mothe-SaintHéray : objets divers trouvés dans les fouilles gallo-romaines de Rom (18861889) ", Revue poitevine et saintongeaise, VII, p. 374-380.

Poux M.

2002a : Corent : festin et pratiques religieuses -II- Fouille programmée du sanctuaire du Puy de Corent (Veyre-Monton, Puy-de-Dôme), Rapport de la campagne 2002.

2002b : " Corent : rites et festins gaulois ", L'Archéologue, Archéologie nouvelle, 59, avril-mai 2002, p. 52-53.

Provost M., MefFre J.-C.

2004 : Vaison-la-Romaine et ses campagnes, Paris, éd. de la MSH (coll. CAG, 84/1), 553 p., 789 fig.

PROVOST M. ET AL.

1999 : Le Gard, Paris, éd. de la MSH (coll. $C A G, 30 / 2$ et 30/3).

Provost M., hiernard J., Pascal J., BERNARD E., SIMON-HIERNARD D.

1996 : La Vendée, Paris, éd. de la MSH (coll. $C A G, 85), 246$ p., 173 fig.

Provost M., Vallat P., Vinatié A. 1996 : Le Cantal, Paris, éd. de la MSH (coll. $C A G, 15), 217$ p., 174 fig.
PY M.

1972 : « La sépulture de Boissières (Gard) 》, Cahiers ligures de préhistoire et d'archéologie, 21, p. 75-88.

\section{RAMONAT R., SAHUC M.}

1988 : « Les tombes à incinération galloromaines de Navitau, Castelnau-le-lez (Hérault) ", Archéologie en Languedoc, 4, p. $45-164$.

REBOURG A.

1993 : Autun, Paris, éd. de la MSH (coll. CAG, 71/1), 238 p., 165 fig.

\section{REINACH S.}

1886 : « Manche de strigile gravé, découvert à Myrina ", Bulletin de correspondance hellénique, 10, p. 299-314.

RÉMY B., BALlet F., FERbER E.

1996 : La Savoie, Paris, éd. de la MSH (coll. $C A G, 73), 247$ p., 141 fig.

\section{RICH A.}

1995 : Dictionnaire des Antiquités grecques et romaines, Paris, Payot, $740 \mathrm{p}$.

\section{RIHA E.}

1986 : Römisches Toilettgerät und medizinische Instrumente aus Augst und Kaiseraugst, Augst (coll. Forschungen in Augst, 10).

ROGERET I.

1998 : La Seine-Maritime, Paris, éd. de la MSH (coll. CAG, 76), 662 p., 556 fig.

ROTHÉ M.-P., TRÉZINY H.

2005 : Marseille et ses alentours, Paris, éd. de la MSH (coll. CAG, 13/3), 928 p., 1301 fig.

SABlayrolles R., Beyrie A.

2006 : Le Comminges, Paris, éd. de la MSH (coll. $C A G, 31 / 2$ ), 515 p., 620 fig.

SALIN E.

1951 : « Les techniques de la damasquinure en Gaule mérovingienne ", Gallia, 9, p. $31-52$.

1953a : «L'emploi du laiton en matière de damasquinure à l'époque galloromaine ", Cuivre, laiton, alliages, 14 p. 34-37.

1953b : « L'emploi du laiton en matière de damasquinure à l'époque galloromaine ", Cuivre, laiton, alliages, 15, p. $50-53$.

\section{SAUTEL J.}

1942 : Vaison dans l'Antiquité -II- Catalogue des objets romains trouvés à Vaison et dans son territoire, Supplément : Travaux et recher- ches de 1927 à 1940, Avignon, Rullière Frère, p. 26.

\section{SCHÖNFELDER M.}

1996 : Die Metallbeigaben aus dem Wagengrab von Boé (Dep. Lot-et-Garonne) : zur Stellung eines spätkeltischen Prunkgrabes in Aquitanien, Magisterarbeit, Universität Marburg/ Lahn.

SCHÖNFELDER M., SION K., SION H.

2000 : « Le mobilier métallique de la tombe à char tardo-celtique de Boé (Lot-etGaronne) ", Aquitania, 17, p. 59-81.

SéGuier J.-M., Mallet F., Clavel B., Frère S., LAUbenheimer F., PILON F., VIAND A.

2005 : « Le faciès augustéen de la Plaine de France d'après le mobilier des établissements de Charny et de Compans (Seine-et-Marne) ", in RIVET L. (DIR.), Spécificités et diffusion de la céramique galloromaine en région Centre, Actes du congrès de la SFECAG, Blois, 5-8 mai 2005, Marseille, SFECAG, p. 529-560.

\section{SIMON-HIERNARD D.}

1990 : Poitiers : la nécropole du quartier BlossacSaint-Hilaire (I ${ }^{e r}-I V^{e}$ s. apr. J.-C.), Poitiers (coll. Mémoire de l'Association des publications chauvinoises, V).

SINTÈS C. (DIR.)

1996: Musée de l'Arles antique : collections archéologiques d'Arles, Arles, éd. Musée de l'Arles antique et Actes Sud, 173 p.

SUDRES G.

1981 : « La nécropole gallo-romaine de Courac ", Revue archéologique Sites, 11, p. $17-24$.

1983 : «Autour d'une nécropole, Courac I ", Rhodania, 8, p. 3-14.

\section{Tendille C.}

1981 : "Mobiliers métalliques protohistoriques de la région nîmoise : instruments de toilette et vaisselle (IV) ", Documents d'archéologie méridionale, 4, p. 61-82.

THUILLIER J.-P.

1989 : « Les strigiles de l'Italie antique », $R A$ 1989, p. 339-342.

1996 : Le Sport dans la Rome antique, Paris, éd. Errance.

\section{TOULOUZE E.}

1890 : «Un témoin des âges antiques à Lutèce ( $2^{\mathrm{e}}$ fouille) ", $R A, 1890$, I, p. 351-377, fig. 1-36. 
1892 : « Un témoin des âges antiques à Lutèce : découverte d'une voirie romaine », $R A$, 1892, I, p. 323-350.

\section{VAN OSSEl P., DEFGNÉE A.}

2001 : Champion, Hamois : une villa chez les Condruses, archéologie, environnement et économie d'une exploitation agricole antique de la Moyenne Belgique, Namur, Ministère de la région wallone (coll. Études et documents, archéologie, 7).
VAUVILlé O.

1911 : "Découvertes aux "Longues Raies" ", Bulletin de la Société nationale des Antiquaires de France, 1911, p. 300-304.

VIAL J.

2003 : Le Montpelliérais, Paris, éd. de la MSH (coll. CAG, 34/3).

VELAY P. (DIR.)

1989 : Les Bronzes antiques de Paris, Catalogue d'exposition, Paris, Musée Carnavalet, Paris, éd. Musées (coll. du Musée Carnavalet).

WAbont M., Albert F., VermeERsCh D. 2006 : Le Val-d'Oise, Paris, éd. de la MSH (coll. $C A G, 95), 495 \mathrm{p}$.

WOIMANT G.-P.

1995 : L'Oise, Paris, éd. de la MSH (coll. CAG, 60), 570 p., 400 fig. 